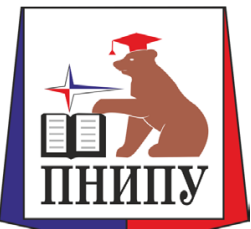

PNRPU MECHANICS BULLETIN

№ 3-4, 2018

http://vestnik.pstu.ru/mechanics/about/inf/

DOI: $10.15593 /$ perm.mech/eng.2018.3.11

UDC 621.7.011+539.442.23+620.163.2

\title{
A SET OF TESTS FOR STUDYING THE EFFECT OF THE STRESS STATE ON ULTIMATE METAL PLASTICITY AT HIGH TEMPERATURE
}

\author{
S.V. Smirnov, D.I. Vichuzhanin, A.V. Nesterenko \\ Institute of Engineering Science, UrB RAS, Ekaterinburg, Russian Federation
}

\section{ARTICLE INFO}

Received: 11.07 .2014

Accepted: 20.08 .2014

Published: 25.12.2018

\section{Keywords:}

ultimate plasticity, fracture locus, effect of the stress state, aluminium alloy.

\begin{abstract}
A set of tests that can be used tostudy the effect of the stress state on ultimate metal plasticity at high temperature is proposed. Ultimate plasticity can be characterized quantitatively by the strain accumulated to failure. Dimensionless invariant parameters, such as the triaxiality parameter $k$ and the Lode-Nadai parameter $\mu_{\sigma}$, are used as a characteristic of the stress state. A set of the parameters $k$ and $\mu_{\sigma}$ unambiguously characterizes the stress state under plastic deformation. Being dimensionless, these parameters can be used to compare the stress state of materials with different levels of strength properties. The triaxiality parameter $k$ characterizes the level of normal stresses. If $k>0$, then normal tensile stresses dominate. If $k<0$, then normal compressive stresses dominate. The Lode-Nadai parameter $\mu_{\sigma}$ characterizes the type of the stress state. The value of $\mu_{\sigma}=+1 /-1$ corresponds to the stress state of axisymmetric compression/tension, and $\mu_{\sigma}=0$ under the plane stress state. The set of tests consists of conventional tension tests of cylindrical specimens, tension tests of notched cylindrical specimens, newly developed tests of "bell" specimens and tests of a thick-walled cup with a thinned bottom. This types of tests has allowed us to investigate ultimate plasticity under monotonic deformation in the range of parameters $-1.2<k<1.2$ and $-1<\mu_{\sigma}<+1$ without applying high pressure technique. The stressstrain state under tests was evaluated by the results of mathematical simulation by means of the finite element method in ANSYS. The tests performed on 01570 aluminium alloy specimens. The test temperature was $360^{\circ} \mathrm{C}$. The shear strain rate was $\mathrm{H}=0.1 ; 0.3 ; 0.5 \mathrm{~s}^{-1}$. The fracture locus of the 01570 aluminium alloy has been obtained from the test results. The fracture locus can be used in damage mechanics models to predict alloy fracture under metal forming processes.
\end{abstract}




\section{Introdaction}

The fact that metal materials can be subjected to plastic deformation without failure is usually represented by the value of ultimate plasticity that is quantitatively characterized by the degree of strain accumulated by the time of failure. In addition to the temperature and rate of strain, the stress state also has a considerable effect on ultimate plasticity.

The effects of hydrostatic pressure on the failure of metals were originally established by P. Bridgman in the work [1] when conducting the tests under the external pressure of liquid and were later generalized in the work [2]. The detailed study of the effect of hydrostatic pressure on the plasticity of metals when they are pressed by highpressure liquid is presented in [3].

The work [4-6] suggests invariant parameters that are different from each other by a constant multiplier, consider the level of normal stresses and characterize the stress state stiffness at the place of failure under plastic deformation. The works by the foreign authors [7-9] also widely used similar parameters within the failure models where the damage accumulation is considered as a change in the sizes and form of pores present in the material before deformation. Based on the processing of experimental data from the work [2], [6] presents the functional dependences (known as plasticity charts) of the strain intensity at the time of failure upon the stress state parameter. The work [10] describes the original experiments aimed at specifying tensile plasticity charts under hydrostatic pressure.

The abnormal properties of plasticity of metals that lie in the fact that the shear strain degree at the time of macrofailure in the bend tests of the flat and square section specimens, and also at the time of tension under pressure and torsion, decreased with an increase in the stress state hydrostatic component were indicated in the work [11]. A considerable strain decrease before failure was observed in [12] when moving from axisymmetric to flat specimens in the tensile tests of a number of structural steels. The fact that plasticity depends on the Lode parameter is given in [13]. The results of these works resulted in the necessity of developing a method aimed at studying separate effects of parameters that characterize the stress state stiffness and the stress state type and provide for tensile and torsional tests under the high hydrostatic pressure of liquid. The systematic studies [14-16] confirmed that, in addition to the value of hydrostatic stress, the stress state type characterized by the Lode-Nadai parameter also has a considerable effect on the ultimate shear strain degree.

Today, dimensionless invariant parameters are usually used to describe the dependence of ultimate plasticity on the stress state: stress state parameter $k$ and Lode-Nadai parameter $\mu_{\sigma}$ :

$$
k=\frac{\sigma}{T} \quad \mu_{\sigma}=2 \frac{\sigma_{22}-\sigma_{33}}{\sigma_{11}-\sigma_{33}}-1,
$$

where $\quad \sigma=\frac{1}{3}\left(\sigma_{11}+\sigma_{22}+\sigma_{33}\right) \quad-\quad$ hydrostatic stress; $T=\sqrt{0,5 s_{i j} s_{i j}}$ - shear stress intensity; $s_{i j}$ - stress deviator components; $\sigma_{11}, \sigma_{22}, \sigma_{33}$ - principal stresses. A set of parameters $k$ and $\mu_{\sigma}$ unambiguously characterizes the stress state under plastic deformation. Being dimensionless, these parameters can be used to compare the stress state of materials with different levels of strength properties. Parameter $k$ characterizes the relative level of normal stresses: if $k>0$, then normal tensile stresses dominate, if $k<0$, then normal compressive stresses do. Lode-Nadai parameter $\mu_{\sigma}$ characterizes the stress state type. Value $\mu_{\sigma}=+1 /-1$ corresponds to the stress state of axisymmetric compression/tension, at $\mu_{\sigma}=0$ the plane stress state scheme is implemented.

Some authors [17-24] use Lode angle $\theta$ as a characteristic of the stress state type instead of $\mu_{\sigma}$. The Lode angle may be expressed through the Lode-Nadai parameter according to the formula:

$$
\theta=\arccos \left(\sqrt{3} \mu_{\sigma}\left(\mu_{\sigma}^{2} / 9-1\right)\right) .
$$

Ultimate plasticity plays an important role in the scientific concept of damage mechanics models [11, 25-29] that allow one to forecast failures under plastic forming. For example, models [25, 29] show ultimate plasticity that is represented as the shear strain degree $\Lambda_{P}=\Lambda_{P}\left(\Theta, \mathrm{H}, k, \mu_{\sigma}\right)$ under simple loading, constant temperature $\Theta$ and intensity of the rate of shear strain $H$ ( $\mathrm{H}=\sqrt{2 \eta_{i j} \eta_{i j}}$, where $\eta_{i j}$ - components of the strain rate deviator) and is a most important empirical parameter. The geometrical interpretation of dependence $\Lambda_{P}=\Lambda_{P}\left(\Theta, \mathrm{H}, k, \mu_{\sigma}\right)$ is known as an ultimate plasticity chart.

Several types of tests (where the values of parameters $k$ and $\mu_{\sigma}$ vary) are usually carried out in order to obtain necessary information and create ultimate plasticity charts. Within the range of values $k>0.58$, tests of plastic metals are rather easily carried out at different $\mu_{\sigma}$ by tensioning smooth and notched cylindrical and flat specimens, by extruding membranes. At smaller values $k$, and particularly within the range of compressive stresses, serious difficulties take place when selecting test methods. At the upsetting of cylindrical specimens with no curvature of a side surface due to the effect of friction forces at contact $k=-0.58$ and $\mu_{\sigma}=+1$. However, plastic metals upsetting tests make it difficult to record the time of formation of a crack on a side surface, which reduces the informativeness of such tests. The use of a set of three types of tests (tensile, upsetting and torsional ones) with regard to cylindrical specimens allows one to obtain only 3 points on the chart, which is not 
enough to determine the separate effects of parameters $k$ and $\mu_{\sigma}$ on ultimate plasticity. The most universal tests are those with specimens in the adjustable liquid pressure chamber [16, 25, 29-30] where parameter $k$ may be brought to the range of negative values even under specimens expansion. Main foreign works dedicated to this subject are reflected in the review article [31]. However, these tests are very difficult technically for the purposes of studying the plasticity of metal materials under hot deformation. The studies described in the works [32-38] can be given as few examples of performance of tests in the high pressure chamber at high temperatures.

The objective of this work was to develop a set of tests that can, with no use of high pressure equipment, define dependence $\Lambda_{P}=\Lambda_{P}\left(\Theta, \mathrm{H}, k, \mu_{\sigma}\right)$ under hot deformation within the wide range of changes of parameters $k$ and $\mu_{\sigma}$.

In addition to traditional tensile tests of smooth cylindrical specimens and those having annular grooves, the proposed set of mechanical tests includes new specially developed tests of bell-shaped specimens and those in the form of thick-walled cups. Such specimens are described below. The test methods were developed and approved with the use of specimens of aluminum alloy 01570 that contains $5.18 \% \mathrm{Mg}, 0.23 \% \mathrm{Sc}$ and $0.07 \% \mathrm{Zr}$. The studies were carried out at the temperature of $360{ }^{\circ} \mathrm{C}$ and used the INSTRON 8801 servohydraulic testing system equipped with a hinged furnace. In the course of deformation, all the types of tests maintained the constant intensity of shear strain rates $\mathrm{H}=0.1 ; 0.3 ; 0.5 \mathrm{~s}^{-1}$, except for the extrusion of the thick-walled cup bottom. For this purpose, the speed of the testing machine operating device was not constant but was changed in a certain manner in the course of deformation. The results of each test were averaged according to the measurements of the 3 specimens.

\section{Tensioning the Cylindrical Specimens}

The cylindrical specimens with a smooth side surface had the working part sizes as follows: diameter $D_{0}=$ $=5 \pm 0.05 \mathrm{~mm}$, length $L_{0}=25 \pm 0.5 \mathrm{~mm}$. The diameter of the specimens having annular grooves in the minimum section of a groove was $D_{0}=5 \pm 0.05 \mathrm{~mm}$, the radius of an annular groove in the longitudinal section was $R_{0}=5 \pm 0.05 \mathrm{~mm}$. The intensity of shear strain rate $\mathrm{H}$ and the shear strain degree in the minimum section with current diameter $D$ were determined according to the following formulae:

$$
\begin{aligned}
& \mathrm{H}=2 \sqrt{3} \frac{d D}{d t} \frac{1}{D}, \\
& \Lambda=2 \sqrt{3} \ln \frac{D_{0}}{D} .
\end{aligned}
$$

Due to the fact that today we do not know any analytical dependences that connect a change in the diameter in the minimum section of specimen $\Delta D$ and the length of the working part of specimen $\Delta \mathrm{L}$ at the stage of development of localized strain, this dependence was determined experimentally according to the measurement results of the 3-5 reference specimens tensioned with a different degree of strain. After testing, the reference specimens, including the radius of the specimens neck in longitudinal direction $\mathrm{R}$, were measured with the use of a toolroom microscope. The law of a change in the speed of displacement of active grab $\mathrm{V}(\mathrm{t})$ that must ensure the constancy of strain rate $\mathrm{H}$ at time point $\mathrm{t}$ was defined by using the established dependence and the formula (3). During the tests, it was implemented with the use of the testing machine control software.

The value of parameter $k$ in the course of tension, including at the time of failure, was calculated according to the formula [39]:

$$
k=\frac{1}{\sqrt{3}}\left(1+\frac{3}{4} \frac{D}{R}\right) .
$$

During the tests of the smooth cylindrical specimens (Fig. 1, a) parameter $k$ changed within the range of $0.58 \ldots$ 0.90 , and during the tests of the cylindrical specimens having annular grooves (Fig. 1, b) - within the range of $0.91 \ldots$ 1.04. Parameter $\mu_{\sigma}=-1$ [40].
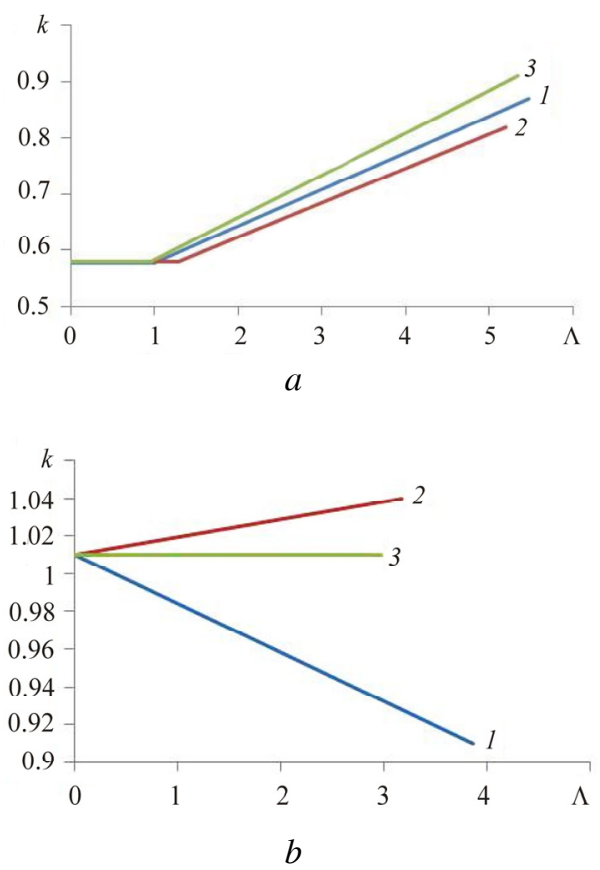

Fig. 1. Change in the stress state parameter $\mathrm{k}$ when tensioning the smooth specimens $(a)$ and those having annular grooves $\frac{D_{0}}{R_{0}}=1$ (b) in the course of tests at strain rate $\mathrm{H}: 1-0.1 ; 2-0.3 ; 3-0.5 \mathrm{~s}^{-1}$

Table 1 presents the values of shear strain degree $\Lambda$ at the places of failure of the specimens when tested and the average integral values of parameter $\bar{k}$ per a deformation process. It is seen that the values of the shear strain degree do not practically depend on the shear strain rate at the time of failure $\Lambda$. 
Table 1

Results of the cylindrical specimens tests

\begin{tabular}{|c|c|c|c|c|}
\hline Type of test & $\Lambda$ & $\begin{array}{c}\text { Average integral } \\
\text { values } \bar{k}\end{array}$ & $\mu_{\sigma}$ & $\mathrm{H}, \mathrm{s}^{-1}$ \\
\hline \multirow{3}{*}{$\begin{array}{l}\text { Tensioning the smooth } \\
\text { cylindrical specimens }\end{array}$} & 5.47 & 0.70 & \multirow{6}{*}{-1} & 0.1 \\
\hline & 5.19 & 0.67 & & 0.3 \\
\hline & 5.34 & 0.72 & & 0.5 \\
\hline \multirow{3}{*}{$\begin{array}{l}\text { Tensioning the cylindrical } \\
\text { specimens having annular } \\
\text { grooves, } \frac{D_{0}}{R_{0}}=1\end{array}$} & 3.87 & 0.96 & & 0.1 \\
\hline & 3.17 & 1.025 & & 0.3 \\
\hline & 2.98 & 1.01 & & 0.5 \\
\hline
\end{tabular}

A connection between strain resistance $\sigma_{S}$ and the shear strain degree was determined according to the results of tensioning of the smooth cylindrical specimens. The shear strain degree was calculated according to the formula (4). The strain resistance was determined taking into account N.N. Davidenkov - Spiridonova's correction for the stress state triaxility within the range of localization of plastic deformation [40]:

$$
\sigma_{S}=\frac{4 F}{\pi D^{2}\left(1+\frac{1}{8} \frac{D}{R}\right)},
$$

where $F$ - tensile force.

As a result, we obtained the dependences of strain resistance $\sigma_{s}$ on shear strain degree $\Lambda$ at the constant rates of shear strains $\mathrm{H}=0.1 ; 0.3$ and $0.5 \mathrm{~s}^{-1}$ (Fig. 2).

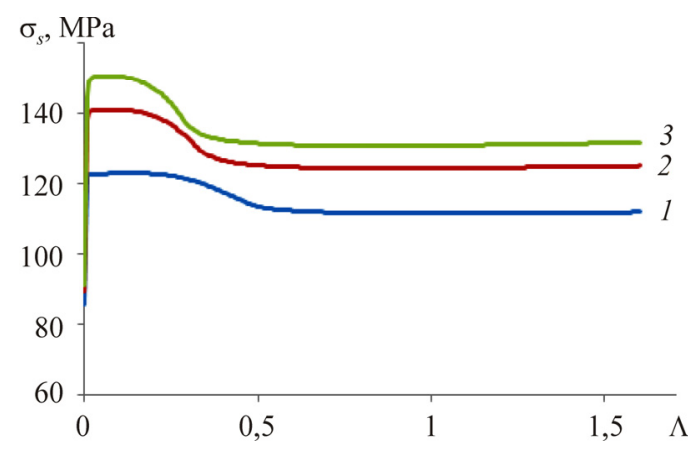

Fig. 2. Dependence of strain resistance $\sigma_{s}$ on shear strain degree $\Lambda$ at shear strain rate $\mathrm{H}: 1-0.1 ; 2-0.3 ; 3-0.5 \mathrm{c}^{-1}$

\section{Testing the Bell-Shaped Specimens}

In addition to torsional tests, flat butterfly specimens [41] that allow one to carry out tests within the wide range of changes in the stress state parameter at constant parameter $\mu_{\sigma}=0$ are used for the studies of the ultimate plasticity of metal at shear $\left(\mu_{\sigma}=0\right)$. However, it is necessary to use a special testing machine equipped with two independent operating devices in order to test such specimens. In this regard, bell-shaped specimens were developed (Fig. 3, a). They can be tested with the use of commercial universal testing machines and allow one to vary the values of parameter $k$ within a wide range at invariable $\mu_{\sigma}=0$. The tested specimens are presented in Fig. 3, $b$ and $c$. During tensile tests, tensile stresses dominate at the place of failure, during compression tests compressive stresses. The stress-strain state under tests was determined according to the results of the mathematical simulation by using the finite element method in ANSYS. An elastic-viscoplastic model of isotropic strain hardening was taken for the specimen strain sensitive material. As the model library of the ANSYS environments does not make it possible to set hardening curves in the form obtained as a result of the experiments (see Fig. 2), dependences $\sigma_{\mathrm{s}}(\Lambda$ ) were set by using the USERMAT program option.

The calculations were made on the assumption of the axisymmetric strain state in a deformation zone, therefore only $1 / 2$ section of the specimen was simulated. The Plane 82 finite elements were used for the calculations. The model consisted of 1,219 elements, boundary conditions were set in displacement speeds (Fig. 4). The sufficiency of refinement (carried out with the use of the "refine" program option) of a finite element grid within the range of the specimens failure was assessed according to a change in the maximum value of equivalent strain. The grid was considered to be sufficiently refined when at the next activation of the "refine" option an increase in the equivalent strain value was less than by $1 \%$ in comparison with a previous value. Similarly, the finite element grid was improved during the simulation of other tests.
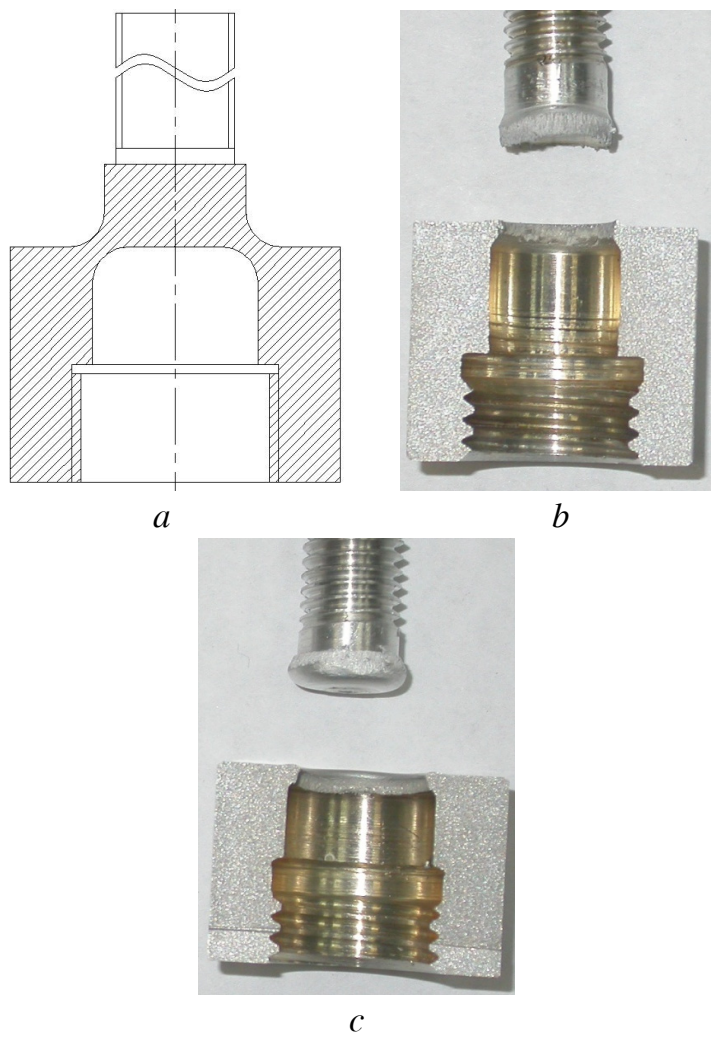

$b$

Fig. 3. Bell-shaped specimen: $a$ - longitudinal section in an initial state (sketch); the specimen section after tensile $(b)$ and compression $(c)$ tests 


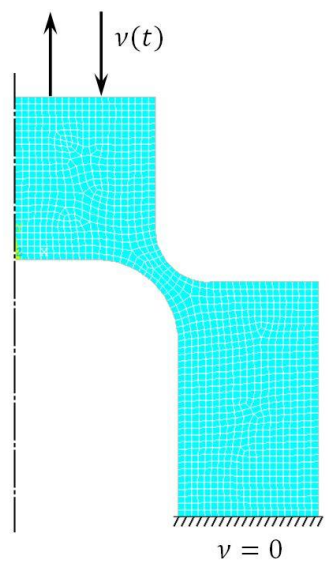

Fig. 4. Finite element grid in the bell-shaped specimen axial section
As an example, Fig. 5 presents the results of the calculation of distribution of equivalent plastic strains $\varepsilon$ along the specimen section under tensile and compression tests. The results correspond to the time of failure specified in the experiment. This type of tests makes it difficult to find the exact place of initiation of failure, therefore the stress-strain state characteristics were averaged along the line of strain localization specified in Fig. 5. Table 2 gives the values of an averaged degree of shear strain $\Lambda^{*}$ at the place of failure and average integral ones of parameter $\bar{k}^{*}$ averaged along the line of strain localization per a deformation process. It is seen that the values of the shear strain degree do not practically depend on the shear strain rate at the place of failure $\Lambda^{*}$.
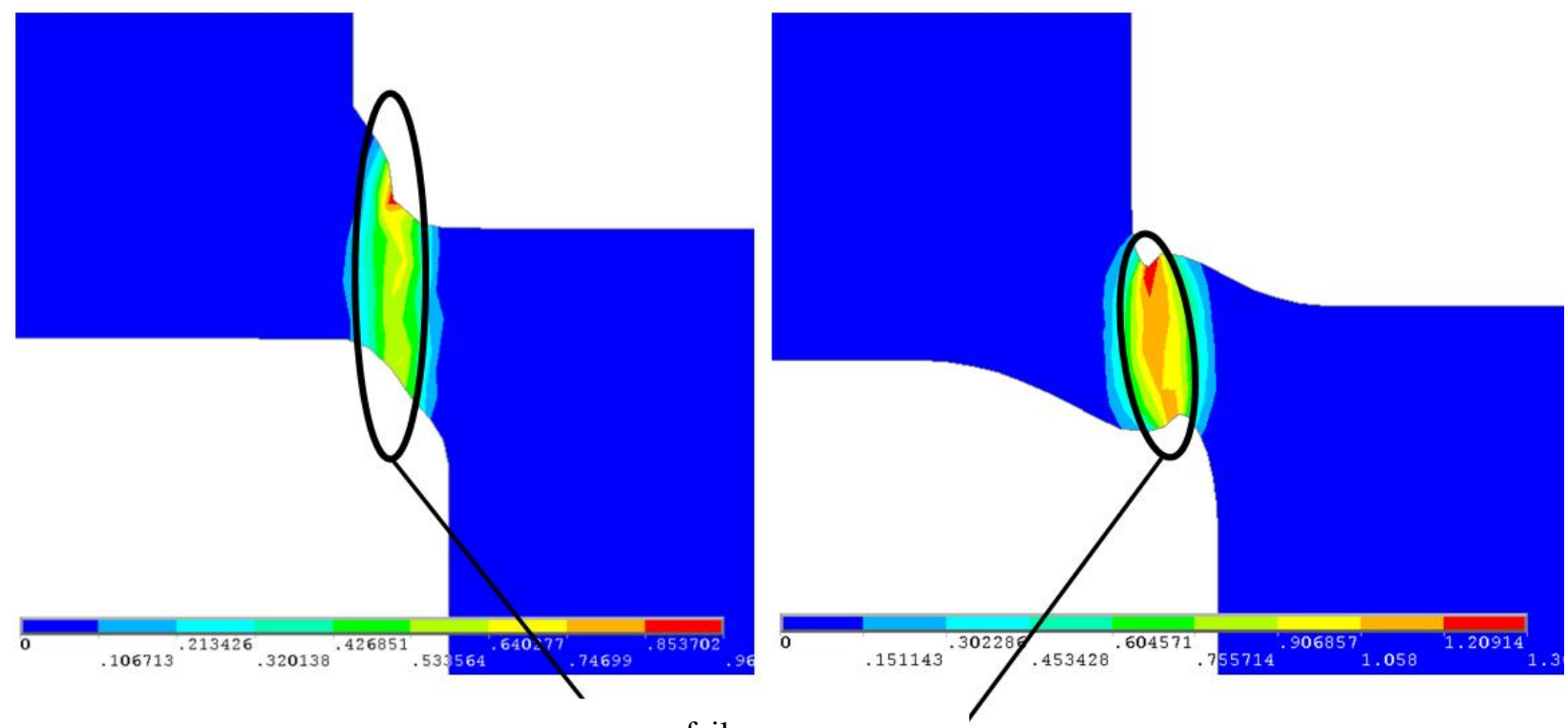

failure area

$b$

Fig. 5. Distribution of equivalent plastic strains $\varepsilon$ along the bell-shaped specimen section by the time of failure under tensile $(a)$ and compression $(b)$ tests

Results of the bell-shaped specimens tests

\begin{tabular}{|c|c|c|c|c|}
\hline Type of test & $\Lambda^{*}$ & Average integral values $\bar{k}^{*}$ & $\mu_{\sigma}$ & $\mathrm{H}, \mathrm{s}^{-1}$ \\
\hline \multirow{3}{*}{ Tension } & 1.50 & 0.97 & \multirow{6}{*}{0} & 0.1 \\
\hline & 1.45 & 0.94 & & 0.3 \\
\hline & 1.46 & 0.93 & & 0.5 \\
\hline \multirow{3}{*}{ Compression } & 3.57 & -0.68 & & 0.1 \\
\hline & 3.28 & -0.63 & & 0.3 \\
\hline & 3.10 & -0.62 & & 0.5 \\
\hline
\end{tabular}


Fig. 6 presents the charts of change of values $k^{*}$ from $\Lambda^{*}$ under tests. The values are averaged along the area of the specimen future failure for the intensity of shear strain rate $\mathrm{H}=0.1 ; 0.3 ; 0.5 \mathrm{~s}^{-1}$. It is seen that during the tensile tests the stress state parameter changes within the range of $0.56<k^{*}<1.24$, and during the compression tests - within the range of $-1.2<k^{*}<0.29$. Parameter $\mu_{\sigma}=0$ throughout the whole deformation process. The adequacy of the simulation-based results was assessed by comparing the strain force obtained from the simulation with the experimental data. The deviation of the design and experimental data did not exceed $12 \%$.
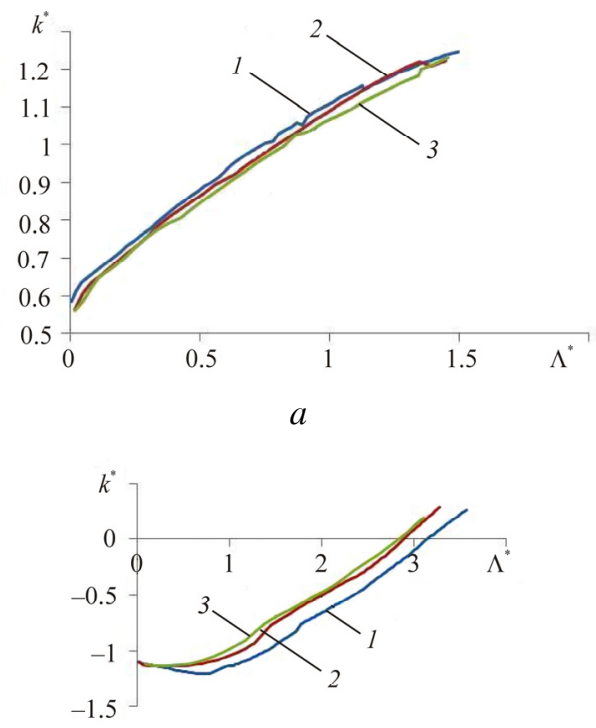

$b$

Fig. 6. Change in the stress state averaged parameter $k^{*}$ under the bell-shaped specimens tests: $a$ - tensile tests; $b$-compression tests: $1-\mathrm{H}=0.1 \mathrm{~s}^{-1} ; 2-\mathrm{H}=0.3 \mathrm{~s}^{-1} ; 3-\mathrm{H}=0.5 \mathrm{~s}^{-1}$

\section{Extruding the Thick-Walled Cup Bottom}

In order to carry out tests where the stress state with parameter $\mu_{\sigma}=+1$ is implemented instead of the extrusion of a thin round membrane by a spherical punch [29], it was suggested to test specimens in the form of thick-walled cups with thinned bottoms intended to localize strain in the bottom central area. The specimens design and kit for their tests are given in Fig. 7, $a$ and 8.

Before testing, specimen 1 is installed on support 2 (Fig. 8), the specimen is fastened with cover 3 from above. A deforming force is put on the ball through punch 7 installed in the testing machine grip. Bearing ball 6 of $9.5 \mathrm{~mm}$ in diameter is used as a deforming tool. A lubricant (powder graphite) is put into a cavity formed by thinning in order to decrease friction.

In cases when it is necessary to carry out tests under dominant compressive stresses, the membranes are extruded with a rest. For this purpose, rest 4 is installed under the membrane; this rest is deformed during the test, thereby creating a compressive stress in the bottom. From below screw 5 fastens the rest. The rest may have the form of a solid cylinder or cup. Materials and sizes used to make such rests are selected on the basis of simulation-based test results. The thinner the rest walls and the stronger the material is, the smaller the value $k$ is reached under tests. In the experiments under discussion the rest was made from the same material as the specimens under test.

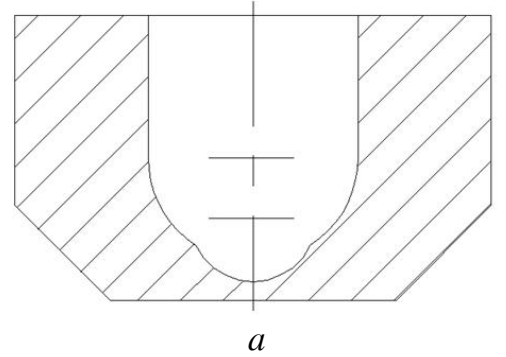

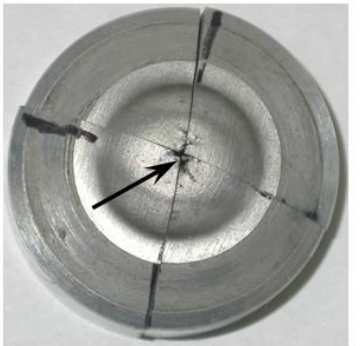

$b$

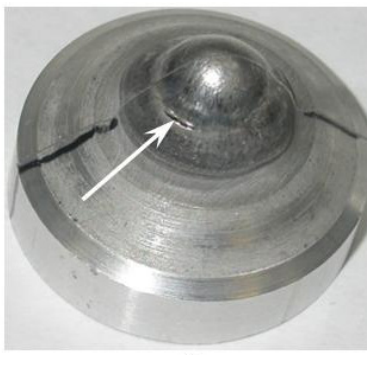

Fig. 7. Specimen in the form of a thick-walled cup with a thinned bottom: $a$ - longitudinal section in an initial state (sketch); the tested specimens without the bottom rest $(b)$ and with the bottom rest $(c)$. The places of initial failure are marked with pointers

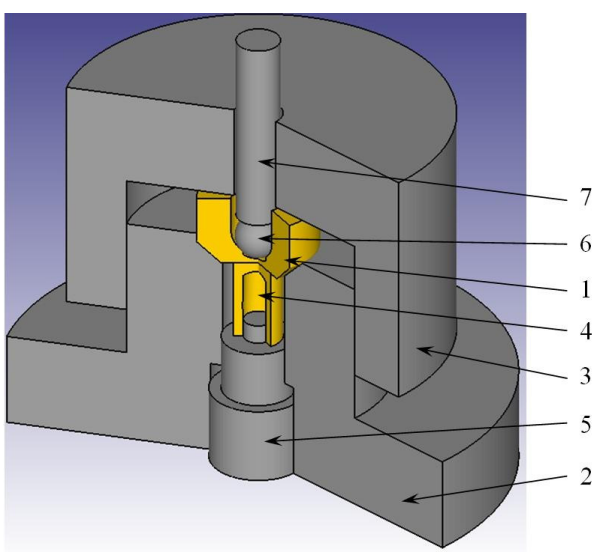

Fig. 8. Outfit for the thick-walled cup with a thinned bottom under tests (keys are given in the text)

The tested specimens are presented in Fig. 7, $b$ and $c$. The formation of a crack in the membrane of plastic metal under test is not accompanied by any registered effects (force or displacement jump, sound effect, etc.). Therefore the time of failure was determined according to the measurement results of the specimen bottom thickness near the crack, with the grounds for supposing that after the occurrence of an initial crack with the punch further displacement the crack spreads further and the bottom does not thin at the place of an initial break. 


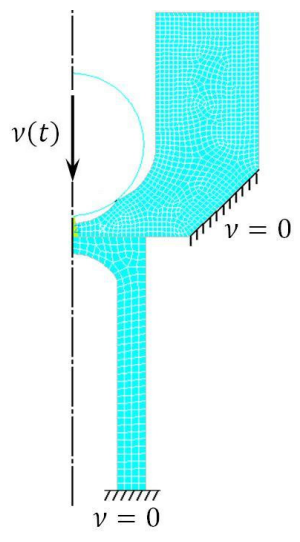

Fig. 9. Finite element grid in the axial section of the thick-walled cup with the rest

The stress-strain state under test was studied according to the results of the finite element simulation in the ANSYS program. In the model the deforming tool (ball) was taken as an absolutely rigid body. An isotropic viscoelastic-plastic model with isotropic strain hardening was taken for the specimen and rest material. The calculations were made on the assumption of the axisymmetric strain state in a deformation zone, therefore $1 / 2$ section of the specimen and the rest was simulated. The Plane 82 finite elements were used for the calculations. The model consists of 1.390 elements, boundary conditions were set in displacement speeds (Fig. 9). The friction between the deforming tool and the metal was calculated with the use of the Siebel friction law. According to the recommendations [42], the friction coefficient was taken equal to 0.3 , as for hot deformation conditions.

The distribution of equivalent plastic strains $\varepsilon$ along the specimen section by the time of failure is given in Fig. 10 . During the tests with the rest, the specimens failure took place not in the bottom center, but at some distance from it (Fig. $7, c$ ). We can draw the same conclusions according to the simulation results presented in Fig. 10. The charts of change of values $k$ and $\Lambda$ at the places of future failure for the different intensities of shear strain rates $\mathrm{H}$ are given in Fig. 11. As can be seen from the charts, during the tests without the rest the stress state is rather rigid (parameter $k>1$ ), which is connected with the occurrence of intensive tensile stresses in circumferential and radial directions. Table 3 presents the values of shear strain degree $\Lambda$ at the place of failure and average integral ones $\bar{k}, \bar{\mu}_{\sigma}$ and $\overline{\mathrm{H}}$ per a process. It is seen from Table 3 that values $\Lambda$ do not practically depend on the shear strain rate.

According to the simulation results, it has been established that value $\mu_{\sigma}=+1$ does not practically change throughout the whole process of deformation under the extrusion without the rest at the place of failure. Under the extrusion with the rest, average integral value $\bar{\mu}_{\sigma}=0.72$ per a testing process. The adequacy of the simulation-based results was assessed by comparing the strain force obtained from the simulation with the experimental data. The deviation of the design and experimental data does not exceed $7 \%$.

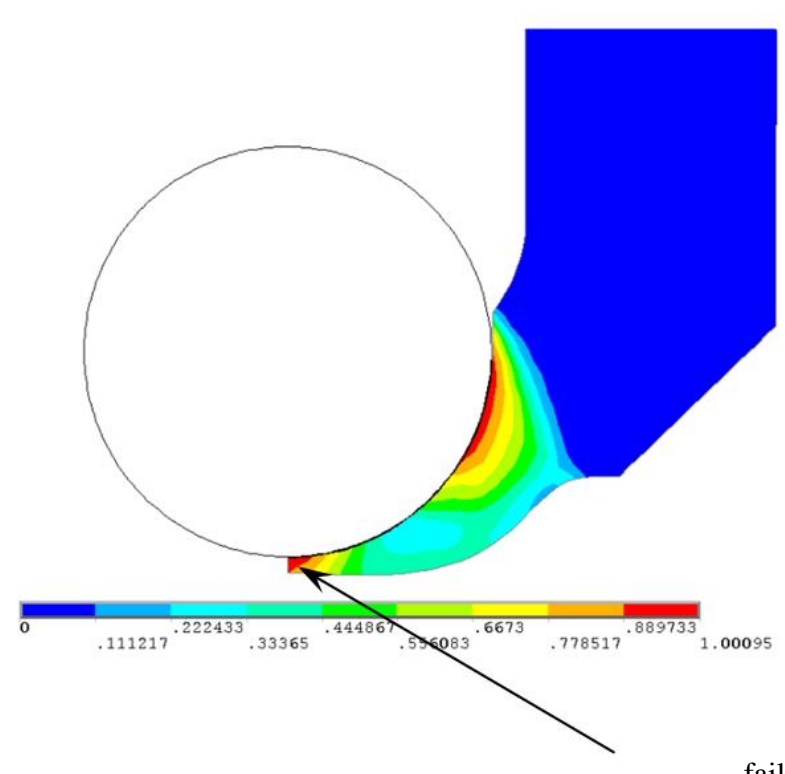

failure place

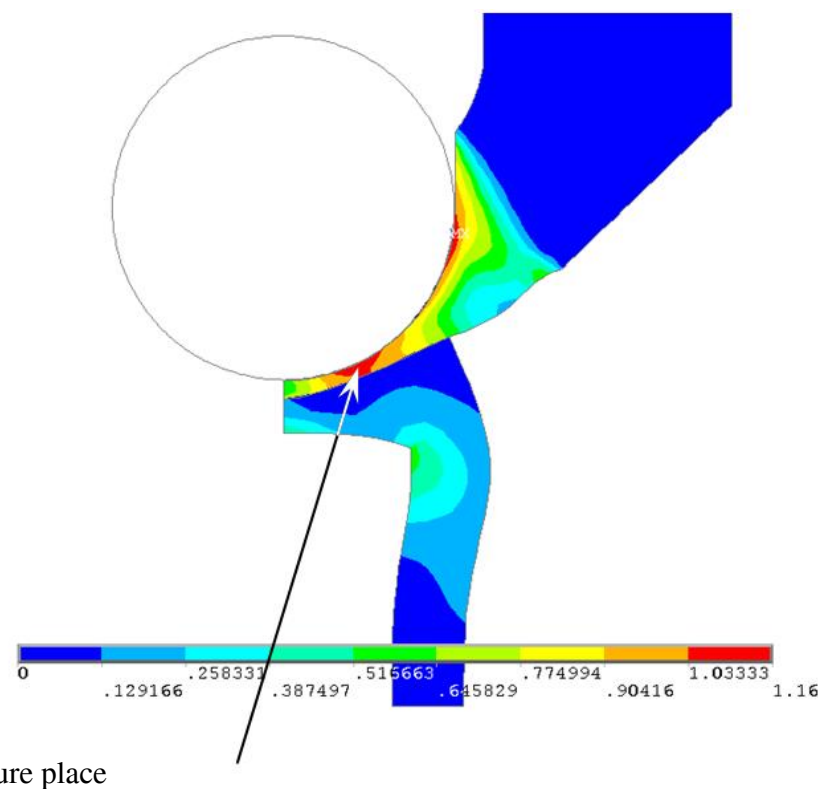

$b$

Fig. 10. Distribution of equivalent plastic strains $\varepsilon$ along the section of the thick-walled cup with a thinned bottom by the time of failure: $a$-without the rest; $b$ - with the rest 

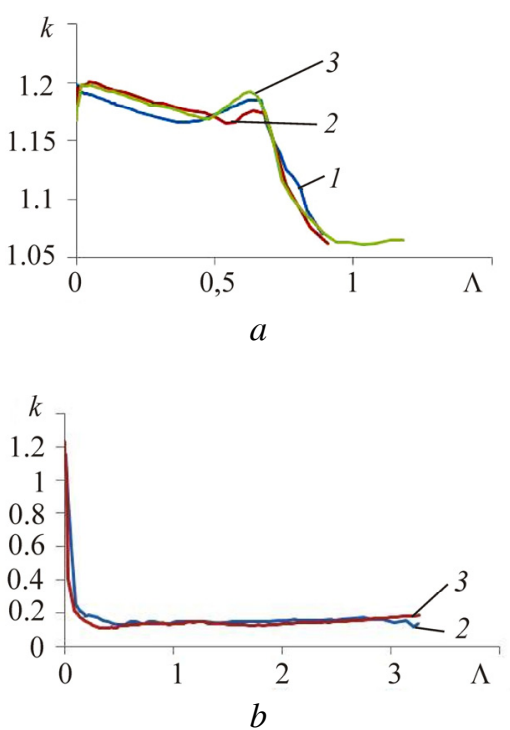

Fig. 11. Change in stress state parameter $k$ when testing the thick-walled cup with a thinned bottom: $a$-without the rest; $b$ - with the rest

Table 3

Test results of the thick-walled cup with a thinned bottom

\begin{tabular}{|c|c|c|c|c|}
\hline \multirow{2}{*}{ Type of test } & \multirow{2}{*}{$\Lambda$} & \multicolumn{3}{|c|}{ Average integral } \\
\hline & & $\bar{k}$ & $\bar{\mu}_{\sigma}$ & $\overline{\mathrm{H}}, \mathrm{s}^{-1}$ \\
\hline \multirow{3}{*}{ Extrusion without the rest } & 0.889 & 1.161 & \multirow{3}{*}{1} & 0.027 \\
\hline & 0.908 & 1.162 & & 0.088 \\
\hline & 1.181 & 1.142 & & 0.297 \\
\hline \multirow{2}{*}{ Extrusion with the rest } & 3.25 & 0.17 & \multirow[t]{2}{*}{0.72} & 0.13 \\
\hline & 3.26 & 0.15 & & 0.38 \\
\hline
\end{tabular}

\section{Identifying the Plasticity Chart}

It follows from Tables 1-3 that the shear strain degree at the place of failure of the specimens of alloy 01570 does not practically depend on the amount of intensity of the shear strain rate within studied range $\mathrm{H}=0.02 \ldots 0.5 \mathrm{~s}^{-1}$. Therefore the function that specifies the ultimate plasticity chart will depend at the fixed test temperature of $360{ }^{\circ} \mathrm{C}$ only on parameters $k, \mu_{\sigma}$ and can be approximated by the formula [40]:

$$
\Lambda_{P}\left(k, \mu_{\sigma}\right)=a_{0}(k)+a_{1}(k) \cdot \mu_{\sigma}+a_{2}(k) \cdot \mu_{\sigma}^{2},
$$

where $a_{0}(k), a_{1}(k), a_{2}(k)$ - unknown functions from stress state parameter $k$ that depend on the material properties. At fixed value $\mu_{\sigma}$, the ultimate plasticity chart is usually described by the exponential dependence $[40,43]$ :

$$
\Lambda_{P}=\alpha \cdot \exp (\beta \cdot k),
$$

where $\alpha$ and $\beta$ are empirical coefficients.

Let us call as $\alpha_{(-1)}, \alpha_{(0)}, \alpha_{(+1)}$ and $\beta_{(-1)}, \beta_{(0)}, \beta_{(+1)}$ of the values of coefficients $\alpha$ and $\beta$ at $\mu_{\sigma}=-1, \mu_{\sigma}=0$, $\mu_{\sigma}=+1$, respectively. Then we can write:

$$
\begin{gathered}
\Lambda_{P}(k,-1)=\alpha_{(-1)} \cdot \exp \left(\beta_{(-1)} \cdot k\right), \\
\Lambda_{P}(k, 0)=\alpha_{(0)} \cdot \exp \left(\beta_{(0)} \cdot k\right), \\
\Lambda_{P}(k,+1)=\alpha_{(+1)} \cdot \exp \left(\beta_{(+1)} \cdot k\right) .
\end{gathered}
$$

After inserting the right parts of equations (9)-(11) and corresponding values $\mu_{\sigma}$ into equation (7), we obtain the following the equation system:

$$
\begin{gathered}
\alpha_{(-1)} \cdot \exp \left(\beta_{(-1)} \cdot k\right)=a_{0}(k)-a_{1}(k)+a_{2}(k), \\
\alpha_{(0)} \cdot \exp \left(\beta_{(0)} \cdot k\right)=a_{0}(k), \\
\alpha_{(+1)} \cdot \exp \left(\beta_{(+1)} \cdot k\right)=a_{0}(k)+a_{1}(k)+a_{2}(k) .
\end{gathered}
$$

When solving the system of equations (12), we express $a_{0}(k), \quad a_{1}(k)$ and $a_{2}(k)$ through $\alpha_{(-1)}, \alpha_{(0)}, \alpha_{(+1)}$, $\beta_{(-1)}, \beta_{(0)}, \beta_{(+1)}$ we obtain:

$$
a_{0}(k)=\alpha_{(0)} \cdot \exp \left(\beta_{(0)} \cdot k\right),
$$

$$
\begin{gathered}
a_{1}(k)=\alpha_{(+1)} \cdot \exp \left(\beta_{(+1)} \cdot k\right) / 2-\alpha_{(-1)} \cdot \exp \left(\beta_{(-1)} \cdot k\right) / 2, \\
a_{2}(k)=\alpha_{(+1)} \cdot \exp \left(\beta_{(+1)} \cdot k\right) / 2+\alpha_{(-1)} \cdot \exp \left(\beta_{(-1)} \cdot k\right) / 2- \\
-\alpha_{(0)} \cdot \exp \left(\beta_{(0)} \cdot k\right) .
\end{gathered}
$$

After inserting formulae (13) into equation (7), we finally obtain:

$$
\begin{gathered}
\Lambda_{P}=\alpha_{(0)} \cdot \exp \left(\beta_{(0)} \cdot k\right)+ \\
+\left(\alpha_{(+1)} \cdot \frac{\exp \left(\beta_{(+1)} \cdot k\right)}{2}-\alpha_{(-1)} \cdot \frac{\exp \left(\beta_{(-1)} \cdot k\right)}{2}\right) \cdot \mu_{\sigma}+ \\
+\left(\alpha_{(+1)} \cdot \frac{\exp \left(\beta_{(+1)} \cdot k\right)}{2}+\alpha_{(-1)} \cdot \frac{\exp \left(\beta_{(-1)} \cdot k\right)}{2}-\right. \\
\left.-\alpha_{(0)} \cdot \exp \left(\beta_{(-1)} \cdot k\right)\right) \cdot \mu_{\sigma}^{2} .
\end{gathered}
$$

In order to determine unknown coefficients in formula (14), we used a failure criterion for the linear damage accumulation model [11] as an objective function:

$$
\omega=\int_{0}^{\Lambda_{1}} \frac{d \Lambda_{P}}{\Lambda_{P}\left(k, \mu_{\sigma}\right)}=1,
$$

where $\Lambda_{1}-$ shear strain degree at the time of failure, and function $\Lambda_{P}\left(k, \mu_{\sigma}\right)$ is approximated by formula (14).

It is seen from Tables 1 and 2 that during the tensioning of the cylindrical and bell-shaped specimens the values of 
parameter $\mu_{\sigma}$ do not change in the course of tests and are equal to -1 and 0 respectively, therefore at the known history of change $k(\Lambda)$ and $k^{*}\left(\Lambda^{*}\right)$ (Fig. 1 and 6) and experimental values $\Lambda$ and $\Lambda^{*}$ coefficients $\alpha_{(-1)}=15.5$; $\alpha_{(0)}=2.39 ; \beta_{(-1)}=-1.53 ; \beta_{(0)}=-0.51$ were determined by minimizing the functional of square deviations from the achievement of criterion (15) individually for each type of tests:

$$
\sum_{i=1}^{N}\left(1-\omega_{j}\right)^{2} \rightarrow \min ,
$$

where $j=1 \ldots N$ - number of the tested specimen.

The variation of the unknown coefficients in formula (14) and those included in (15) respectively was carried out by the Hooke-Jeeves method [44]. Due to the fact that a research result may lead to a local minimum of the functional of square deviations (16) we selected not one initial search point, but a set of them. The Hooke-Jeeves method procedure was performed for each initial search point.

As a result of the made calculations equation (14) had two unknown coefficients $\alpha_{(+1)}$ and $\beta_{(+1)}$ that were determined by using a procedure similar to the above minimization of functional (16) concretized for the test results with regard to the thick-walled cups with thinned bottoms (Fig. 11). As a result, values $\alpha_{(+1)}=6.60$ and $\beta_{(+1)}=-1.74$ were obtained. Fig. 11 shows the ultimate plasticity chart with regard to alloy 01570. This chart is based on formula (14) with established empirical coefficients. The chart allows one to assess the alloy ultimate plasticity within the ranges of change of parameters $\mu_{\sigma}=-1 \ldots+1$ and $k=-0.6 \ldots+1.2$ as well as can be used when forecasting a failure with the use of damage models in plastic forming processes.

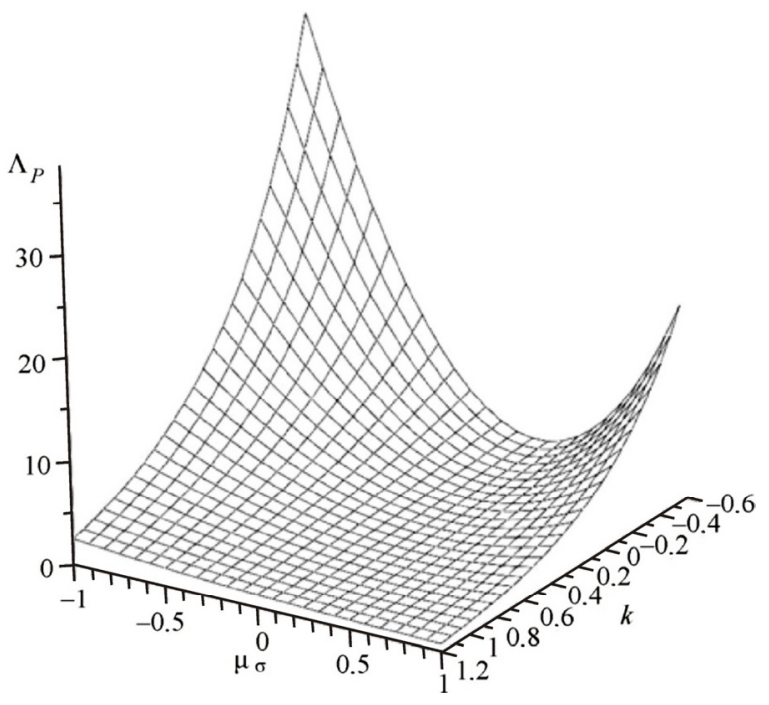

Fig. 12. Plasticity chart of alloy 01570

\section{Conclusion}

1. We propose a set of tests that can be used to study the separate effects of stress state parameter $k$ and Lode parameter $\mu_{\sigma}$ on the ultimate plasticity of metal materials at increased temperatures. In addition to traditional tensile tests of smooth cylindrical specimens and those having annular grooves, the proposed set of mechanical tests includes new specifically developed tests of bell-shaped specimens and those as thick-walled cups.

2. The test method was developed and approved with the use of the specimens of aluminum alloy 01570. The studies were carried out at the temperature of $360{ }^{\circ} \mathrm{C}$ and used the INSTRON 8801 servohydraulic testing system equipped with a hinged furnace.

3 . The mathematical simulation of the proposed new types of tests was performed for the purpose of determining the stress-strain state parameters. The adequacy of the simulation results was determined by comparing the experimental strain force with the model calculation results.

4. We established the absence of the strain rate effect on the studied alloy ultimate plasticity within the range of intensities of the shear strain rate $0.1<\mathrm{H}<0.5 \mathrm{~s}^{-1}$. The presence of the strain rate effect on ultimate plasticity does not critically change the used methodical approach but only increases the number of experiments.

5. According to the results of the proposed set of tests, we obtained the ultimate plasticity chart with regard to alloy 01570. This chart, when using damage mechanics models, can be used to forecast the studied alloy failure in plastic forming processes.

This work was financially supported by the Russian Science Foundation (Grant No. 14-19-01358) regarding the development and justification of the new methods of study of the stress state effect on the deformability of metal materials at high temperatures. The tests were conducted with the use of the equipment of the Center for Collective Use "Plastometria" of the Institute of Machines Science of the Ural Branch of the Russian Academy of Sciences.

\section{References}

1. Bridgman P.W. The Physics of High Pressure. London: G Bell and Sons, 1931. 398 p.

2. Bridgman P.W. Studies in large plastic flow and fracture with special emphasis on the effects of hydrostatic pressure. New York: McGraw-Hill, 1952. 362 p.

3. Beresnev B.I. et al. Some problems of large plastic deformation of metals at high pressure. New York: Pergamon press, $1963.79 \mathrm{p}$.

4. Kolmogorov V.L., Shishmintsev V.F. Ductility of steel as a function of hydrostatic pressure. Physics of Metals and Metallography, 1966, vol. 21, no. 6, pp. 97-101.

5. Babichkov V.A. Ob eksperimental'nykh teoreticheskikh osnovaniiakh mekhanicheskoi teorii prochnosti [About experimental and theoretical foundation of mechanical theory of strength]. Trudy MIIT. Moskow: Transzheldorizdat, 1951, pp. 15-19. 
6. Smirnov-Aliaev G.A., Rozenberg V.M. Teoriia plasticheskikh deformatsii metallov: mekhanika konechnogo formoizmeneniia [The theory of metal deformation: the final forming mechanics]. Moscow; Leningrad: Mashgiz., 1956. 367 p.

7. McClintock F.A. A criterion of ductile fracture by the growth of holes. Journal of Applied Mechanics, 1968, vol. 35, pp. 363-371. DOI: org/10.1115/1.3601204

8. Rice J.R., Tracey D.M. On the ductile enlargement of voids in triaxial stress fields. Journal of the Mechanics and Physics of Solids, 1969, vol. 17, pp. 201-217. DOI: org/10.1016/00225096(69)90033-7

9. Hancock J.W., Mackenzie A.C. On the mechanisms of ductile failure in high-strength steels subjected to multi-axial stress-states. Journal of the Mechanics and Physics of Solids, 1976, vol. 24 (2-3), pp. 147-160. DOI: org/10.1016/00225096(76)90024-7

10. Kolmogorov V.L., Shishmintsev V.F., Matveev G.A Ultimate deformability of metals tensile tested to failure under hydrostatic pressure. Physics of Metals and Metallography, 1967, vol. 23, no. 1, pp. 170-171.

11. Kolmogorov V.L. et al. Plastichnost' i razrushenie [Plasticity and destruction]. Moscow: Metallurgiia, 1977. 336 p.

12. Clausing D.P., Effect of plastic strain state on ductility and toughness. International Journal of Fracture Mechanics, 1970, vol. 6 (1), pp. 71-85. DOI: 10.1007/BF00183662

13. Lebedev A.A., Pisarenko G.S. Voprosy vysokotemperaturnoi prochnosti $\mathrm{v}$ mashinostroenii [Problems of high temperature plasticity in mechanical engineering]. Kiev: Akademiia nauk USSR, $1963.76 \mathrm{p}$.

14. Kolmogorov V.L. et al. The investigation of hydrostatic pressure and stress state influence on the plasticity of metals. High Temperatures - High Pressures, 1976, vol. 8, no. 6, pp. 675-676.

15. Vazhentsev Yu.G., Sedokov L.M. Strength and plasticity of some brittle materials under hydrostatic pressure. High Temperatures - High Pressures, 1976, vol. 8, no. 6, pp. 667-668.

16. Bogatov A.A. [et al.] Study of metal plasticity under hydrostatic-pressure. Fizika Metallov I Metallovedenie, 1978, vol.45, no. 5, pp. 1089-1094.

17. Xue L. Damage accumulation and fracture initiation in uncracked ductile solids subject to triaxial loading. International Journal of Solids and Structures, 2007, vol. 44, pp. 5163-5181. DOI: org/10.1016/j.ijsolstr.2006.12.026

18. Bai Y., Wierzbicki T. A new model of metal plasticity and fracture with pressure and Lode dependence. International Journal of Plasticity, 2008, vol. 24, no. 6, pp. 1071-1096. DOI: org/10.1016/j.ijplas.2007.09.004

19. Bai Y., Atkins T. Tension and shear cracking during indentation of ductile materials by opposed wedges. Engineering Fracture Mechanics, 2012, vol. 96, pp. 49-60. DOI: org/10.1016/j.engfracmech.2012.06.014

20. Xue L. Constitutive modeling of void shearing effect in ductile fracture of porous materials. Engineering Fracture Mechanics, 2008, vol. 75(11), pp. 3343-3366. DOI: 10.1016/j.engfracmech.2007.07.022

21. Xue L. Stress based fracture envelope for damage plastic solids. Engineering Fracture Mechanics, 2009, vol. 76, pp. 419-438. DOI: org/10.1016/j.engfracmech.2008.11.010

22. Mirone G., Corallo D. A local viewpoint for evaluating the influence of stress triaxiality and Lode angle on ductile failure and hardening. International Journal of Plasticity, 2010, vol. 26, pp. 348-371. DOI: 10.1016/j.ijplas.2009.07.006
23. Khan A.S., Liu H. A new approach for ductile fracture prediction on Al 2024-T351 alloy. International Journal of Plasticity, 2012, vol. 35, pp. 1-12. DOI: org/10.1016/j.ijplas.2012.01.003

24. Malcher L., Mamiya E.N. An improved damage evolution law based on continuum damage mechanics and its dependence on both stress triaxiality and the third invariant. International Journal of Plasticity, 2014, vol. 56, pp. 232-261. DOI: org/10.1016/j.ijplas.2014.01.002

25. Kolmogorov V.L. Napriazheniia, deformatsii, razrushenie [Stresses, strains, destruction]. Moscow: Metallurgiia, 1970. 229 p.

26. Del' G.D. Tekhnologicheskaia mekhanika [Technological mechanics]. Moscow: Mashinostroenie, 1978. 178 p.

27. Parshin V.A., Zudov E.G., Kolmogorov V.L. Deformiruemost' i kachestvo [Deformability and quality]. Moscow: Metallurgiia, 1979. $192 \mathrm{p}$.

28. Ogorodnikov V.A. Otsenka deformiruemosti metallov pri obrabotke davlenim [Evaluation of metals deformability under metal forming]. Kiev: Vishcha shkola, 1983. 176 p.

29. Bogatov A.A., Mizhiritskii O.I., Smirnov S.V. Resurs plastichnosti metallov pri obrabotke davleniem [Resource of metal plasticity under metal forming]. Moscow: Metallurgiia, 1984. 144 p.

30. Smirnov S.V., Vichuzhanin D.I., Nesterenko A.V. Metodika parametricheskoi identifikatsii diagrammy plastichnosti pri monotonnoi deformatsii [Fracture locus calibration method for monotonic deformation]. Vestnik Iuzhno-Ural'skogo gosudarstvennogo universiteta. Metallurgiia, 2011, no. 36 (253), pp. 70-75.

31. Lewandowski J.J., Lowhaphandu P. Effects of hydrostatic pressure on mechanical behavior and deformation processing of materials. International Materials Reviews, 1998, vol. 43, pp. 145-187.

32. Nishihara M., Miura S., Hirano T. Mechanical behavior of molybdenum and tantalum under high pressures at elevated temperatures. High Temperatures - High Pressures, 1972, vol. 4, pp. 281-291.

33. Vatamanu L.O., Lewandowski J.J. Pressure and temperature effects on tensile strength and plasticity of metallic glasses. Mechanics of Materials, 2013, vol. 67, pp. 86-93. DOI: 10.1016/j.mechmat.2012.11.011

34. Smirnov S.V. [et al.] An installation for material plasticity investigation under complex stressstrain state condition. Proc. of Int. Conf. MECAMAT-92. Paris, 1992, pp. 716-727.

35. Smirnov S.V. et al. Metodiki opredeleniia tekhnologicheskikh svoistv metalla i ego otdel'nykh so-stavliaiushchikh v usloviiakh slozhnogo nagruzheniia [Methods of determination of metal technological properties and its individual components under complicated load]. Izvestiia vuzov. Tsvetnaia metallurgiia, 1995, no. 2 , pp. 42-49.

36. Smirnov S.V. et al. Sravnitel'noe issledovanie plastichnosti prutkov iz vol'framovogo splava VA posle rotatsionnoi kovki i prokatki [A comparative study of plasticity of bars made of tungsten alloy VA after rotational forging and rolling]. Kuznechno-shtampovochnoe proizvodstvo. Obrabotka metallov davleniem, 1994, no. 8, pp. 2-4.

37. Smirnov S.V. et al. Deformation properties of sintered tungsten-based heavy alloys. Russian metallurgy (Metally), 2007, vol. 6, pp. 506-513. DOI: org/10.1134/S0036029507060110

38. Smirnov S.V., Nesterenko A.V., Shveikin V.P. Deformiruemost' molibdena pri izgotovlenii tonkostennyh trub [The deformability of molybdenum in the manufacture of thinwalled tubes]. Russian metallurgy (Metally), 2008, vol. 5, pp. 425-433. DOI: org/10.1134/S003602950805011X 
39. Davidenkov N.N., Spiridonova N.I. Mechanical methods of testing. Analysis of the state of stress in the neck of a tension test specimen. Proc. ASTM, 1946, vol. 46, pp. 1147-1158.

40. Smirnov S.V., Shveikin V.P. Plastichnost' i deformiruemost' uglerodistykh stalei pri obrabotke davleniem [Plasticity and deformability of carbon steels under metal forming]. Ekaterinburg: Ural'skoe otdelenie Rossiiskoi akademii nauk, 2009. 255 p.

41. Bao Y., Wierzbicki T. On fracture locus in the equivalent strain and stress triaxiality spase. International Journal of Mechanical Sciences, 2004, vol. 46 (1), pp. 81-98. DOI: 10.1016/j.ijmecsci.2004.02.006
42. Levanov A.N. et al. Kontaktnoe trenie v protsessakh obrabotki metallov davleniem [Contact friction in the processes of metal forming]. Moscow: Metallurgiia, 1976. $416 \mathrm{p}$.

43. Smirnov S.V., Domilovskaya T.V., Bogatov A.A. Definition of the form for kinetic equation of damage during the plastic deformation. Advanced Methods in Materials Processing Defects. Ed. by M. Predeleanu, P. Gilormini. Elsivier Science, 1997, pp. 71-80.

44. Hooke R., Jeeves T.A. Direct search. solution of numerical and statistical problems. Journal of the ACM, 1961, vol. 8, pp. 212-229. DOI: org/10.1145/321062.321069

Original Russian Text:

Smirnov S.V., Vichuzhanin D.I., Nesterenko A.V. A set of tests for studying the effect of the stress state on ultimate metal plasticity at high temperature. PNRPU Mechanics Bulletin. 2015, no. 3, pp. 146-164. DOI: 10.15593/perm.mech/2015.3.11 


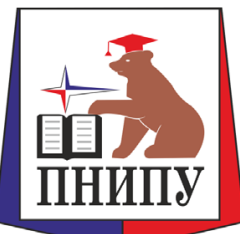

\title{
PNRPU MECHANICS BULLETIN
}

№ 3-4, 2018

http://vestnik.pstu.ru/mechanics/about/inf/

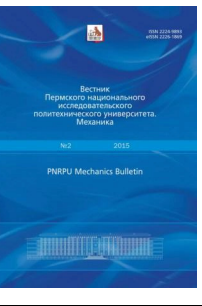

DOI: $10.15593 /$ perm.mech/eng.2018.3.12

UDC 539.4

\section{COMPLETE ASYMPTOTIC EXPANSION M. WILLIAMS NEAR THE CRACK TIPS OF COLLINEAR CRACKS OF EQUAL LENGTHS IN AN INFINITE PLANE MEDIUM}

\section{L.V. Stepanova, P.S. Roslyakov}

\author{
Samara State University, Samara, Russian Federation
}

\section{ARTICLE INFO}

Received: 11.07.2014

Accepted: 20.08.2014

Published: 25.12.2018

\section{Keywords:}

multiparametric description of the near crack tip stress filed, analytical solution, infinite plate with two collinear cracks, asymptotic expansion, amplitude coefficients of the complete asymptotic Williams expansions, higher-order terms.

\begin{abstract}
The paper is aimed at analytical determination of the coefficients in crack tip expansions for two collinear finite cracks of equal length in an infinite plane medium under mixed mode loading conditions. The study is based on the solutions of the complex variable theory in plane elasticity theory and the complete asymptotic Williams expansion of the stress field in the vicinity of the crack tip. From the practical point of view, it is very important to know: 1) analytical dependence of coefficients on geometrical parameters of specimens and applied loads; 2) the number of higherorder terms in the asymptotic Williams expansions that we need to keep to accurately describe the stress and displacement fields in the neighborhood of the crack tip. In the paper the authors have provided a multiparametric presentation of the stress filed near the crack tips in the infinite plate with two collinear cracks of finite length. We have presented the analytical determination method of coefficients related to the complete asymptotic expansion. The method is based on the complex variable theory and the classical Kolosoff-Muskhelishvili approach. The expansion of the KolosoffMuskhelishvili's potential in the vicinity of the crack tip allows to find the analytical presentation for coefficients of the complete Williams asymptotic expansion. The analytical solution gives the dependence of the amplitude coefficients on the lengths of the crack and the applied loads for pure mode I, pure mode II and mixed mode I/II conditions. It is shown that together with the main term including the stress intensity factor and the term called T-stress, it is necessary to hold higherorder terms in the asymptotic solution. The obtained solution permits to construct the asymptotic stress field expansion containing an arbitrary preassigned number of higher-order terms.
\end{abstract}




\section{Introduction. Asymptotic fields near the crack tip in the linear elastic material}

Describing the stress field in the vicinity of a crack, incision or a corner cut by means of an asymptotic expression containing high-order terms is an actual task of fracture mechanics $[1,2]$. Fracture mechanics has recently demonstrated [3-35], that the engineering applications of the traditional linear fracture mechanics, based on the only parameter, being the stress intensity factor, as the fault propagation criterion, require improvement and consideration of higher approximations in the complete asymptotic Williams expansion [39]. The multiparameter description of a stress field in the vicinity of a crack tip was suggested back in the year 1957 by M. Williams [39]. Since then, the solution of $\mathrm{M}$. Williams has been the classic solution of the linear fracture mechanics, where, however, in the most engineering applications only the first term was used, with the amplitude coefficient getting the title of the stress intensity factor. Only in the latest times, on the basis of the theoretical investigations, experimental works and computer simulation modelling [3-33], the fracture mechanics has formed a clear understanding of the need to hold the higher approximations within the complete asymptotic expression of the stress field in the vicinity of the crack tip.

The paper [3] review the researches dedicated to the assessment of T-stresses in the complete M. Williams solution in the vicinity of the crack tip. The authors describe various aspects of the impact made by T-stresses on the crack propagation trajectory, on the reproduction of the isochromatic lines picture, on the evaluation of the dimensions and the shape of the plastic yield area. The article discusses various methods of T-stress detection: experimental, analytical and numerical (finite element method). Authors provide a critical review of the existing researches and arrive at the conclusion that consideration of T-stress alone cannot ensure the accurate and reliable forecast of the crack propagation direction. For this reason, it requires the consideration of the high terms in the asymptotic expression of the stress field in the vicinity of the crack tip.

[4] discusses weak properties of the stress field in the vicinity of the crack tip (a typical example of which would be free edges of the laminate composite materials and the point lying in the joint lines of several materials) and the need for improved fracture criteria that would consider weaker singularity of the stress field. The work presents two models of crack formation at the junction of two materials.

Shlyannikov V.N. and Zakharov A.P. [5] made an experimental and numeric evaluation of the fatigue crack propagation rate under different systems of biaxial loading. $\mathrm{T}$-stresses were calculated for the $\mathrm{X}$-shaped specimens under mixed mode loading conditions. The mixed loading experiment analysis carried out by the authors is based on including the T-stresses into the computation model.
In [6] it is remarked that in many practical situations the contribution of high terms in the complete Williams expansion (besides the stress intensity factor and T-stresses) in engineering applications is not negligible. The main objective of [6] was to present equations that would accurately describe the stress fields in the vicinity of the crack tip, especially in the cases when the stress intensity factors for the opening mode cracks and transverse shear cracks combined with T-stresses cannot describe the stress distribution by the crack tip with the required accuracy. [6] studies a plane with a central crack under mixed mode loading conditions to demonstrated the need of holding the high terms. It is demonstrated that the deformation energy may be analytically computed with high accuracy provided that the four terms following the main asymptotic expansion member and T-stress are held.

[7] performs a systematic research of T-stresses and their contribution into the common stress field in the vicinity of the crack tip in a compact specimen. It studies the dependence of $\mathrm{T}$-stresses of the geometrical properties of the specimen. The objective of [8] is the determination of the stress intensity factors, T-stresses and three more terms in the complete asymptotic M. Williams expansion for two disc-shaped specimens in the complete diapason of mixed deformation forms. The work calculates the dimensionless functions of the factors of the singular, second and third members in the asymptotic stress expansions near the crack tip in disc-shaped specimens under mixed mode loading conditions (as a rule, they are defined $A_{3}, B_{3}$ for opening mode cracks and transverse shear cracks correspondingly). It is demonstrated that the amplitude scale coefficient in the third term is an important parameter characterizing the stress field near the crack tip.

In [9], the theoretical and experimental marble fracture research based on a number of specimens and mixed loading tests demonstrated that the high terms in complete asymptotic M. Williams expansion may make a significant impact on the assessment of rock resistance power. To determine the direction of crack propagation, the authors used the modified maximal tangential stress criterion that considered the non-singular terms in the asymptotic expansion as a component of stress tensor (T-stresses, $\left.A_{3}, B_{3}\right)$ in addition to the singular terms. The modified criterion was used for the analysis of triangular-shaped specimens. It was proved that the modified criterion considering the high approximations in the asymptotic $\mathrm{M}$. Williams expansion ensures a better compliance with the experimental data.

[10] notices the need of accurate analysis of the stress fields in the vicinity of the crack tip for a great number of engineering applications. The authors demonstrate that the higher-order terms in the asymptotic M. Williams expansion should not be neglected.

The objective of [11] is to describe the stress fields and shears in vicinity of the crack tip and at a distance from it in a number of experimental specimens for the determination 
of the fracture mechanics parameters. The article suggests specimens of new geometry for considering a wide scale of loading types and evaluating the dimensions of the nonlinear deformation areas occurring near the crack tip. For a four-point bending test, incised prismatic shapes were offered. Along with the experimental research, a numerical modeling for the same samples was done. In the asymptotic stress field expansion, the singular term, T-stress and higher approximations (non-singular terms) were held. The article compares the experimental results, the numerical analysis and the suggested asymptotic expansions depending on their distance to the crack tip, and the number of held terms in the asymptotic expansions. It demonstrates the efficiency of the suggested approach for the determination of the nonlinear deformation area size by the incision tip in the composite silicate material. Such materials are characterized with quasi-brittle behavior when fractured with the nonlinear softening zone by the crack tip. It has been stated that in the case of bending, the changes in the proportions of the geometric parameters of the tested specimens and the fulcrum position do not make a significant impact on the width of the non-linear area.

The work [12] presents the analysis of stress fields and shears by the crack tip in specimens with an edge crack used for penetration tests. In English literature, such specimens are referred to as WST-specimens. A multiparameter analysis of the stress field has been made, after which the non-singular terms were held in the asymptotic M. Williams expansion. The impact made by the edge conditions (specimen fixation conditions) on the stress intensity factor and the T-stresses has been studied. All in all, the analysis allows to consider up to 12 terms in the asymptotic expansion. The coefficients have been determined from the experimental data. The determined asymptotic expansion coefficients were used for the stress field reconstruction and further comparison with the computations based on the finite element method. The comparison clearly demonstrates that for long cracks and long distances from the crack tip, the asymptotic description of the stress field requires holding several terms in the complete asymptotic expansion of the stress field by the crack tip.

Article [13] considers three specimens, classic for fracture mechanics: a plate with one side incision, a place with a central crack in the uniaxial extension conditions and a plate with a central crack in the pure shear conditions. For describing the stress field by the crack tip, M. Williams asymptotic expression with held higher-order approximations was used. The amplitude expansion factors (scale coefficients) were determined from the finite element modeling results carried out with the multipurpose finiteelement program that allows studying specimen with various geometric proportions. The amplitude coefficients were found with the deterministic method suggested in [14], and the performed multiparameter analysis proves that one or even two M. Williams asymptotic expansion members are not enough. For acquiring reliable evaluations and for widening the asymptotic M. Williams expansion scope (for widening the asymptotic scope), the higher approximations shall be held.

The authors of [15] remark, that the main task in designing ceramic laminar materials is increasing the fracture energy of the "body - crack" system in the process of the energy release cased by the crack formation and its further propagation. For the ceramic composite materials, the occurrence of cracks in the composite layers and their bifurcate behavior is typical; for this reason, it is essential to forecast the direction of the crack propagation in modeling the ceramic composite materials. The experiments show that the second term in the asymptotic M. Williams expansion may be relevant in the description of the bifurcate behavior of a crack.

On the example of a bar with an edge incision exposed to a four-point bending test, the authors of [16] evaluate the impact of the higher terms in the complete asymptotic M. Williams expansion. The considered loading pattern may be used for practicing the loading of the cracked specimens and studying the various values of the mixed loading parameter. Relying on the Rankine criterion, the authors determine the plastic yield area configuration in the direct vicinity from the crack tip for the studied specimen. The article presents the computer modeling of loading of the described specimen with the finite element method in order to calculate the parameters of the complete asymptotic M. Williams expansion and to evaluate the geometry of the plastic yield area. The calculation results demonstrate that the higher approximations in the asymptotic expression of the stress field may be relevant, if the stretch of the nonlinear deformation area is large enough in comparison to the dimensions of the specimen. [17] presents the analytical presentations of the factors of the complete asymptotic expansion of the stress field by the finite crack tip in an infinite linear elastic plate. On the basis of the analytical solution of the elementary crack problem, the dependence of the scale coefficients on the crack length and system of applied loads was found for 1) an opening mode crack; 2) a pure transverse plane shear with an incision and 3) a mixed mode loading of a plate with a fault. $[18,19]$ discuss the issues of multi-parameter presentation of the stress field near the crack tip in an isotropic linear elastic material on the basis of the complete M. Williams expansion, and the accuracy of the deterministic method for the complete asymptotic expansion coefficient computation. The articles [20-28] are dedicated to various aspects of the polynomial asymptotic expansions of the stress field in the vicinity of the crack tip in linear elastic materials [21], in media with more compound rheology [22-28], and the issues of solving the related non-linear eigenvalue problems. [25] considers the solutions of the boundary problems obtained with regard to the higher approximations in the asymptotic presentations of the stress tensor components by the track tip for the cases of mixed deformation of specimens with faults.

[29] demonstrates the need for considering both singular and non-singular stress tensor components by the 
crack tip and the incision in the parametric and criterial problems of fracture mechanics. It discusses the spacial and two-dimensional models and criteria taking the T-stresses into account. Their use is demonstrated on the example of solving the problems of fracture mechanics including analysis of the stressed-deformed conditions in the vicinity of the crack tip, the experimental detection of crack resistance, the master-curve and the general diagram of crack resistance of bodies with cracks and incisions, forecasting of the mixed mode cracks propagation directions.

[30] presents the models and criteria of the fracture mechanics for the bodies with cracks, considering the nonsingular expansion terms of the stresses by the crack tip, developed for the analysis of fracture of the bodies with incisions in case of a normal fracture. It provides the criterial equations and ultimate curves for the fracture assessment. The authenticity of the suggested criterion is confirmed by the test results obtained on the specimen with through-cracks under various temperatures.

[31] presents the method of detecting the singular and non-singular components of the stress field in the neighborhood of the crack tip in the presence of the initial data error caused by the experimental or modeling inaccuracies. On the basis of the numeric experiments it was proved that the method of expansion of the tapered incision elasticity theory problem solution (asymptotic M. Williams solution) in eigenfunctions provides the opportunity of detecting the sought parameters with the accuracy consistent for engineering practice even in the presence of a significant error. The work presents the method of approximate assessment of the area where the modeling conditions of a plane elastic problem, caused by the presence of plastic deformation, geometric peculiarities or other factors, are not satisfied.

[33] suggests a method for detecting the stress and T-stress intensity factor for the opening mode crack on the basis of measuring the local deformation responses caused by the small increments of its length. The responses in the form of tangential displacement fields are registered with the electronic (digital) speckle interferometry. The experimental data interpretation is based on the complete asymptotic M. Williams expansion.

Matvienko Yu.G. considered [34] two possible models and criterial equations of the fracture mechanics of the bodies with incisions, considering the non-singular expansion terms by the incision (crack) tip and based on the crack resistance diagrams and the master curve. A criterial equation of the general crack resistance diagram, equally acceptable for a body with a crack and incision and considering the change in the deformation constraint by the incision tip as a result of the finiteness of the rounding radius of its tip and the non-singular component of the stresses ( $T$-stresses) is provided. The article introduces the definition of effective $T$-stresses, determined through averaging the $T$-stresses before the incision tip in the prefracture area, characterized with an effective distance.
The basic dependence of the fracture toughness in the function of the effective $T$-stresses (master curve) of pipe steel is built for the given incision geometry. [35] presents the promising models and criteria of the two-parameter fracture mechanics, considering the properties of the stressstrain behavior in the neighborhood of the crack-like fault tip. It draws the theoretical and experimental conclusions, allowing to assess the crack trajectory, construction strength and durability of the damaged critical elements with regard to the non-singular stress field component near the crack (incision) tip.

It can be concluded, therefore, that in the today's fracture mechanics there is an established clear understanding of the need of holding the high approximations in the complete asymptotic M. Williams expansion and the necessity for developing the methods and approaches for acquiring analytical dependences of the coefficients on the specimen geometry and the applied loading systems, and, therefore, for expanding the tables containing the found assessments for the stress intensity factors for various specimens, presentations for the higher term coefficients.

The present work studies the deformation of a plate with two collinear finite cracks of equal length, in the vicinity of which the asymptotic expressions of the stress field containing higher terms are built. It provides analytical expressions for the scale factors (coefficients) as functions of the crack length, crack tip coordinates and the applied load.

\section{Complete asymptotic M. Williams expansion of the stress field by the crack tip}

Complete asymptotic expression of the stress field in the neighborhood of the crack tip containing high-order terms, the asymptotic M. Williams solution, is the general description of the stress field near the crack tip [1, 2]. Asymptotic M. Williams expansion for each specimen configuration contains a sequence of coefficients depending on the geometric parameters of the specimen and the applied loading system. There are widely known analytical expressions for the first two terms in the asymptotic expansions of the stress field: for the stress intensity factors and $\mathrm{T}$-stresses for the great number of configurations of specimens with cracks $[1,17]$. Determination of the higher approximation coefficients as functions of the applied load and the geometry of the studied specimen with a crack is a more complicated task to solve. This work presents analytic expressions for the coefficients of the complete asymptotic M. Williams expansion of the stress field in the neighborhood of the tips of two collinear cracks in an infinite plane medium under mixed mode loading conditions, when the infinite medium is exposed to tension and shear load. The identification of the complete asymptotic M. Williams expansion coefficients is based on the precise analytic solution of the problem obtained with the classic comprehensive presentation of the plane 
elasticity theory problem solution [40, 41]. Using the eigenfunctions expansion method, M. Williams [39] presented Airy stress function in the neighborhood of the crack tip in the form $\chi(r, \theta)=\sum_{i} f_{i}(\theta) r^{\lambda_{i}}$, where $f_{i}(\theta)$ and $\lambda_{i}$ are eigenfunctions and eigenvalues correspondingly. At that, the stress tensor components in the neighborhood of the crack tip get the form

$$
\sigma_{i j}(r, \theta)=\sum_{m=1}^{2} \sum_{k=-\infty}^{\infty} a_{k}^{m} f_{k}^{m, i j}(\theta) r^{k / 2-1},
$$

where index $m$ corresponds to the load type $(m=1$ corresponds to the normal fracture, $m=2$ corresponds to transverse shear), coefficients $a_{k}^{m}$ depend on the geometry of the cracked specimens and the applied loading system, $f_{k}^{m, i j}(\theta)$ are the universal angular distributions determined in the process of the boundary problem solving. The angular stress distributions are well known [17] in (1):

$$
\begin{aligned}
& f_{k}^{1,11}(\theta)= k\left[\left(2+k / 2+(-1)^{k}\right) \cos (k / 2-1) \theta-\right. \\
&-(k / 2-1) \cos (k / 2-3) \theta] / 2, \\
& f_{k}^{1,22}(\theta)= k\left[\left(2+k / 2-(-1)^{k}\right) \cos (k / 2-1) \theta+\right. \\
&+(k / 2-1) \cos (k / 2-3) \theta] / 2, \\
& f_{k}^{1,12}(\theta)=k[(k / 2-1) \sin (k / 2-3) \theta- \\
&\left.-\left(k / 2+(-1)^{k}\right) \sin (k / 2-1) \theta\right] / 2, \\
& f_{k}^{2,11}(\theta)=-k\left[\left(2+k / 2-(-1)^{k}\right) \sin (k / 2-1) \theta-\right. \\
&-(k / 2-1) \sin (k / 2-3) \theta] / 2, \\
& f_{k}^{2,22}(\theta)=-k\left[\left(2-k / 2+(-1)^{k}\right) \sin (k / 2-1) \theta+\right. \\
&+(k / 2-1) \sin (k / 2-3) \theta] / 2, \\
& f_{k}^{2,12}(\theta)=k[(k / 2-1) \cos (k / 2-3) \theta- \\
&\left.-\left(k / 2-(-1)^{k}\right) \cos (k / 2-1) \theta\right] / 2 .
\end{aligned}
$$

Such properties of the crack mechanics boundary problems as the geometry of the incised area, the nature and intensity of the applied load do not constitute a part of either the radial or angular distribution of the stress tensor components. Therefore, the entire variety of fracture

mechanics problems is solved with the coefficients $a_{k}^{m}$. According to the definition, the stress intensity factor equal to

$$
K_{\mathrm{I}}=\lim _{r \rightarrow+0} \sqrt{2 \pi r} \sigma_{22}(r, 0), \quad K_{\mathrm{II}}=\lim _{r \rightarrow+0} \sqrt{2 \pi r} \sigma_{12}(r, 0) .
$$

Considering the (1-3) correlation, it is possible to find

$$
\begin{gathered}
K_{\mathrm{I}}=\sqrt{2 \pi} a_{1}^{1} f_{1}^{1,22}(0), \quad K_{\mathrm{II}}=\sqrt{2 \pi} a_{1}^{2} f_{1}^{2,12}(0), \\
T=a_{2}^{1} f_{2}^{1,11}(0) .
\end{gathered}
$$

By the present moment, fracture mechanics has developed a clear understanding of the need of holding the high-order terms in the complete asymptotic M. Williams expansion, and, therefore, of the necessity of determining its coefficients $a_{k}^{m}$ for various specimens frequently used in engineering practice [6-36]. One of the promising methods of finding the analytic expressions for the asymptotic expansion coefficients is the method based on the comprehensive stress field presentation - the KolosoffMuskhelishvili approach [40, 41] and the further merge of the analytic solution obtained with the complex variable function theory with the asymptotic solution of $\mathrm{M}$. Williams. The analytic presentations of the complete asymptotic M. Williams expansion coefficients for the infinite plate medium with two collinear cracks are shown below (Fig. 1).

\section{Comprehensive presentation of the plane medium with two collinear incisions loading problem solution}

The complex variable function theory provides a convenient mathematic tool for solving the plane elasticity problems. The approach initially suggested by Kolosoff [40] and developed by Muskhelishvili [41] is based on the introduction of the Airy stress function determined with the expressions

$$
\begin{gathered}
\sigma_{11}\left(x_{1}, x_{2}\right)=\frac{\partial^{2} \Phi}{\partial x_{2}^{2}}, \quad \sigma_{22}\left(x_{1}, x_{2}\right)=\frac{\partial^{2} \Phi}{\partial x_{1}^{2}}, \\
\sigma_{12}\left(x_{1}, x_{2}\right)=-\frac{\partial^{2} \Phi}{\partial x_{1} \partial x_{2}} .
\end{gathered}
$$

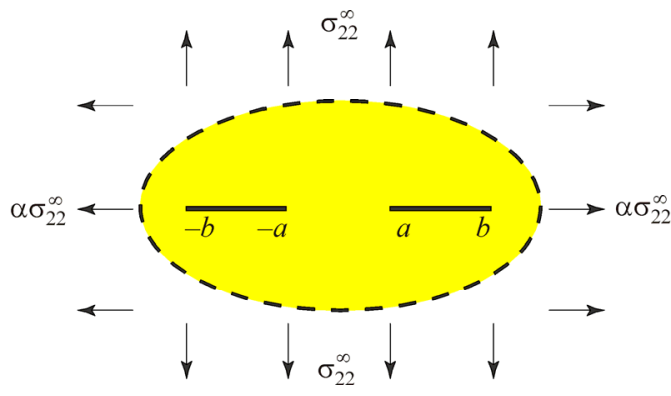

$a$

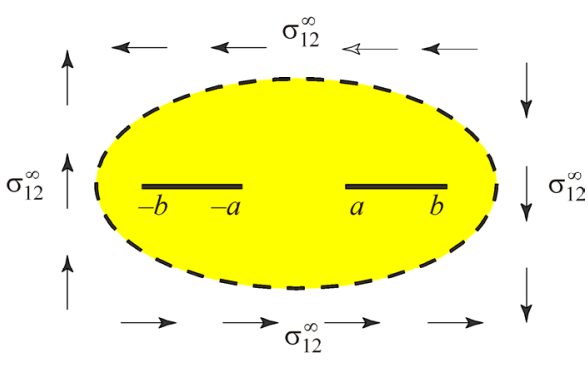

$b$

Fig. 1. Loading the plate with two collinear cracks of equal length: $a$ ) symmetric, $b$ ) asymmetric 
Following the Kolosoff-Muskhelishvili formalism, the biharmonic equation solution for the Airy stress function can be presented with the two complex potentials of the variable $z=x_{1}+i x_{2}$ :

$$
\Phi\left(x_{1}, x_{2}\right)=\operatorname{Re}[\bar{z} \varphi(z)+\chi(z)]
$$

where $\operatorname{Re}[]$ stands for the real part of the complex variable function. Combining the two latter correlations, it is possible to get the classic presentation of the stress tensor components

$$
\begin{gathered}
\sigma_{11}(z)+\sigma_{22}(z)=4 \operatorname{Re}\left[\varphi^{\prime}(z)\right], \\
\sigma_{22}(z)-\sigma_{11}(z)+2 i \sigma_{12}(z)=2\left[\bar{z} \varphi^{\prime \prime}(z)+\chi^{\prime}(z)\right] .
\end{gathered}
$$

Below, the complex solutions for the plate medium with two collinear cracks in the conditions of 1) normal fracture; 2) transverse shear; 3 ) mixed mode loading (normal fracture and transverse shear, index 1 corresponding to the normal fractures and 2 - to transverse shear) will be used. Since it is obvious that for a linear elastic isotropic medium the superposition principle is valid, the linear combination of solutions for the cases 1) and 2) provides an opportunity to get a comprehensive solution for mixed mode loading in the complete diapason of mixed forms of deformation of the plate with two collinear cracks.

For the normal fracture crack, the edge conditions on the infiniteness are formulated as follows

$$
\lim _{|z| \rightarrow+\infty}\left[\sigma_{11}(z), \sigma_{12}(z), \sigma_{22}(z)\right]=[\alpha, 0,1] \sigma_{22}^{\infty},
$$

for a transverse shear crack, the conditions in the point of infinity have the form of

$$
\lim _{|z| \rightarrow+\infty}\left[\sigma_{11}(z), \sigma_{12}(z), \sigma_{22}(z)\right]=[0,1,0] \sigma_{12}^{\infty} .
$$

In case of the biaxial symmetric strain of the plate (Fig. 1, a) the comprehensive stress field presentation has the form $[17,40,41]$

$$
\begin{gathered}
\sigma_{11}^{1}(z)=2 \operatorname{Re}\left[\varphi_{1}^{\prime}(z)\right]-2 x_{2} \operatorname{Im}\left[\varphi_{1}^{\prime \prime}(z)\right]+(\alpha-1) \sigma_{22}^{\infty} / 2, \\
\sigma_{22}^{1}(z)=2 \operatorname{Re}\left[\varphi_{1}^{\prime}(z)\right]+2 x_{2} \operatorname{Im}\left[\varphi_{1}^{\prime \prime}(z)\right]-(\alpha-1) \sigma_{22}^{\infty} / 2, \\
\sigma_{12}^{1}(z)=-2 x_{2} \operatorname{Re}\left[\varphi_{1}^{\prime \prime}(z)\right] .
\end{gathered}
$$

The complex potential $\varphi_{1}{ }^{\prime}(z)$ of the plate medium with two collinear cracks is determined with the formula [41]

$$
\varphi_{1}^{\prime}(z)=\frac{\sigma_{22}^{\infty}}{2} \frac{z^{2}-c}{\sqrt{\left(z^{2}-a^{2}\right)\left(z^{2}-b^{2}\right)}}+(\alpha-1) \frac{\sigma_{22}^{\infty}}{4},
$$

$c=b^{2} E(\pi / 2, k) / F(\pi / 2, k), \quad k=\sqrt{1-a^{2} / b^{2}}, \quad$ where $F(\pi / 2, k), \quad E(\pi / 2, k)$ are complete normal Legendre elliptic integral of the first kind. Expressions (4) with regard to (5) for the symmetric load of the crack (Fig. 1,a) get the form

$$
\begin{aligned}
& \sigma_{11}^{1}(z)=\sigma_{22}^{\infty}\left\{\operatorname{Re}\left[\frac{z^{2}-c}{\sqrt{\left(z^{2}-a^{2}\right)\left(z^{2}-b^{2}\right)}}\right]+(\alpha-1) \sigma_{22}^{\infty}-\right. \\
& \left.-x_{2} \operatorname{Im}\left[z \frac{2\left(z^{2}-a^{2}\right)\left(z^{2}-b^{2}\right)-\left(z^{2}-c\right)\left(2 z^{2}-a^{2}-b^{2}\right)}{\left(z^{2}-a^{2}\right)^{3 / 2}\left(z^{2}-b^{2}\right)^{3 / 2}}\right]\right\} \text {, } \\
& \sigma_{22}^{1}(z)=\sigma_{22}^{\infty}\left\{\operatorname{Re}\left[\frac{z^{2}-c}{\sqrt{\left(z^{2}-a^{2}\right)\left(z^{2}-b^{2}\right)}}\right]+\right. \\
& \left.+x_{2} \operatorname{Im}\left[z \frac{2\left(z^{2}-a^{2}\right)\left(z^{2}-b^{2}\right)-\left(z^{2}-c\right)\left(2 z^{2}-a^{2}-b^{2}\right)}{\left(z^{2}-a^{2}\right)^{3 / 2}\left(z^{2}-b^{2}\right)^{3 / 2}}\right]\right\} \\
& \sigma_{12}^{1}(z)=-\sigma_{22}^{\infty} x_{2}\left\{\operatorname { R e } \left[\frac{2 z}{\sqrt{\left(z^{2}-a^{2}\right)\left(z^{2}-b^{2}\right)}}-\right.\right. \\
& \left.\left.-\frac{z\left(z^{2}-c\right)\left(2 z^{2}-a^{2}-b^{2}\right)}{\left(z^{2}-a^{2}\right)^{3 / 2}\left(z^{2}-b^{2}\right)^{3 / 2}}\right]\right\} \text {. }
\end{aligned}
$$

For the transverse shear crack (Fig. 2, $b$ ), the stress field is determined with the complex potential $\varphi_{2}^{\prime}(z)$ :

$$
\begin{gathered}
\sigma_{11}^{2}(z)=2 \operatorname{Re}\left[\varphi_{2}^{\prime}(z)\right]-2 x_{2} \operatorname{Im}\left[\varphi_{2}^{\prime \prime}(z)\right], \\
\sigma_{22}^{2}(z)=2 x_{2} \operatorname{Im}\left[\varphi_{2}^{\prime \prime}(z)\right], \\
\sigma_{12}^{2}(z)=-2 \operatorname{Im}\left[\varphi_{2}^{\prime}(z)\right]-2 x_{2} \operatorname{Re}\left[\varphi_{2}^{\prime \prime}(z)\right]-C_{2} .
\end{gathered}
$$

In accordance with [41], the complex potential $\varphi_{2}^{\prime}(z)$ has the form

$$
\begin{gathered}
\varphi_{2}^{\prime}(z)=-i\left(\sigma_{12}^{\infty} / 2\right)\left[\left(z^{2}-c\right) / \sqrt{\left(z^{2}-a^{2}\right)\left(z^{2}-b^{2}\right)}\right]+i \sigma_{12}^{\infty} / 2 \\
C_{2}=\sigma_{12}^{\infty}
\end{gathered}
$$

The stress tensor components for the asymmetric loading of the crack get the form

$$
\begin{gathered}
\sigma_{11}^{2}(z)=\sigma_{12}^{\infty}\left\{2 \operatorname{Im}\left[\frac{z^{2}-c}{\sqrt{\left(z^{2}-a^{2}\right)\left(z^{2}-b^{2}\right)}}\right]+\right. \\
\left.+x_{2} \operatorname{Re}\left[z \frac{2\left(z^{2}-a^{2}\right)\left(z^{2}-b^{2}\right)-\left(z^{2}-c\right)\left(2 z^{2}-a^{2}-b^{2}\right)}{\left(z^{2}-a^{2}\right)^{3 / 2}\left(z^{2}-b^{2}\right)^{3 / 2}}\right]\right\} \\
\sigma_{22}^{2}(z)=-\sigma_{12}^{\infty} x_{2} \operatorname{Re}\left[\frac{2 z}{\sqrt{\left(z^{2}-a^{2}\right)\left(z^{2}-b^{2}\right)}}-\right. \\
\left.-\frac{z\left(z^{2}-c\right)\left(2 z^{2}-a^{2}-b^{2}\right)}{\left(z^{2}-a^{2}\right)^{3 / 2}\left(z^{2}-b^{2}\right)^{3 / 2}}\right]
\end{gathered}
$$




$$
\begin{gathered}
\sigma_{12}^{2}(z)=\sigma_{12}^{\infty}\left\{\operatorname{Re}\left[\frac{z^{2}-c}{\sqrt{\left(z^{2}-a^{2}\right)\left(z^{2}-b^{2}\right)}}\right]-\right. \\
\left.-x_{2} \operatorname{Im}\left[z \frac{2\left(z^{2}-a^{2}\right)\left(z^{2}-b^{2}\right)-\left(z^{2}-c\right)\left(2 z^{2}-a^{2}-b^{2}\right)}{\left(z^{2}-a^{2}\right)^{3 / 2}\left(z^{2}-b^{2}\right)^{3 / 2}}\right]\right\} .
\end{gathered}
$$

Fig. 2-4 demonstrates the lines of equal levels of the stress tensor components and the stress intensity in the plate medium with two collinear cracks of equal length for different types of mixed mode loading in the full diapason of loads characterized with the promiscuity parameter $M^{e}=(2 / \pi) \operatorname{arctg}\left(\sigma_{22}^{\infty} / \sigma_{12}^{\infty}\right):$ from normal fracture $\left(M^{e}=1\right)$
(Fig. 2, a) to transverse shear $\left(M^{e}=0\right)$ (Fig. 4, a). The diagrams are constructed with the formulae (6) for normal fracture, (8) for transverse shear and superposition of solutions (6) and (8) for mixed mode loading. The geometric parameters of the collinear cracks equal to $a /(2 l)=1, b /(2 l)=2$, where $l$ is the crack half-length.

Fig. $4, b$ shows the level lives of the stress tensor component for closer located cracks: for the following values of the geometric parameters $a /(2 l)=0.25, b /(2 l)=1.25$. The figures show that at $a /(2 l)=0.25, b /(2 l)=1.25$ the cracks make a stronger impact on each other in comparison to the previously considered geometric parameters $a /(2 l)=1, b /(2 l)=2$.

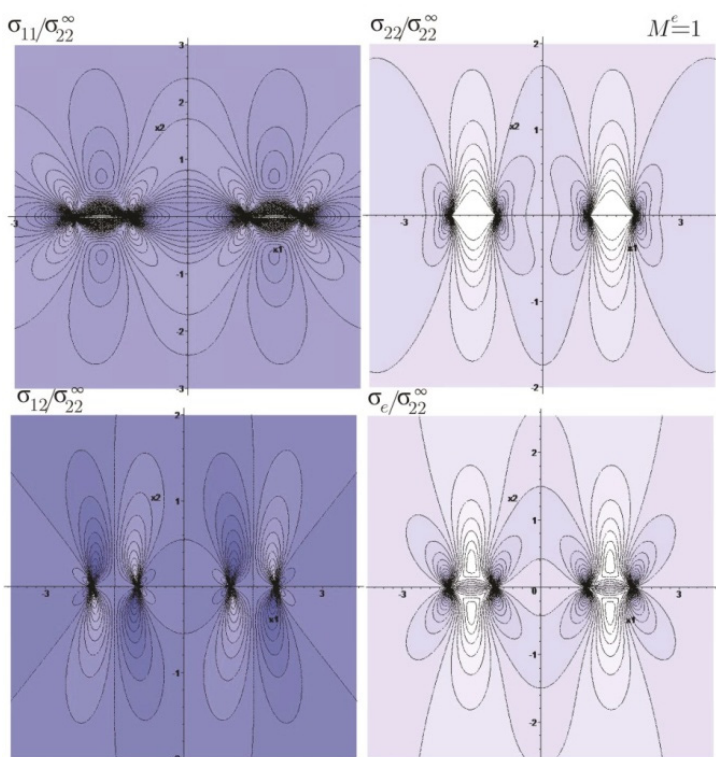

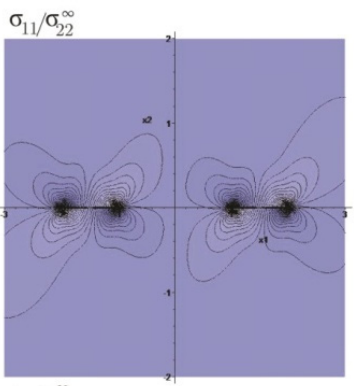

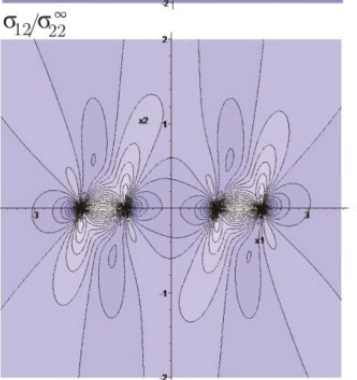

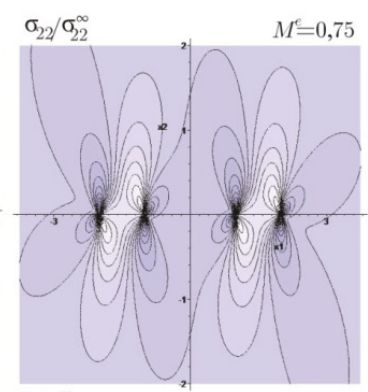

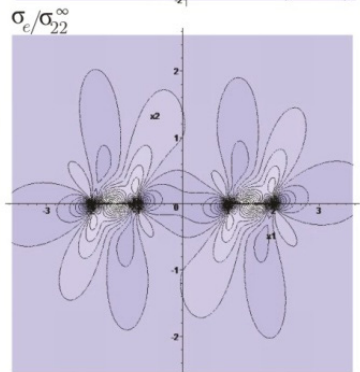

$b$

Fig. 2. The level lines of the stress tensor components and stress intensity for the plate medium with two collinear cracks of equal length: a) normal fracture; $b$ ) loading complying with the loading promiscuity parameter $M^{e}=0.75$
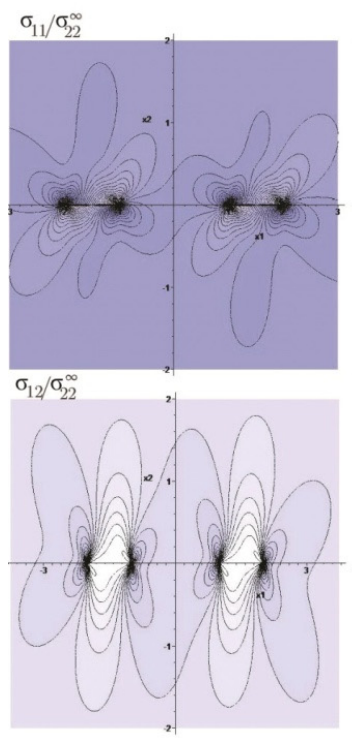

a
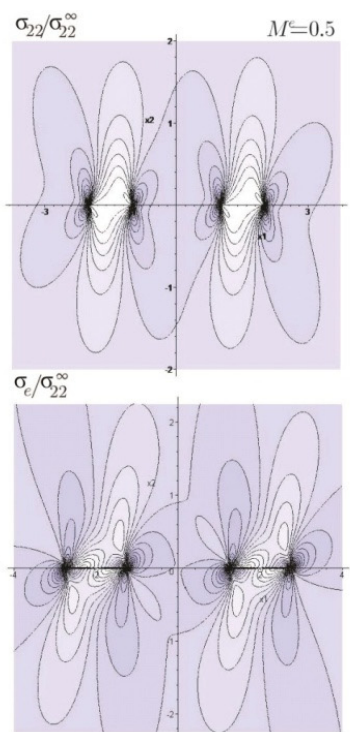
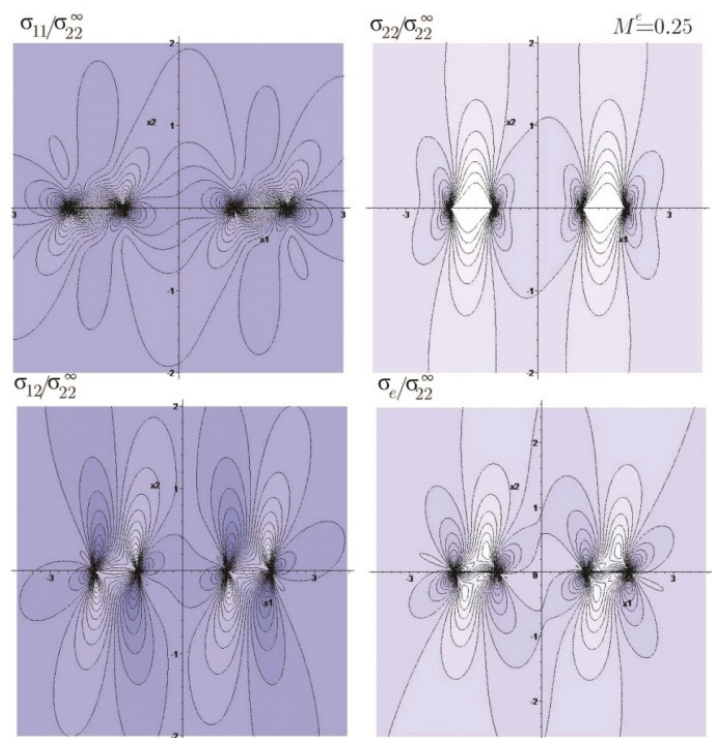

Fig. 3. The level lines of the stress tensor components and stress intensity (mixed mode loading of a plate medium with two collinear cracks of equal length): a) mixed mode loading complying with $M^{e}=0.5 ; b$ ) mixed mode loading complying with $M^{e}=0.25$ 

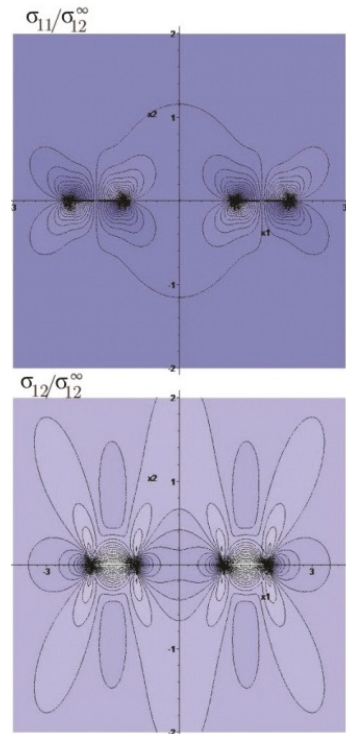

$a$
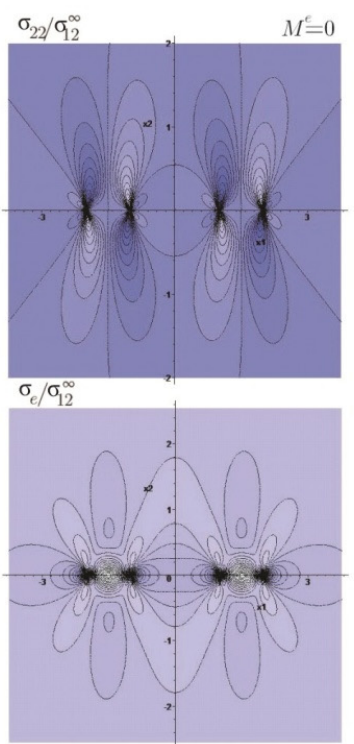
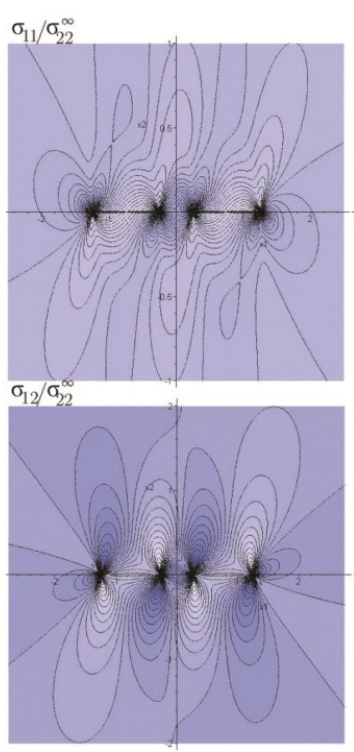

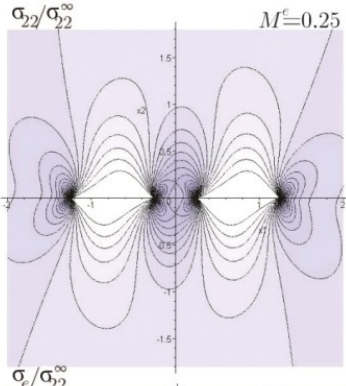

$\sigma_{e} / \sigma_{22}^{\infty}$

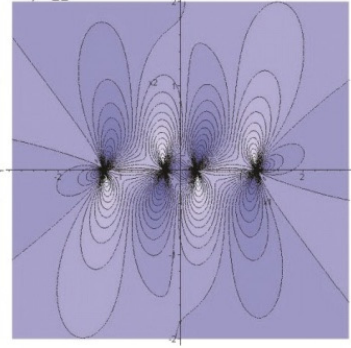

$b$

Fig. 4. Asymmetric loading of a plate medium with two collinear cracks of equal length (transverse shear) (a) and mixed loading of a plate for close cracks $(b)$

Comparing the asymptotic solution of M. Williams with the angular distributions (1) and (5), it is possible to find the stress intensity factor $K_{\mathrm{I}}(b)=$ $=\sqrt{\pi} \sigma_{22}^{\infty} b^{3 / 2}[1-E(\pi / 2, k) / F(\pi / 2, k)] / \sqrt{b^{2}-a^{2}}$ and the T-stress $T=(\alpha-1) \sigma_{22}^{\infty}$ or in a more general form for the transverse shear and axial separation cracks ( $2 l$ being the crack length and $d$ being the distance between the middles of two cracks)

$$
\left\{K_{\mathrm{I}}(b), K_{\mathrm{II}}(b), K_{\mathrm{III}}(b)\right\}=G(b)\left\{\sigma_{22}^{\infty}, \sigma_{12}^{\infty}, \sigma_{23}^{\infty}\right\} \sqrt{\pi l},
$$

where

$$
G(b)=\frac{d+2 l}{4 l}\left(\frac{d+2 l}{d}\right)^{1 / 2}\left[1-\frac{E(k)}{F(k)}\right] .
$$

Similarly the stress intensity factors can be found for another crack tip

$$
\left\{K_{\mathrm{I}}(a), K_{\mathrm{II}}(a), K_{\mathrm{III}}(a)\right\}=G(a)\left\{\sigma_{22}^{\infty}, \sigma_{12}^{\infty}, \sigma_{23}^{\infty}\right\} \sqrt{\pi l},
$$

where

$$
\begin{gathered}
G(a)=\frac{d-2 l}{4 l}\left(\frac{d-2 l}{d}\right)^{1 / 2}\left[\left(\frac{d+2 l}{d-2 l}\right)^{2} \frac{E(k)}{F(k)}-1\right], \\
l=(b-a) / 2, d=a+b .
\end{gathered}
$$

\section{Analytic Determination of the Complete Asymptotic M. Williams Expansion Coefficients of the Stress Field for the Normal Fracture Crack Tip}

The asymptotic expansion of a complex potential (5) in the neighborhood of the crack tip $z(r, \theta)=b+r e^{i \theta}$, $x_{2}=r \sin \theta$ has the form

$$
\varphi_{1}^{\prime}(z)=\frac{\sigma_{22}^{\infty}}{2} \sum_{n=0}^{\infty} q_{n}(z-b)^{n-1 / 2}+(\alpha-1) \frac{\sigma_{22}^{\infty}}{4},
$$

where

$$
\begin{gathered}
q_{n}=\sum_{k=0}^{n+1} p_{k} d_{n-k}, \quad p_{n}=\sum_{k=0}^{n+1} c_{k} e_{n-k}, \quad e_{n}=\sum_{k=0}^{n+1} a_{k} b_{n-k}, \\
d_{0}=b^{2}-c, \quad d_{1}=2 b, \quad d_{2}=1, \quad d_{k}=0, k>2, \\
a_{k}=(-1)^{k} \frac{(|2 k-1| ! !)}{2^{k} k !}(b-a)^{-(2 k+1) / 2}, \\
b_{k}=(-1)^{k} \frac{(|2 k-1| ! !)}{2^{k} k !}(a+b)^{-(2 k+1) / 2}, \\
c_{k}=(-1)^{k} \frac{(|2 k-1| ! !)}{2^{k} k !}(2 b)^{-(2 k+1) / 2} .
\end{gathered}
$$

Formulae (10)-(13) contain the dependence of the asymptotic expansion coefficients of the complex potential on the geometric parameters of the specimen $a, b$ and the applied strain load $\sigma_{22}^{\infty}$. Substituting the expression (9) into the Kolosoff-Muskhelishvili formulae (5) and comparison with the complete asymptotic M. Williams expansion (1) leads to the determination of the amplitude coefficients of the expansion:

$$
\begin{gathered}
a_{k}^{1}=\sigma_{22}^{\infty} q_{k} / f_{k}^{1,11}(\theta=0), \\
a_{2}^{1}=(\alpha-1) \sigma_{22}^{\infty} / 4, \quad a_{2 k}^{1}=0, \forall k>1 .
\end{gathered}
$$

Below, the analytic expressions for the first thirteen coefficients of the complete asymptotic M. Williams expansion, obtained with the expressions (10)-(13), are presented: 


$$
\begin{gathered}
a_{1}^{1}=\frac{\sigma_{22}^{\infty}}{\sqrt{2 b}} \frac{b^{2}-c}{\sqrt{b^{2}-a^{2}}}, a_{2}^{1}=\frac{(\alpha-1)}{4} \sigma_{22}^{\infty}, \quad a_{2 k}^{1}=0, \forall k>1, \\
a_{3}^{1}=\frac{\sigma_{22}^{\infty} \sqrt{2}}{24} \frac{3 b^{4}-7 a^{2} b^{2}+5 b^{2} c-a^{2} c}{b^{3 / 2}\left(b^{2}-a^{2}\right)^{3 / 2}}, \\
=-\frac{\sigma_{22}^{\infty} \sqrt{2}}{320} \frac{2 a^{2} b^{2} c-34 a^{2} b^{4}-19 a^{4} b^{2}+43 b^{4} c+5 b^{6}+3 a^{4} c}{b^{5 / 2}\left(b^{2}-a^{2}\right)^{5 / 2}}, \\
\times\left(-5 a^{6} c+137 a^{2} b^{4} c+11 a^{4} b^{2} c+177 b^{6} c+\right. \\
\left.+13 a^{6} b^{2}+7 b^{8}-113 a^{2} b^{6}-227 a^{4} b^{4}\right) /\left(b^{7 / 2}\left(b^{2}-a^{2}\right)^{7 / 2}\right), \\
\left.-124 a^{6} b^{2} c-67 a^{8} b^{2}-132 a^{6} b^{4}-1636 a^{2} b^{8}-7170 a^{4} b^{6}\right\},(14) \\
\times\left\{45 b^{10}+5732 a^{2} b^{6} c+450 a^{4} b^{4} c+2867 b^{8} c+35 a^{8} c-\right. \\
a_{92}^{1} \sqrt{2} \\
a_{9}^{1}=-\frac{\sigma_{22}^{\infty} \sqrt{2}}{36864} \frac{1}{b^{9 / 2}\left(b^{2}-a^{2}\right)^{9 / 2}} \times
\end{gathered}
$$

$\times\left\{10398 a^{4} b^{6} c+42997 a^{2} b^{8} c+77 b^{12}-10986 a^{6} b^{6}-\right.$

$$
-367 a^{8} b^{4}-646 a^{6} b^{4} c+295 a^{8} b^{2} c+11531 b^{10} c-
$$

$$
\begin{gathered}
\left.-6189 a^{2} b^{10}-47150 a^{4} b^{8}-63 a^{10} c+103 a^{10} b^{2}\right\}, \\
a_{13}^{1}=\frac{\sigma_{22}^{\infty} \sqrt{2}}{1703936} \frac{1}{b^{13 / 2}\left(b^{2}-a^{2}\right)^{13 / 2}} \times \\
\times\left\{48014 a^{2} b^{12}+559049 a^{4} b^{10}+329124 a^{6} b^{8}+11729 a^{8} b^{6}-\right. \\
-92479 b^{12} c-1810 a^{10} b^{4}-273 b^{14}+343 a^{12} b^{2}- \\
-551534 a^{2} b^{10} c+1330 a^{10} b^{2} c- \\
\left.-298169 a^{4} b^{8} c-1764 a^{6} b^{6} c-3329 a^{8} b^{4} c-231 a^{12} c\right\} .
\end{gathered}
$$

Substituting the asymptotic presentation for the complex potential (9) into (4), it is possible to acquire the asymptotic presentations of the stress tensor components in vicinity of the crack tip $z=b$

$$
\sigma_{i j}^{1}(r, \theta)=\sigma_{22}^{\infty}\left[\sum_{n=0}^{\infty} q_{n} g_{n}^{1, i j}(\theta) r^{n-1 / 2}+(\alpha-1) \delta_{i 1} \delta_{j 1}\right],
$$

where the angular distributions $g_{n}^{m, i j}(\theta)$ are determined as

$$
g_{n}^{1,11}(\theta)=
$$

$[(n+3 / 2) \cos (n-1 / 2) \theta-(n-1 / 2) \cos (n-5 / 2) \theta] / 2$,

$$
g_{n}^{1,22}(\theta)=
$$

$=[(-n+5 / 2) \cos (n-1 / 2) \theta+(n-1 / 2) \cos (n-5 / 2) \theta] / 2$,

$$
g_{n}^{1,12}(\theta)=
$$

$=[(-n+1 / 2) \sin (n-1 / 2) \theta+(n-1 / 2) \sin (n-5 / 2) \theta] / 2$.

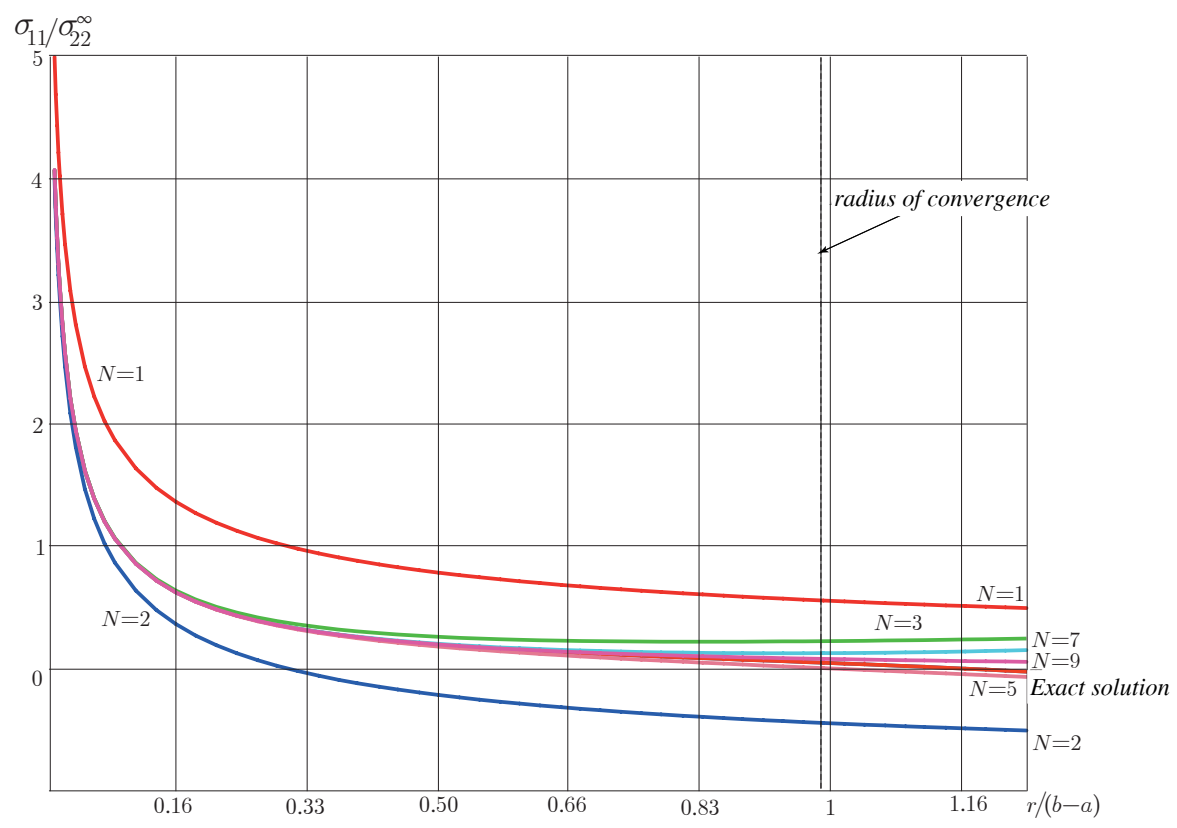

Fig. 5. Radial distribution of the component $\sigma_{11}^{1}$ near the crack tip $z=b$, constructed with the exact solution and the $k$-nomial asymptotic expansion, where $k=1,2,3,4,5,6,7,8,9$ 


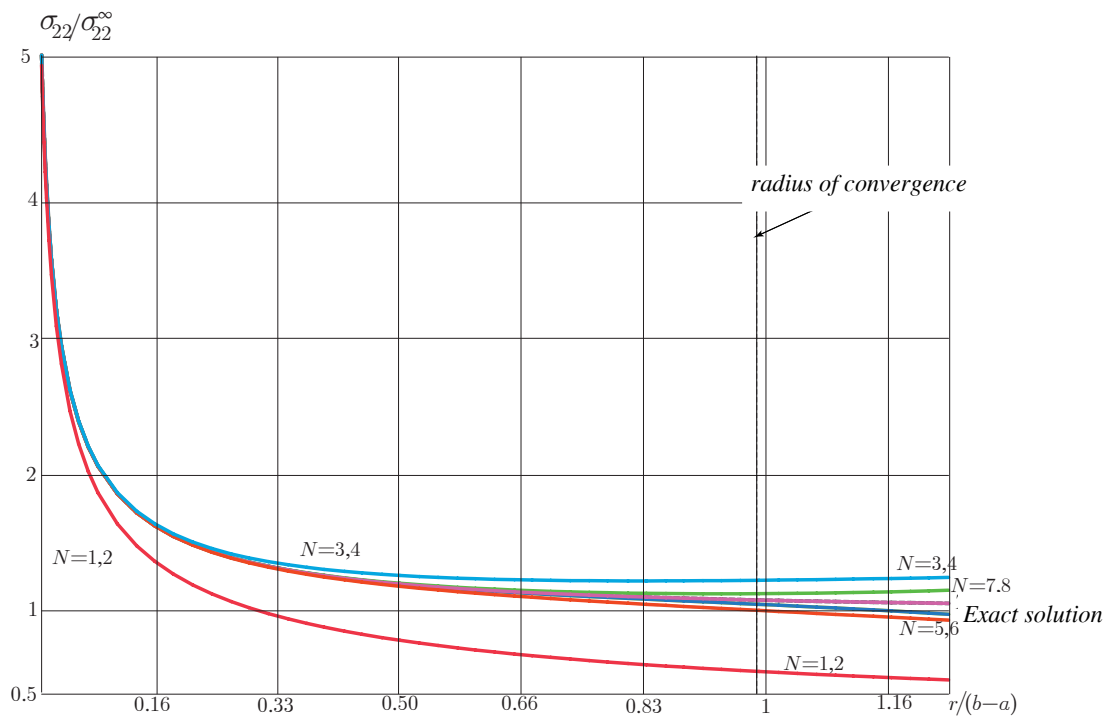

Fig. 6. Radial distribution of the component $\sigma_{22}^{1}$ near the crack tip $z=b$, constructed with the exact solution and the $k$-nomial asymptotic expansion, where $k=1,2,3,4,5,6,7,8,9$

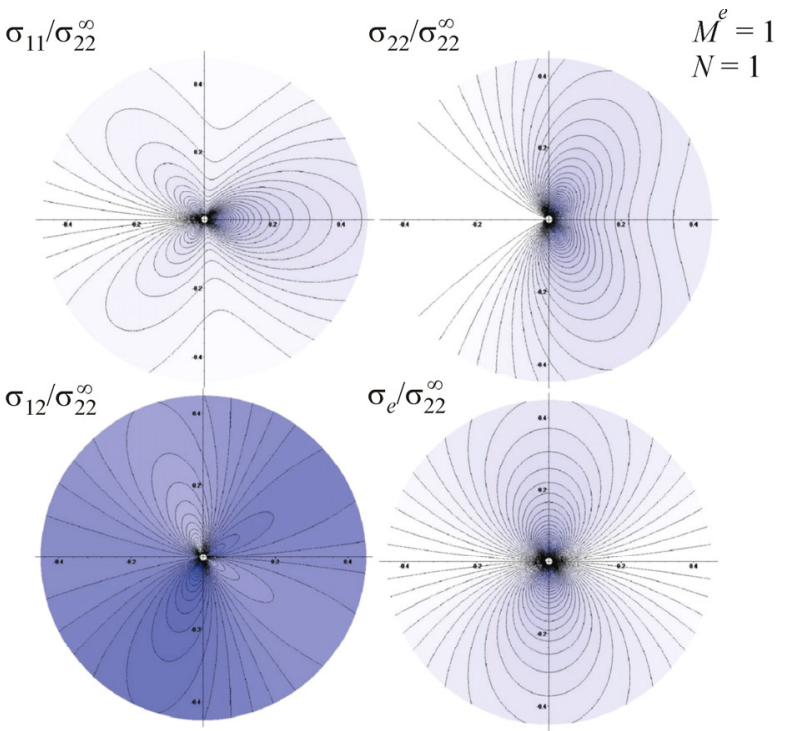

$a$

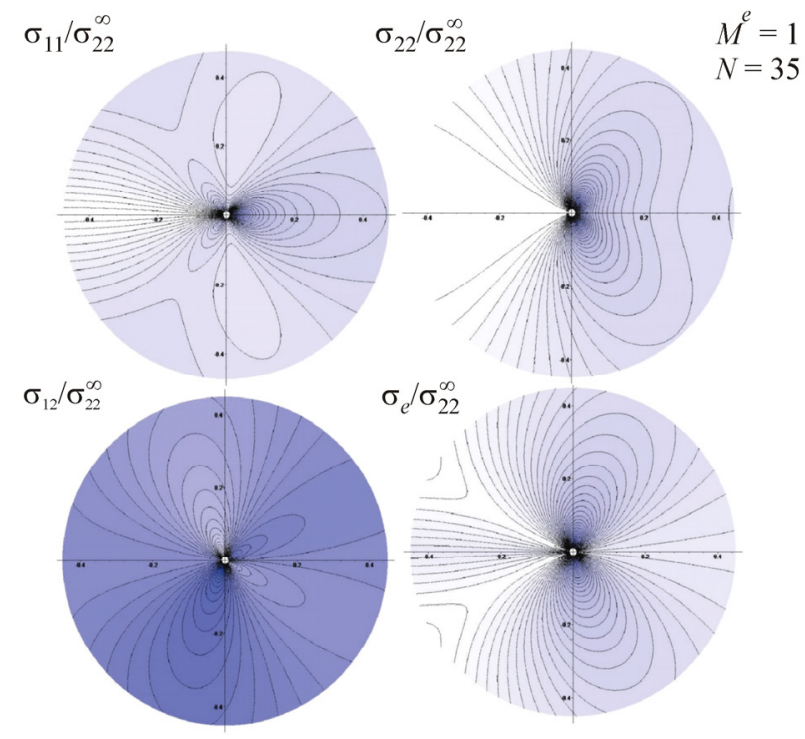

$b$

Fig. 7. Distribution of the stress tensor components and the stress intensity (level lines) in the vicinity of the tip $z=b$ for the fracture crack, built with the mononomial asymptotic expansions $(a)$ and thirty-five-nomial asymptotic expansions $(b)$

Fig. 5, 6 demonstrate the radial distributions of the normal stress tensor components $\sigma_{11}^{1}$ and $\sigma_{22}^{1}$ near the crack tip $z=b$, constructed with the exact solution and the $k$-nomial asymptotic expansions, where $k=1,2,3,4,5,6,7,8,9$. Fig. 5, 6 show that the T-stress makes a significant contribution into the asymptotic expansion of the stress tensor component $\sigma_{11}^{1}$. Moreover, Fig. 5, 6 lead to the conclusion that it is wrong to focus on the T-stress only, as the binomial asymptotic expansion of the considered stress tensor components is significantly different from the radial distribution, constructed on the basis of the exact solution. The presented figures demonstrate that the curves, determined with the asymptotic expansions containing the
9 terms, coincide with the exact solution (Fig. 5, 6). Fig. 7, 8 show the equal level lines of the stress tensor components $\sigma_{i j}^{1}$ and the shearing strain intensity in the neighborhood of the crack tip $z=b$, built with the mononomial (Fig. 7, $a$ ) and thirty-five-nomial asymptotic expansions (Fig. 7, b). Comparison Fig. 7, $a$ and $b$ shows that the level lines change and the higher approximation are critical for consideration. Fig. 8 demonstrates the intensity level lines of the shearing strain intensity in the neighborhood of the tip $z=b$ for the fracture crack, constructed with the main member of the asymptotic expansion (Fig. 8, $a$ and $b$ ) and the thirty-five-nomial asymptotic expansion (Fig. 8, c). Level lines in Fig. 8, $a$ and $b$ are obtained for different 
distances from the crack tip. Fig. 8, $c$ shows that the complete asymptotic M. Williams expansion, constructed with consideration of the higher approximations in the neighborhood of the tip $z=b$ has a greater fairness scope, as it "detects" the presence of the tip $z=a$. However for constructing the complete picture of the level lines of stress tensor components, a compound expansion, built with consideration of the asymptotic stress field both in the vicinity of the tip $z=b$, and in the vicinity of the tip $z=a$, the determination of which is an independent task not covered by this research, is required.

Fig. 9-12 present the angular distributions of the stress tensor components $\sigma_{11}^{1}$ in the vicinity of the fracture crack tip in different distances from the crack tip. Fig. 9, $a$ show the angular distributions in the distance $\hat{r}=r / a=0.075$. Fig. 9 demonstrates that the angular distribution determined with the mononomial asymptotic expansion (red curve) significantly differs from the angular distribution built with the binomial expansion (blue curve). However, the curves built with the trinomial, five-nomial and $k$-nomial asymptotic expansion of the stress field are not distinguishable. Therefore, in the given distance from the crack tip it is enough to hold three members in the asymptotic M. Williams expansion. If it is necessary to expand the asymptotic work scope $(1,2)$, then higher approximations shall remain in the asymptotic presentation. For example, Fig. 9, $b$ shows the angular distributions of the stress tensor components $\sigma_{11}^{1}$ in the distance $\hat{r}=r / a=0.15$. The trinomial asymptotic M. Williams expansion becomes distinguishable from the five-nomial expansion (green and violet curves in the Figure). The curves built with the seven-nomial, nine-nomial and $k$-nomial expansions are not distinguishable. Further increase of the distance from the crack tip causes the need of holding the following terms in the asymptotic presentation (Fig. 10, 11). Fig. 12, $a, b$ shows the angular distributions of the stress tensor components under $\hat{r}=r / a=0.5$, built with the held terms of different numbers in the asymptotic expansion, starting from the mononomial asymptotic expansion and finishing with the asymptotic expansion of 50 terms. Fig. 12 shows that the curves stop being different from each other only starting from the asymptotic expansion of 15 terms.

Therefore to expand the scope of the stress field asymptotic expansion in the vicinity of the crack tip, it is required to hold the higher approximations.

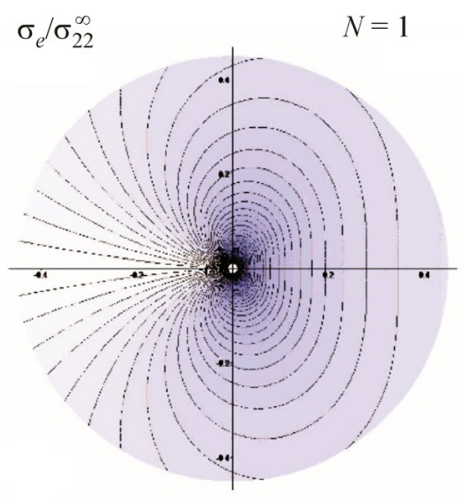

$a$

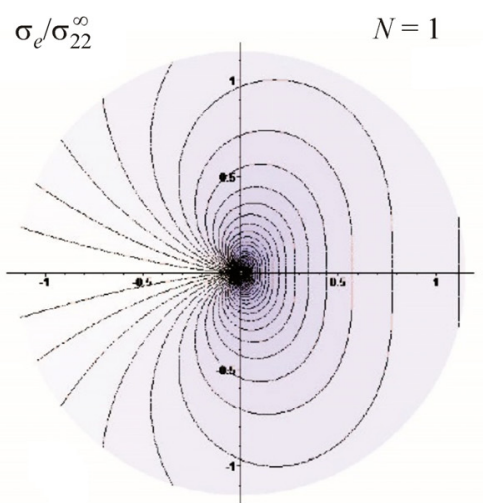

$b$

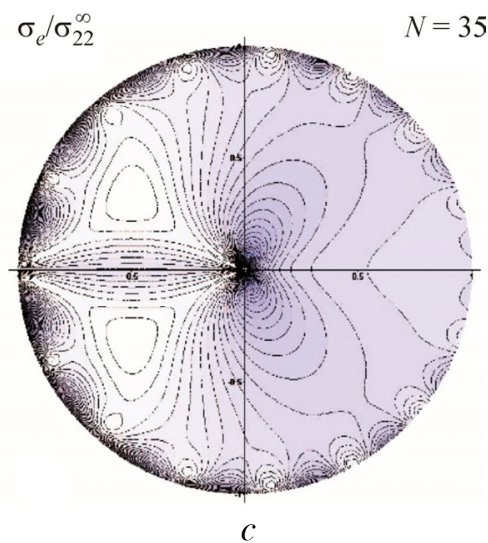

Fig. 8. Distribution of the stress intensity (level lines) in the vicinity of the tip $z=b$ for the fracture crack, built with a mononomial asymptotic expansion $(a)$ and for greater distances from the crack tip $(b)$ and the thirty-five-nomial asymptotic expansion $(c)$
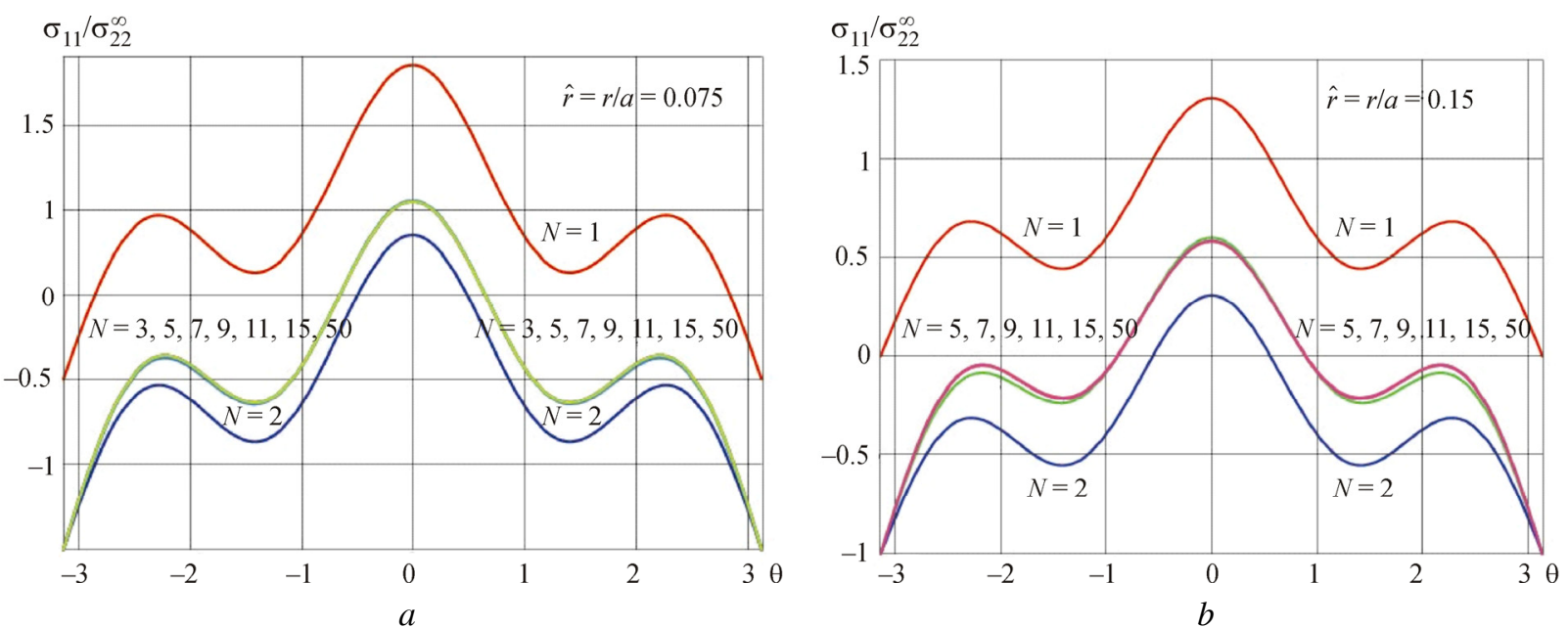

Fig. 9. The angular distribution of the stress tensor component $\sigma_{11}^{1}$ in the neighborhood of the crack tip $z=b$ in different distances from the crack tip: $a$ ) for $\hat{r}=r / a=0.075 ; ; b)$ for $\hat{r}=r / a=0.15$ 

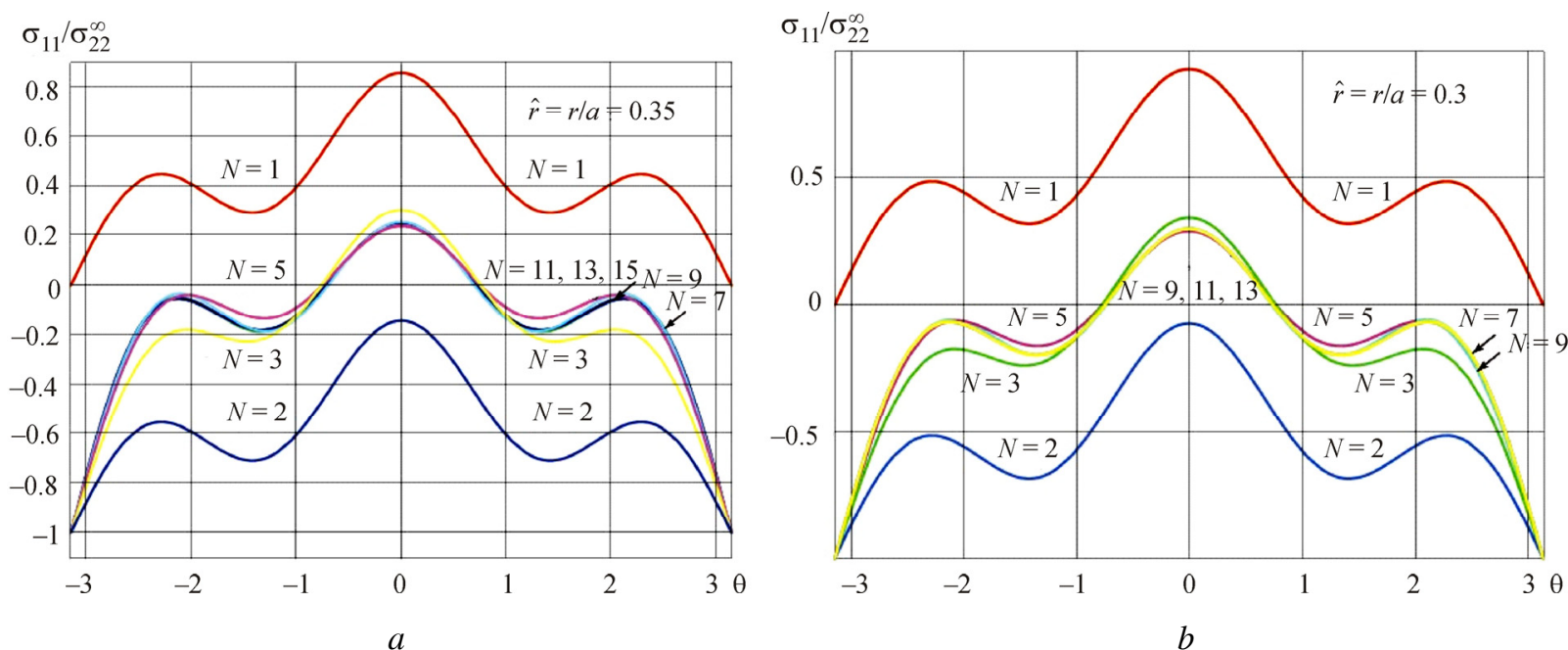

Fig. 10. The angular distribution of the stress tensor component $\sigma_{11}^{1}$ in the neighborhood of the crack tip $z=b$ in different distances from the crack tip: $a$ ) for $\hat{r}=r / a=0.3 ; b$ ) for $\hat{r}=r / a=0.35$
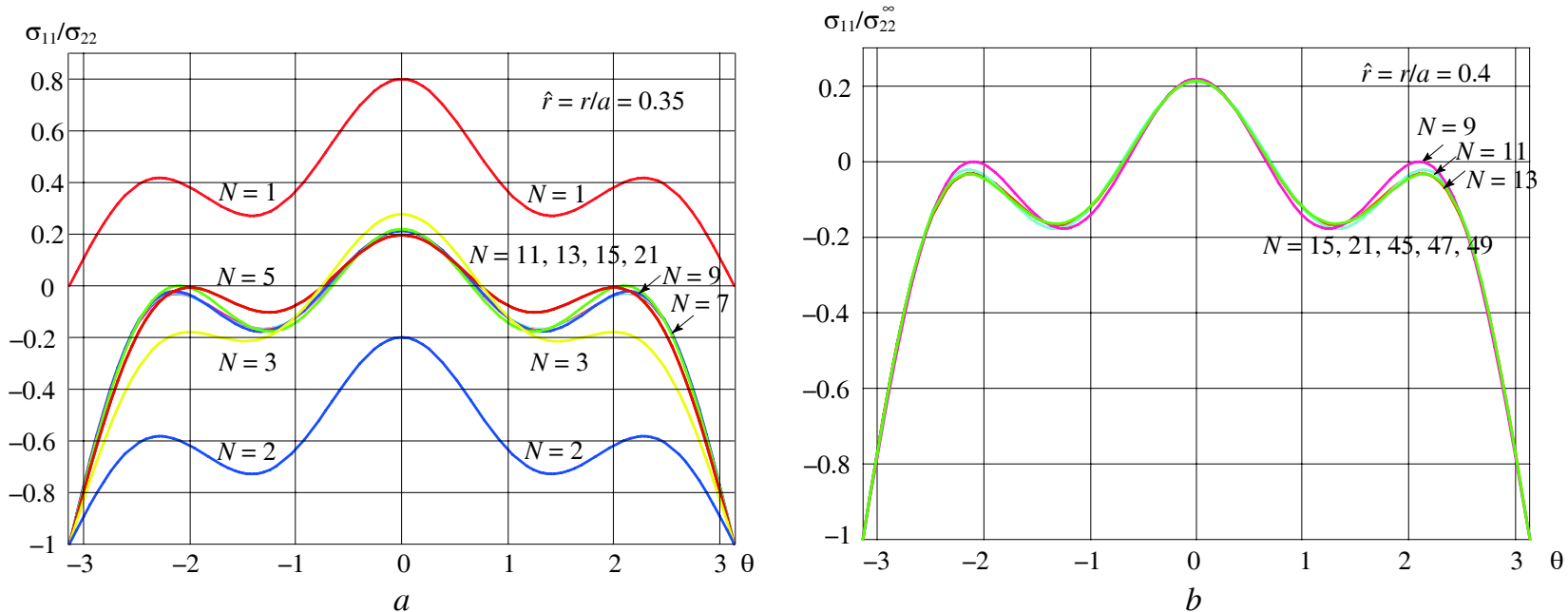

Fig. 11. The angular distributions of the stress tensor component $\sigma_{11}^{1}$ in the neighborhood of the crack tip $z=b$ for $\hat{r}=r / a=0.4$, built with the higher approximations in the asymptotic expansion
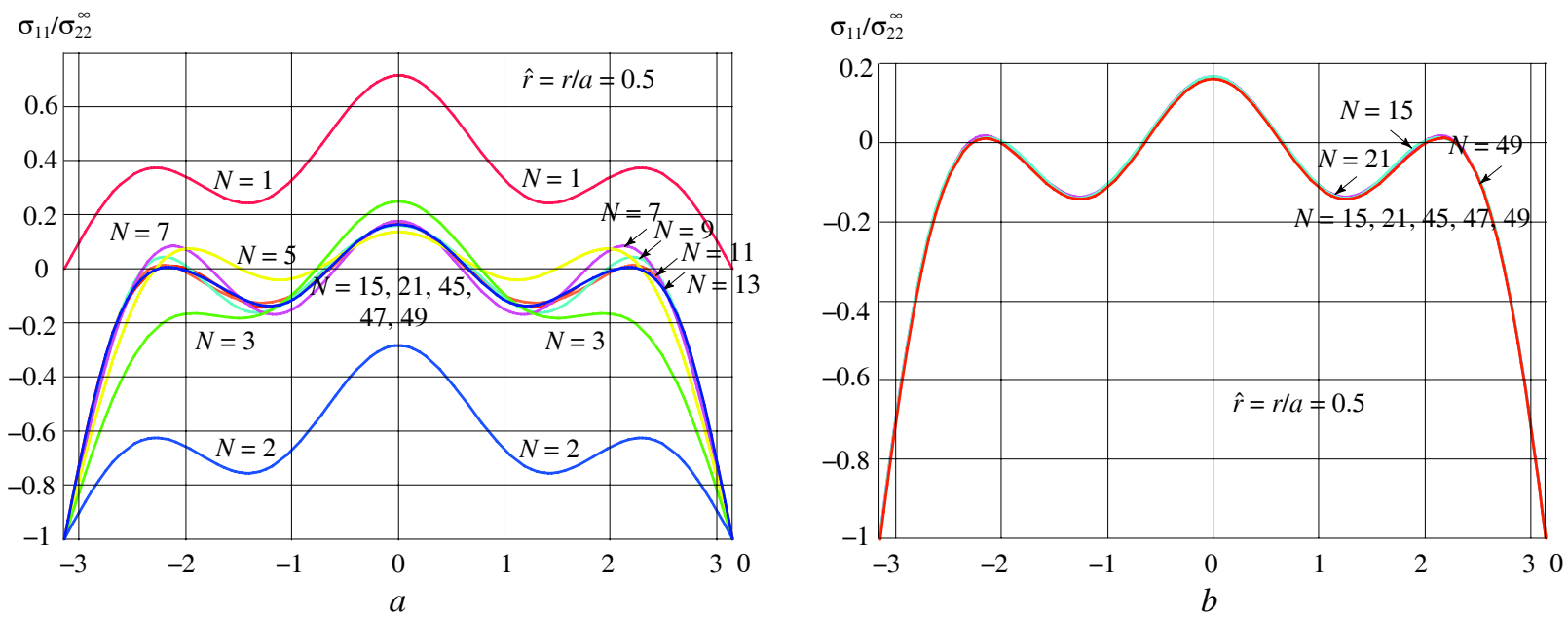

Fig. 12. The angular distributions of the stress tensor component $\sigma_{11}^{1}$ in the neighborhood of the crack tip $z=b$, built with the higher approximations in the asymptotic expansion 
Similarly, it is possible to obtain the complete asymptotic expansion in the vicinity of the tip $z=a$. Expanding the complex potential in a Taylor's series in the vicinity of the tip $z=a+r e^{i \theta}$, it is possible to find

$$
\varphi_{1}^{\prime}(z)=\frac{\sigma_{22}^{\infty}}{2} \sum_{n=0}^{\infty} \delta_{n}(z-a)^{n-1 / 2}+(\alpha-1) \frac{\sigma_{22}^{\infty}}{4},
$$

where

$$
\begin{gathered}
\delta_{n}=\sum_{k=0}^{n+1} \alpha_{k} \chi_{n-k}, \quad \chi_{n}=\sum_{k=0}^{n+1} \beta_{k} \xi_{n-k}, \quad \xi_{n}=\sum_{k=0}^{n+1} \varsigma_{k} \eta_{n-k}, \\
\eta_{0}=a^{2}-c, \quad \eta_{1}=2 a, \quad \eta_{2}=1, \quad \eta_{k}=0, k>2, \\
\alpha_{k}=(-1)^{k} \frac{(|2 k-1| ! !)}{2^{k} k !}(2 a)^{-(2 k+1) / 2}, \\
\beta_{k}=\frac{(|2 k-1| ! !)}{2^{k} k !}(b-a)^{-(2 k+1) / 2}, \\
\varsigma_{k}=(-1)^{k} \frac{(|2 k-1| ! !)}{2^{k} k !}(a+b)^{-(2 k+1) / 2} .
\end{gathered}
$$

Formulae (16)-(19) contain the dependence of the asymptotic expansion coefficients of the complex potential on the geometric parameters of the specimen $a, b$ and the applied strain load $\sigma_{22}^{\infty}$. Substituting the expression (15) into the Kolosoff-Muskhelishvili formulae (5) and comparison with the complete asymptotic M. Williams expansion (1) leads to the determination of the amplitude coefficients of the expansion:

$$
a_{k}^{1}=\sigma_{22}^{\infty} q_{k} / f_{k}^{1,11}(\theta=0), a_{2 k}^{1}=0, \forall k \geq 1 .
$$

Below, the analytic expressions for the first thirteen coefficients of the complete asymptotic M. Williams expansion, obtained with the expressions (16)-(19), are presented:

$$
\begin{gathered}
a_{1}^{1}=\frac{\sigma_{22}^{\infty}}{\sqrt{2 a}} \frac{a^{2}-c}{\sqrt{b^{2}-a^{2}}}, a_{2}^{1}=\frac{(\alpha-1)}{4} \sigma_{22}^{\infty}, \quad a_{2 k}^{1}=0, \forall k>1, \\
a_{3}^{1}=-\frac{\sigma_{22}^{\infty} \sqrt{2}}{24} \frac{3 a^{4}-7 a^{2} b^{2}+5 a^{2} c-b^{2} c}{a^{3 / 2}\left(b^{2}-a^{2}\right)^{3 / 2}}, \\
=-\frac{\sigma_{22}^{\infty} \sqrt{2}}{320} \frac{2 a^{2} b^{2} c-34 b^{2} a^{4}-19 b^{4} a^{2}+43 a^{4} c+5 a^{6}+3 a^{4} c}{a^{5 / 2}\left(b^{2}-a^{2}\right)^{5 / 2}} \\
a_{7}^{1}=-\frac{\sigma_{22}^{\infty} \sqrt{2}}{1792} \times \\
\times\left(-5 b^{6} c+137 b^{2} a^{4} c+11 b^{4} a^{2} c+177 a^{6} c+\right. \\
\left.+13 b^{6} a^{2}+7 a^{8}-113 b^{2} a^{6}-227 a^{4} b^{4}\right) /\left(a^{7 / 2}\left(b^{2}-a^{2}\right)^{7 / 2}\right)
\end{gathered}
$$

$$
\begin{gathered}
a_{9}^{1}=-\frac{\sigma_{22}^{\infty} \sqrt{2}}{36864} \frac{1}{a^{9 / 2}\left(b^{2}-a^{2}\right)^{9 / 2}} \times \\
\times\left\{45 a^{10}+5732 b^{2} a^{6} c+450 a^{4} b^{4} c+2867 a^{8} c+35 b^{8} c-\right. \\
\left.-124 b^{6} a^{2} c-67 b^{8} a^{2}-132 b^{6} a^{4}-1636 b^{2} a^{8}-7170 b^{4} a^{6}\right\} \\
\times\left\{10398 b^{4} a^{6} c+42997 b^{2} a^{8} c+77 a^{12}-10986 a^{6} b^{6}-63 b^{10} c-\right. \\
-367 b^{8} a^{4}-646 b^{6} a^{4} c+295 b^{8} a^{2} c+11531 a^{10} c- \\
\left.-6189 b^{2} a^{10}-47150 b^{4} a^{8}+103 b^{10} a^{2}\right\} \\
\left.-1764 a^{6} b^{6} c-3329 b^{8} a^{4} c+1330 b^{10} a^{2} c-231 b^{12} c\right\} \\
a_{13}^{1}=\frac{\sigma_{22}^{\infty} \sqrt{2}}{1703936} \frac{1}{a^{13 / 2}\left(b^{2}-a^{2}\right)^{13 / 2}} \times \\
\times\left\{48014 b^{2} a^{12}+559049 b^{4} a^{10}+329124 b^{6} a^{8}+11729 b^{8} a^{6}-\right. \\
-92479 a^{12} c-1810 b^{10} a^{4}-273 a^{14}+343 b^{12} a^{2}-
\end{gathered}
$$

Fig. 13 demonstrates the intensity level lines of the shearing strain intensity in the neighborhood of the tip $z=a$, built with the expansion (15), where the expansion coefficients are calculated with the formulae (16)-(19). Fig. 13 presents the results of a computation based on holding the main member of the stress tensor component asymptotic expansion (Fig. 13,a), and with the binomial asymptotic expansions (Fig. 13, b). The presented formulae mean that the second term, the T-stress, makes an impact on the component $\sigma_{11}^{1}$ and the stress intensity. Fig. 13, $b$ shows the level lines obtained through holding 15 terms. The further increase of the number of the terms held in the asymptotic expansion shows that there is no difference for the considered distances to the crack tip.

Table presents the numerical values of the stress intensity factors by the crack tip $z=a$ and $z=b$ for the plate medium with two collinear cracks. As we can see in Table, the stress intensity factors depend on the geometry of the plate medium with two cracks: on their lengths and distances between them. The farther from each other the cracks are in the plate, the weaker is their impact on each other. For the distances between the crack centers of the order $d>10 l$ each crack behaves as a separate crack and hardly interacts with the other crack in the plate medium. It is confirmed with the approximation of the numerical values of the stress intensity coefficients as the distances between the two cracks of the same length in the plate medium are increased. 


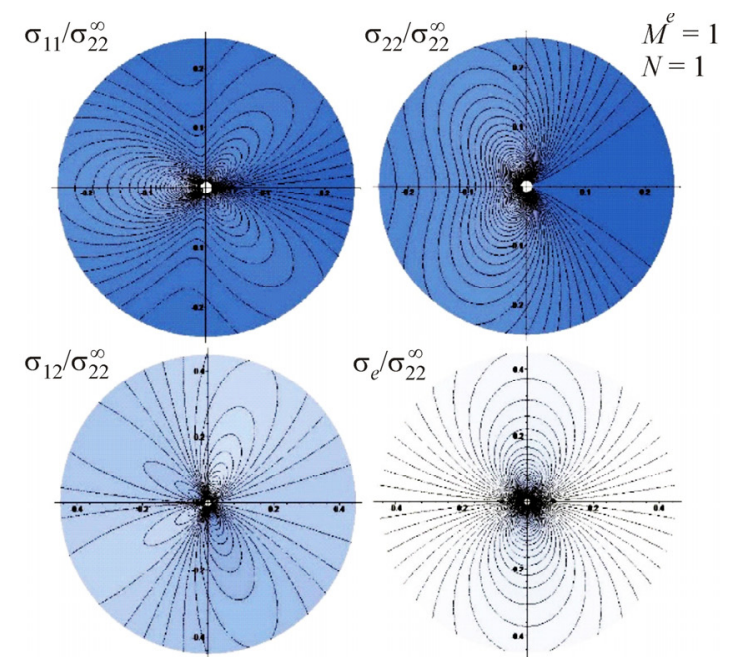

$a$
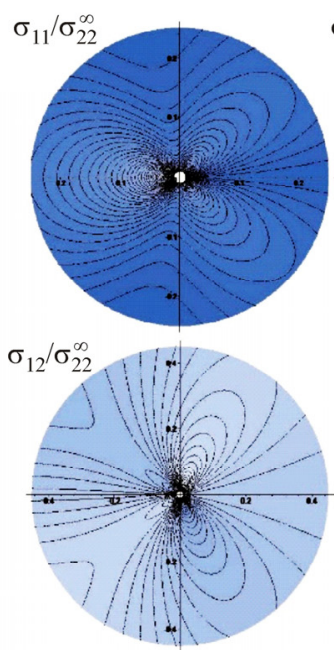

b
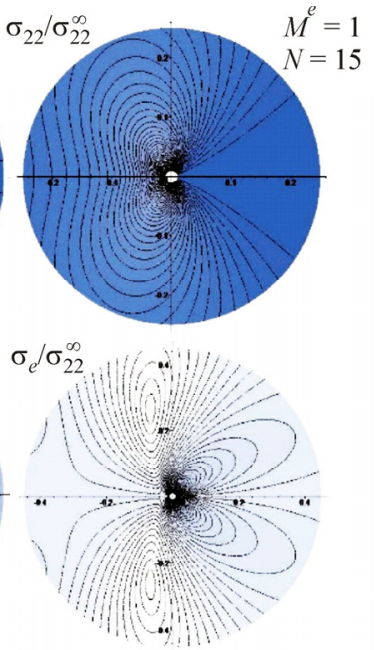

Fig. 13. The level lines of the stress tensor and stress intensity in the vicinity of the tip $z=a$, built with the mononomial $(a)$ and the fifteen-nomial asymptotic expansions $(b)$

Numerical values of the stress intensity factors for the plate medium with two collinear cracks

\begin{tabular}{|c|c|c|c|c|c|c|}
\hline \multicolumn{7}{|c|}{$\begin{array}{l}\text { Numerical values of the stress intensity factors for the plate medium with two collinear cracks of the length } 2 l \\
\text { and the distance between the crack middles } d\end{array}$} \\
\hline Crack half-length & $l, \mathrm{~cm}$ & 0.55 & 0.55 & 0.55 & 0.55 & 0.55 \\
\hline Distance between the crack middles & $d, \mathrm{~cm}$ & 1.11 & 1.65 & 2.75 & 3.85 & 5.5 \\
\hline Stress intensity factor by the tip $z=a$ & $K_{I}(a) / \sigma_{22}^{\infty}, \mathrm{cm}^{1 / 2}$ & 4.0823 & 1.4623 & 1.3502 & 1.3308 & 1.3219 \\
\hline Stress intensity factor by the tip $z=b$ & $K_{I}(\mathrm{~b}) / \sigma_{22}^{\infty}, \mathrm{cm}^{1 / 2}$ & 1.5886 & 1.3824 & 1.3380 & 1.3266 & 1.3206 \\
\hline Crack half-length & $l, \mathrm{~cm}$ & 0.6 & 0.6 & 0.6 & 0.6 & 0.6 \\
\hline Distance between the crack middles & $d, \mathrm{~cm}$ & 1.21 & 1.8 & 3 & 4.2 & 6 \\
\hline Stress intensity factor by the tip $z=a$ & $K_{I}(a) / \sigma_{22}^{\infty}, \mathrm{cm}^{1 / 2}$ & 4.3957 & 1.5274 & 1.4102 & 1.3899 & 1.3807 \\
\hline Stress intensity factor by the tip $z=b$ & $K_{I}(\mathrm{~b}) / \sigma_{22}^{\infty}, \mathrm{cm}^{1 / 2}$ & 1.6625 & 1.4439 & 1.3975 & 1.3856 & 1.3793 \\
\hline Crack half-length & $l, \mathrm{~cm}$ & 0.8 & 0.8 & 0.8 & 0.8 & 0.8 \\
\hline Distance between the crack middles & $d, \mathrm{~cm}$ & 1.61 & 2.4 & 4 & 4.8 & 8 \\
\hline Stress intensity factor by the tip $z=a$ & $K_{I}(a) / \sigma_{22}^{\infty}, \mathrm{cm}^{1 / 2}$ & 5.6205 & 1.7636 & 1.6284 & 1.6050 & 1.5943 \\
\hline Stress intensity factor by the tip $z=b$ & $K_{I}(\mathrm{~b}) / \sigma_{22}^{\infty}, \mathrm{cm}^{1 / 2}$ & 1.9318 & 1.6673 & 1.6137 & 1.6000 & 1.5927 \\
\hline Crack half-length & $l, \mathrm{~cm}$ & 1 & 1 & 1 & 1 & 1 \\
\hline Distance between the crack middles & $d, \mathrm{~cm}$ & 2.1 & 3 & 5 & 7 & 10 \\
\hline Stress intensity factor by the tip $z=a$ & $K_{I}(a) / \sigma_{22}^{\infty}, \mathrm{cm}^{1 / 2}$ & 3.1815 & 1.9718 & 1.8206 & 1.7944 & 1.7825 \\
\hline Stress intensity factor by the tip $z=b$ & $K_{I}(\mathrm{~b}) / \sigma_{22}^{\infty}, \mathrm{cm}^{1 / 2}$ & 2.0401 & 1.8641 & 1.8041 & 1.7888 & 1.7806 \\
\hline Crack half-length & $l, \mathrm{~cm}$ & 3 & 3 & 3 & 3 & 3 \\
\hline Distance between the crack middles & $d, \mathrm{~cm}$ & 6.1 & 9 & 15 & 21 & 30 \\
\hline Stress intensity factor by the tip $z=a$ & $K_{I}(a) / \sigma_{22}^{\infty}, \mathrm{cm}^{1 / 2}$ & 7.7557 & 3.4153 & 3.1534 & 3.1080 & 3.0874 \\
\hline Stress intensity factor by the tip $z=b$ & $K_{I}(\mathrm{~b}) / \sigma_{22}^{\infty}, \mathrm{cm}^{1 / 2}$ & 3.6544 & 3.2286 & 3.1248 & 3.0984 & 3.0842 \\
\hline Crack half-length & $l, \mathrm{~cm}$ & 5 & 5 & 5 & 5 & 5 \\
\hline Distance between the crack middles & $d, \mathrm{~cm}$ & 10.1 & 15 & 25 & 35 & 50 \\
\hline Stress intensity factor by the tip $z=a$ & $K_{I}(a) / \sigma_{22}^{\infty}, \mathrm{cm}^{1 / 2}$ & 11.9075 & 4.4091 & 4.0710 & 4.0124 & 3.9858 \\
\hline Stress intensity factor by the tip $z=b$ & $K_{I}(\mathrm{~b}) / \sigma_{22}^{\infty}, \mathrm{cm}^{1 / 2}$ & 4.7790 & 4.1682 & 4.0341 & 4.0000 & 3.9817 \\
\hline
\end{tabular}




\section{Analytic Determination of the Complete Asymptotic M. Williams Expansion Coefficients of the Stress Field for the Transverse Shear Crack Tip}

The asymptotic expansion of a complex potential (5) in the neighborhood of the crack tip $z(r, \theta)=b+r e^{i \theta}$, $x_{2}(r, \theta)=r \sin \theta$ has the form

$$
\varphi_{2}^{\prime}(z)=-i \frac{\sigma_{12}^{\infty}}{2} \sum_{n=0}^{\infty} q_{n}(z-b)^{n-1 / 2}+i \frac{\sigma_{12}^{\infty}}{2}
$$

where

$$
\begin{gathered}
q_{n}=\sum_{k=0}^{n+1} p_{k} d_{n-k}, \quad p_{n}=\sum_{k=0}^{n+1} c_{k} e_{n-k}, \quad e_{n}=\sum_{k=0}^{n+1} a_{k} b_{n-k}, \\
d_{0}=b^{2}-c, \quad d_{1}=2 b, \quad d_{2}=1, \quad d_{k}=0, k>2, \\
a_{k}=(-1)^{k} \frac{(|2 k-1| ! !)}{2^{k} k !}(b-a)^{-(2 k+1) / 2}, \\
b_{k}=(-1)^{k} \frac{(|2 k-1| ! !)}{2^{k} k !}(a+b)^{-(2 k+1) / 2}, \\
c_{k}=(-1)^{k} \frac{(|2 k-1| ! !)}{2^{k} k !}(2 b)^{-(2 k+1) / 2} .
\end{gathered}
$$

Formulae (21)-(24) contain the dependence of the asymptotic expansion coefficients of the complex potential on the geometric parameters of the specimen $a, b$ and the applied load $\sigma_{12}^{\infty}$. Substituting the expression (20) into the Kolosoff-Muskhelishvili formulae (5) and comparison with the complete asymptotic M. Williams expansion (1) leads to the determination of the amplitude coefficients of the expansion:

$$
a_{k}^{2}=\sigma_{12}^{\infty} q_{k} / f_{k}^{2,12}(\theta=0), \quad a_{2 k}^{1}=0, \forall k \geq 1 .
$$

Below, the analytic expressions for the first thirteen coefficients of the complete asymptotic M. Williams expansion, obtained with the expressions (21)-(24), are presented:

$$
\begin{gathered}
a_{1}^{2}=\frac{\sigma_{12}^{\infty}}{\sqrt{2 b}} \frac{b^{2}-c}{\sqrt{b^{2}-a^{2}}}, a_{2 k}^{2}=0, \forall k \geq 1, \\
a_{3}^{2}=\frac{\sigma_{12}^{\infty} \sqrt{2}}{24} \frac{3 b^{4}-7 a^{2} b^{2}+5 b^{2} c-a^{2} c}{b^{3 / 2}\left(b^{2}-a^{2}\right)^{3 / 2}}, \\
a_{5}^{2}=-\frac{\sigma_{12}^{\infty} \sqrt{2}}{320} \times \\
\frac{2 a^{2} b^{2} c-34 a^{2} b^{4}-19 a^{4} b^{2}+43 b^{4} c+5 b^{6}+3 a^{4} c}{b^{5 / 2}\left(b^{2}-a^{2}\right)^{5 / 2}}, \\
a_{7}^{2}=\frac{\sigma_{12}^{\infty} \sqrt{2}}{1792} \times
\end{gathered}
$$

$$
\begin{gathered}
\times\left(-5 a^{6} c+137 a^{2} b^{4} c+11 a^{4} b^{2} c+177 b^{6} c+\right. \\
\left.+13 a^{6} b^{2}+7 b^{8}-113 a^{2} b^{6}-227 a^{4} b^{4}\right) /\left(b^{7 / 2}\left(b^{2}-a^{2}\right)^{7 / 2}\right) \\
a_{9}^{2}=-\frac{\sigma_{12}^{\infty} \sqrt{2}}{36864} \frac{1}{b^{9 / 2}\left(b^{2}-a^{2}\right)^{9 / 2}} \times \\
\times\left\{45 b^{10}+5732 a^{2} b^{6} c+450 a^{4} b^{4} c+2867 b^{8} c+35 a^{8} c-\right. \\
\left.-124 a^{6} b^{2} c-67 a^{8} b^{2}-132 a^{6} b^{4}-1636 a^{2} b^{8}-7170 a^{4} b^{6}\right\} \\
a_{11}^{2}=\frac{\sigma_{12}^{\infty} \sqrt{2}}{180224} \frac{1}{b^{11 / 2}\left(b^{2}-a^{2}\right)^{11 / 2}} \times \\
\times\left\{10398 a^{4} b^{6} c+42997 a^{2} b^{8} c+77 b^{12}-10986 a^{6} b^{6}-\right. \\
-367 a^{8} b^{4}-646 a^{6} b^{4} c+295 a^{8} b^{2} c+11531 b^{10} c- \\
\left.-6189 a^{2} b^{10}-47150 a^{4} b^{8}-63 a^{10} c+103 a^{10} b^{2}\right\}
\end{gathered}
$$

Substituting the asymptotic presentation for the complex potential (20) into (4), it is possible to acquire the asymptotic presentations of the stress tensor components in vicinity of the crack tip $z=b$ under the transverse shear conditions

$$
\sigma_{i j}^{2}(r, \theta)=\sigma_{12}^{\infty} \sum_{n=0}^{\infty} q_{n} g_{n}^{2, i j}(\theta) r^{n-1 / 2}
$$

where the angular distributions $g_{n}^{m, i j}(\theta)$ are determined as

$$
g_{n}^{2,11}(\theta)=
$$

$=[(n+7 / 2) \sin (n-1 / 2) \theta-(n-1 / 2) \sin (n-5 / 2) \theta] / 2$,

$$
g_{n}^{2,22}(\theta)=
$$

$$
\begin{gathered}
=[(-n+1 / 2) \sin (n-1 / 2) \theta+(n-1 / 2) \sin (n-5 / 2) \theta] / 2, \\
g_{n}^{2,12}(\theta)=
\end{gathered}
$$$$
=[(n+3 / 2) \cos (n-1 / 2) \theta-(n-1 / 2) \cos (n-5 / 2) \theta] / 2 \text {. }
$$

Fig. 14 shows the level lines of the stress tensor components and the stress intensity in the vicinity of the tip $z=b$, built with the mononomial $(a)$ and the thirty-fivenomial asymptotic expansions $(b)$. Fig. 15 presents the angular shearing strain distributions $\sigma_{12}^{2}$ in the vicinity of the crack tip $z=b$ in different distances from the crack tip. It is found that in the close vicinity from the crack tip it is quite hard to hold the three terms in the neighborhood of the crack tip (Fig. 15, a) while as the distance increases, the trinomial, five-nomial and seven-nomial asymptotic expansions become distinguishable and the higher approximations need to be held. 


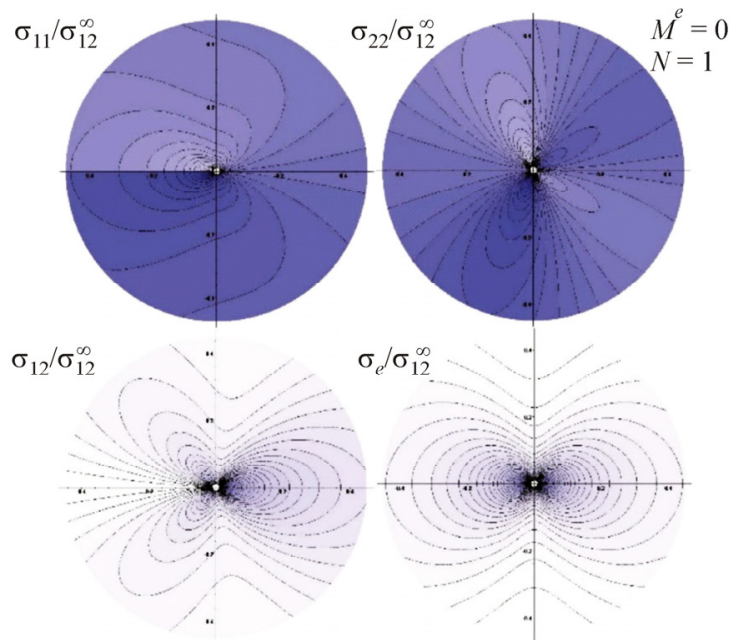

$a$
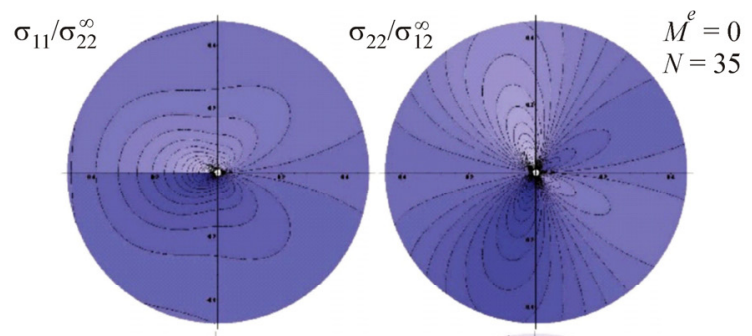

$\sigma_{12} / \sigma_{12}^{\infty}$

$\sigma_{e} / \sigma_{12}^{\infty}$

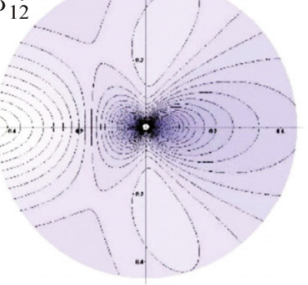

Fig. 14. The stress tensor component expansion near the crack tip $z=b$ for the main member of the asymptotic expansion $(a)$ and for the expansion of 35 terms $(b)$
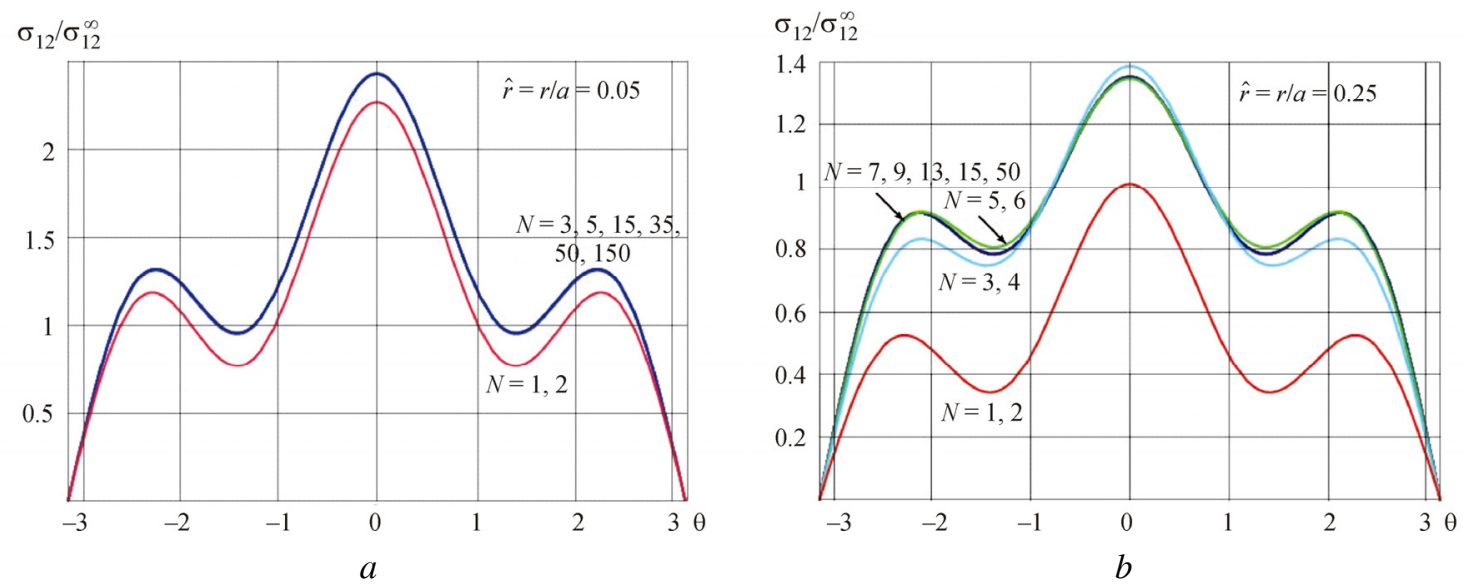

Fig. 15. Angular shearing strain distributions $\sigma_{12}^{2}$ in the vicinity of the crack tip $z=b: a$ ) for $\left.\hat{r}=r / a=0.05 ; b\right)$ for $\hat{r}=r / a=0.25$
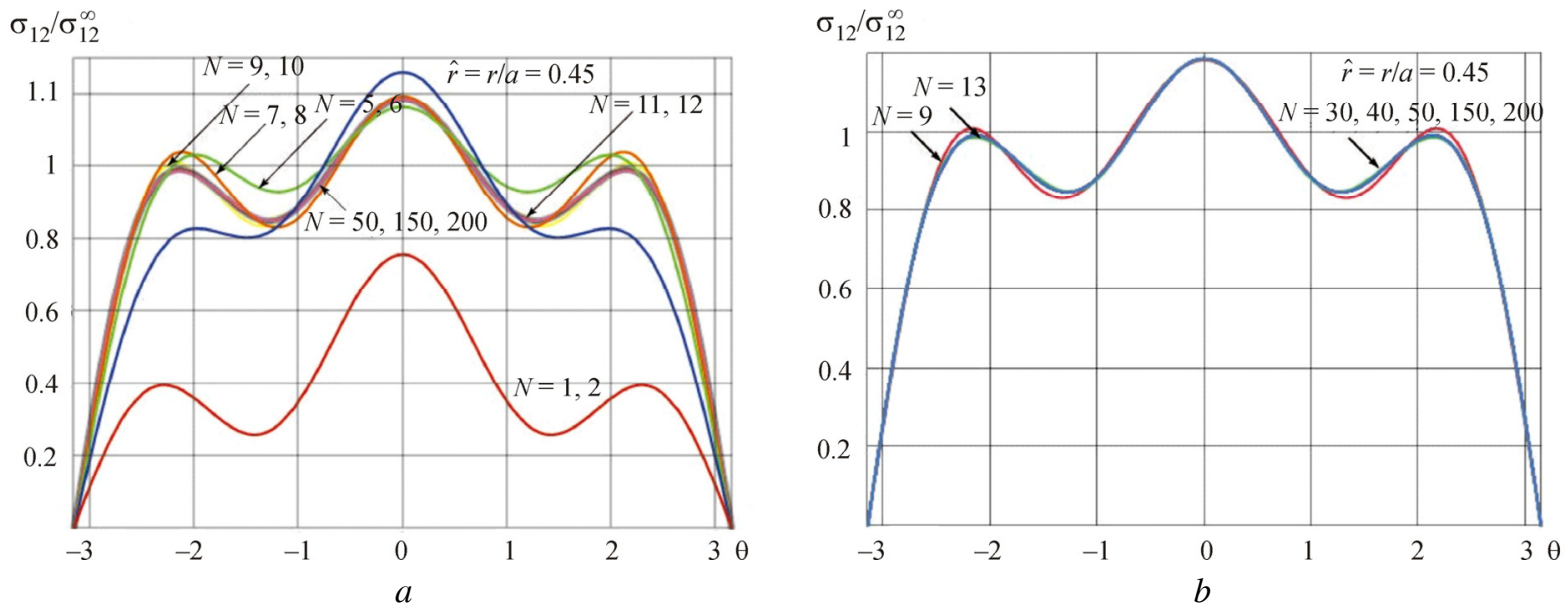

Fig. 16. Angular stress distributions $\sigma_{12}^{2}$ in the neighborhood of the crack tip $z=b$, built with the multiparameter asymptotic expansion with holding various numbers of terms in the asymptotic expansion

Fig. 16 presents the angular shearing strain $\sigma_{12}^{2}$ distributions in the vicinity of the crack tip $z=b$ for $\hat{r}=r / a=0.45$. In Fig. 16 it is seen that the nine-nomial and thirteen-nomial asymptotic expansions are different from each other. Fig. 17 presents the angular distributions of the stress tensor component $\sigma_{12}^{2}$ in the vicinity of the crack tip $z=b$ for $\hat{r}=r / a=0.75$.

From the presented distributions of the stress tensor component $\sigma_{12}^{2}$ we can see, that the expansion of the fairness scope of $\mathrm{M}$. Williams asymptotics requires 

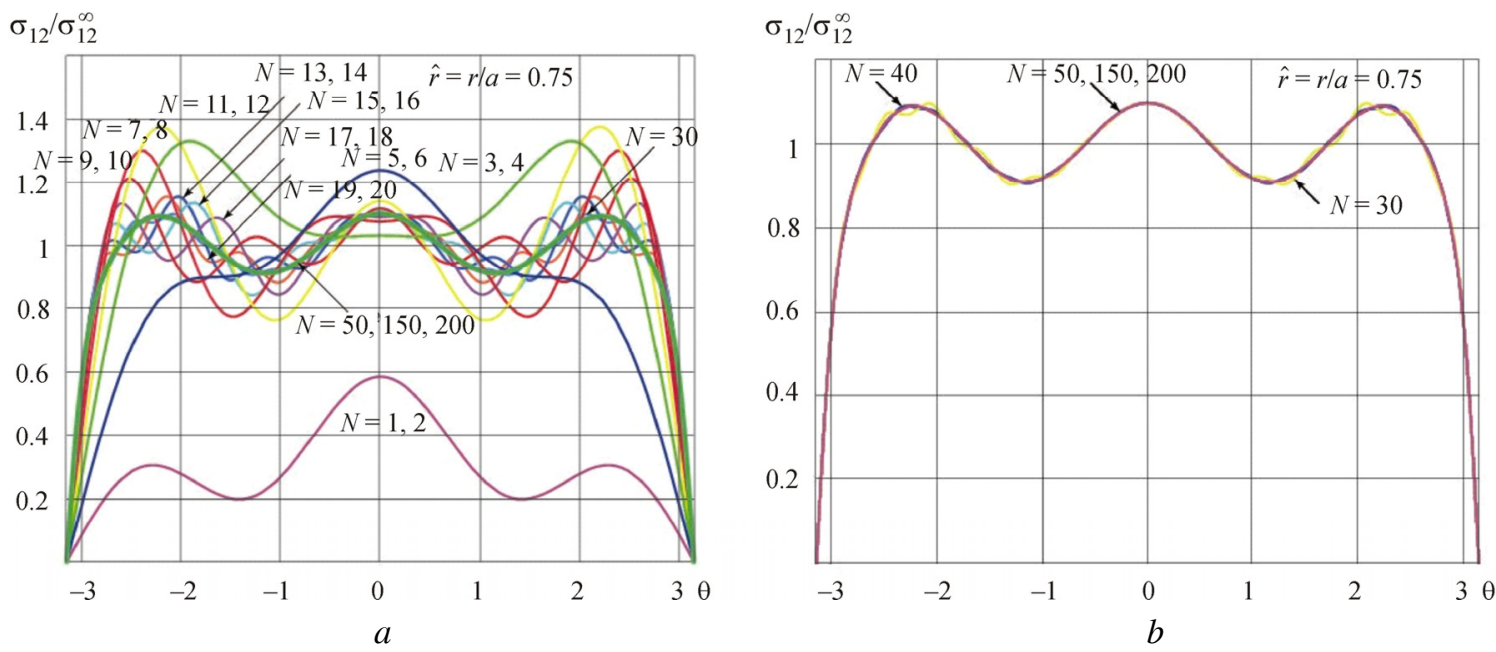

Fig. 17. Angular stress distributions $\sigma_{12}^{2}$ in the neighborhood of the crack tip $z=b$, built with the multiparameter asymptotic expansion with holding various numbers of terms in the asymptotic expansion

holding the higher approximations up to 40 terms. After 40 terms, the angular distributions are not distinguishable anymore: Fig. 17, $b$ shows the angular distributions built with the asymptotic expansions containing 30, 40, 50, 150 and 200 terms. The angular distribution built with 30 terms in an asymptotic expansion, is different from the other curves, as after holding 40 terms the curves are not distinguishable anymore (unlike Fig. 15, $a$ built for $\hat{r}=r / a=0.05$, where three terms of the asymptotic expansion are enough).

The asymptotic expansion of a complex potential (5) in the neighborhood of the crack tip $z(r, \theta)=a+r e^{i \theta}$, $x_{2}(r, \theta)=r \sin \theta$ has the form

$$
\varphi_{2}{ }^{\prime}(z)=-i \frac{\sigma_{12}^{\infty}}{2} \sum_{n=0}^{\infty} \delta_{n}(z-a)^{n-1 / 2}+i \frac{\sigma_{12}^{\infty}}{2},
$$

where

$$
\begin{gathered}
\delta_{n}=\sum_{k=0}^{n+1} p_{k} d_{n-k}, \quad \chi_{n}=\sum_{k=0}^{n+1} \beta_{k} \xi_{n-k}, \quad \xi_{n}=\sum_{k=0}^{n+1} \varsigma_{k} \eta_{n-k}, \\
\eta_{0}=a^{2}-c, \quad \eta_{1}=2 b, \quad \eta_{2}=1, \quad \eta_{k}=0, k>2, \\
\alpha_{k}=(-1)^{k} \frac{(|2 k-1| ! !)}{2^{k} k !}(2 a)^{-(2 k+1) / 2}, \\
\beta_{k}=(-1)^{k} \frac{(|2 k-1| ! !)}{2^{k} k !}(b-a)^{-(2 k+1) / 2}, \\
\varsigma_{k}=(-1)^{k} \frac{(|2 k-1| ! !)}{2^{k} k !}(a+b)^{-(2 k+1) / 2} .
\end{gathered}
$$

Formulae (26)-(30) contain the dependence of the asymptotic expansion coefficients of the complex potential on the geometric parameters of the specimen $a, b$ and the applied load $\sigma_{12}^{\infty}$. Substituting the expression (26) into the Kolosoff-Muskhelishvili formulae (5) and comparison with the complete asymptotic M. Williams expansion (1) leads to the determination of the amplitude coefficients of the expansion:

$$
a_{k}^{2}=\sigma_{12}^{\infty} q_{k} / f_{k}^{2,12}(\theta=0), \quad a_{2 k}^{1}=0, \forall k \geq 1 .
$$

Below, the analytic expressions for the first thirteen coefficients of the complete asymptotic M. Williams expansion, obtained with the expressions (26)-(30), are presented:

$$
\begin{gathered}
a_{1}^{2}=-\frac{\sigma_{12}^{\infty}}{\sqrt{2 b}} \frac{a^{2}-c}{\sqrt{b^{2}-a^{2}}}, a_{2 k}^{2}=0, \forall k \geq 1, \\
a_{3}^{2}=\frac{\sigma_{12}^{\infty} \sqrt{2}}{24} \frac{3 a^{4}-7 a^{2} b^{2}+5 a^{2} c-a^{2} c}{a^{3 / 2}\left(b^{2}-a^{2}\right)^{3 / 2}}, \\
\times \frac{a_{5}^{2}=\frac{\sigma_{12}^{\infty} \sqrt{2}}{320} \times}{a^{2} b^{2} c-34 b^{2} a^{4}-19 b^{4} a^{2}+43 a^{4} c+5 a^{6}+3 b^{4} c} \\
\left.\times 124 b^{6} a^{2} c-67 b^{8} a^{2}-132 b^{6} a^{4}-1636 b^{2} a^{8}-7170 b^{4} a^{6}\right\}(31) \\
\left.\times 13 b^{6} a^{2}+7 a^{8}-113 b^{2} a^{6}-227 b^{4} a^{4}\right) /\left(a^{7 / 2}\left(b^{2}-a^{2}\right)^{7 / 2}\right. \\
\times\left\{4 a^{6} c+137 b^{2} a^{4} c+11 b^{4} a^{2} c+177 a^{6} c+\right. \\
a_{11}^{2}=\frac{\sigma_{12}^{\infty} \sqrt{2}}{180224} \frac{\sigma_{12}^{\infty} \sqrt{2}}{a^{11 / 2}\left(b^{2}-a^{2}\right)^{11 / 2}} \times \\
a_{9}^{2}=\frac{\sigma_{12}^{\infty} \sqrt{2}}{36864} \frac{1}{a^{9 / 2}\left(b^{2}-a^{2}\right)^{9 / 2}} \times
\end{gathered}
$$




$$
\begin{gathered}
\times\left\{10398 b^{4} a^{6} c+42997 b^{2} a^{8} c+77 a^{12}-10986 b^{6} a^{6}-\right. \\
-367 b^{8} a^{4}-646 b^{6} a^{4} c+295 b^{8} a^{2} c+11531 a^{10} c- \\
\left.-6189 b^{2} a^{10}-47150 b^{4} a^{8}-63 b^{10} c+103 b^{10} a^{2}\right\}, \\
a_{13}^{2}=-\frac{\sigma_{12}^{\infty} \sqrt{2}}{1703936} \frac{1}{a^{13 / 2}\left(b^{2}-a^{2}\right)^{13 / 2}} \times \\
\times\left\{48014 b^{2} a^{12}+559049 b^{4} a^{10}+329124 b^{6} a^{8}+11729 b^{8} a^{6}-\right. \\
-92479 a^{12} c-1810 b^{10} a^{4}-273 a^{14}+343 b^{12} a^{2}- \\
-551534 b^{2} a^{10} c-298169 b^{4} a^{8} c-1764 b^{6} a^{6} c- \\
\left.-3329 b^{8} a^{4} c+1330 b^{10} a^{2} c-231 b^{12} c\right\} .
\end{gathered}
$$

With the calculated coefficients (31) it is possible to build the stress tensor components distribution by the crack tip $z=a$, holding various numbers of terms in the asymptotic expansion. Fig. 18, $a$ shows level lines of the stress tensor components and the stress intensities obtained with a mononomial asymptotic expansion. Fig. 18, $b$ demonstrates the same values based on the asymptotic expansions with 15 terms. Obviously, the level line picture materially changes, especially for the stress intensity.

\section{Analytic Determination of the Complete Asymptotic M. Williams Expansion Coefficients of the Stress Field for the Mixed Loading Conditions}

Due to the linear nature of the linear elasticity theory problem, the principle of solution superposition (formula (1)) is right, and with the help of the asymptotic expansions built for the normal fracture cracks and the transverse shear, it is easy to find the stress distributions near the crack tip under mixed mode loading conditions within the full diapason of the mixed deformation forms, setting the loading promiscuity parameter values.

Fig. 19-21 show the level lines of the stress tensor components and the stress intensities in the direct vicinity of the tip $z=a$ for various forms of mixed deformation and various numbers of terms held in the asymptotic expansion. The presented figures demonstrate that the higher approximations in the asymptotic expansions make a visible impact on the stress tensor components distribution in the vicinity of the crack tip. Fig. 19 shows the results of the stress tensor components and stress intensity calculations for the promiscuity parameter $M^{e}=0.75$ for the mononomial (Fig. 19, a) and the binomial (Fig. 19, b) asymptotic stress expansions. The comparison of the figures show that the consideration of higher approximations makes a critical impact on the level lines (Fig. 20, $b$ ).

Fig. 20 presents the polar diagrams of the stress tensor components in the vicinity of the crack tip $z=a$ for the loading promiscuity parameter $M^{e}=0.5$. The conducted analysis and the built diagrams reveal, that considerations of the T-stresses alone do not make a significant impact on the distribution nature of the stress tensor components, making minor changes in the stress intensity. While consideration of the higher approximations is more prominent (Fig. 20, $b$ ).

Fig. 21 shows the level lines of the stress tensor components and the shearing strain intensity in the vicinity of the crack $z=a$ for $M^{e}=0.25$. For constructing the curves in Fig. 21, $a$, the mononomial asymptotic expansions of the stress tensor components were used. The analysis

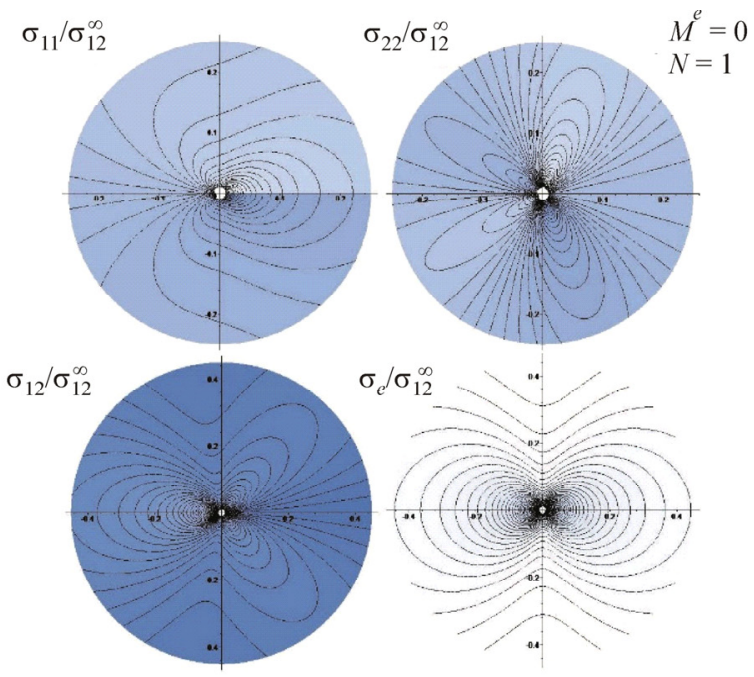

$a$

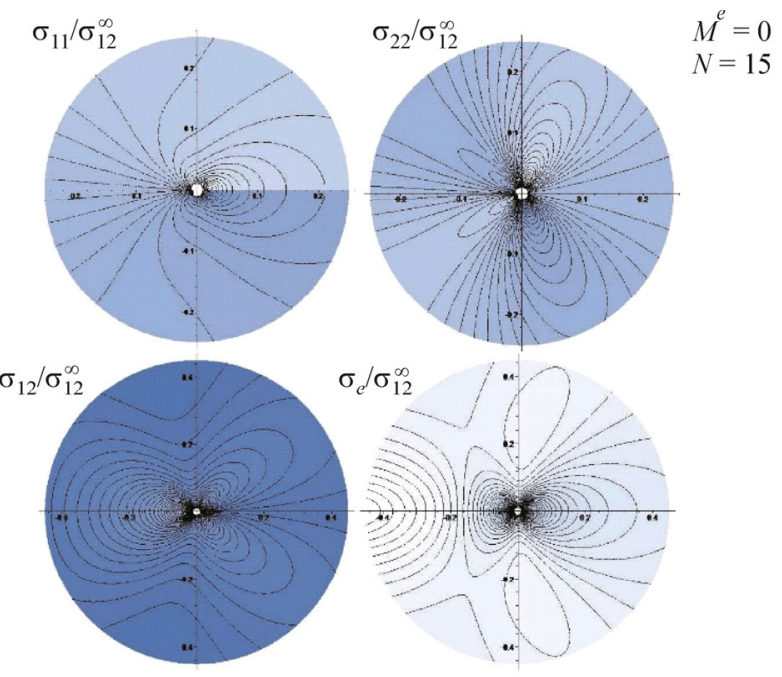

$b$

Fig. 18. The lines of equal values of the stress tensor component in the vicinity of the crack tip $z=a$ for a transverse shear crack, built with a mononomial $(a)$ and fifteen-nomial asymptotic expansion $(b)$ 


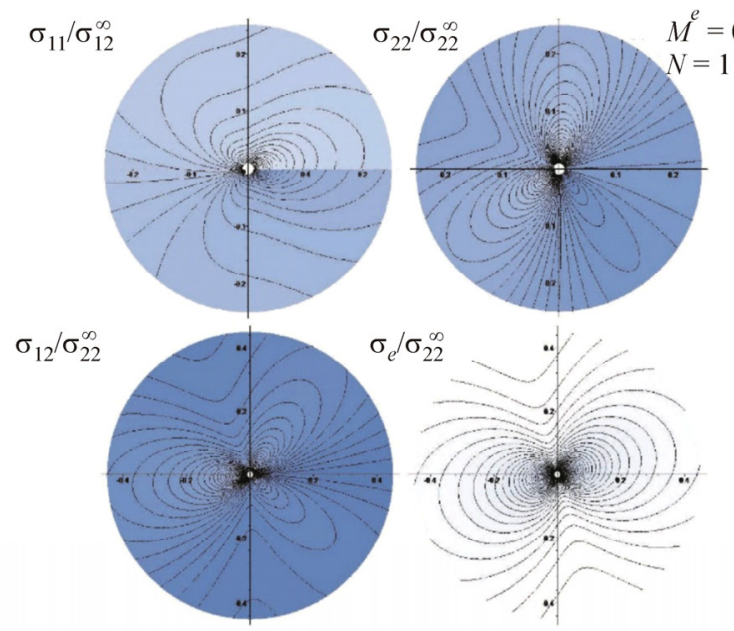

$a$
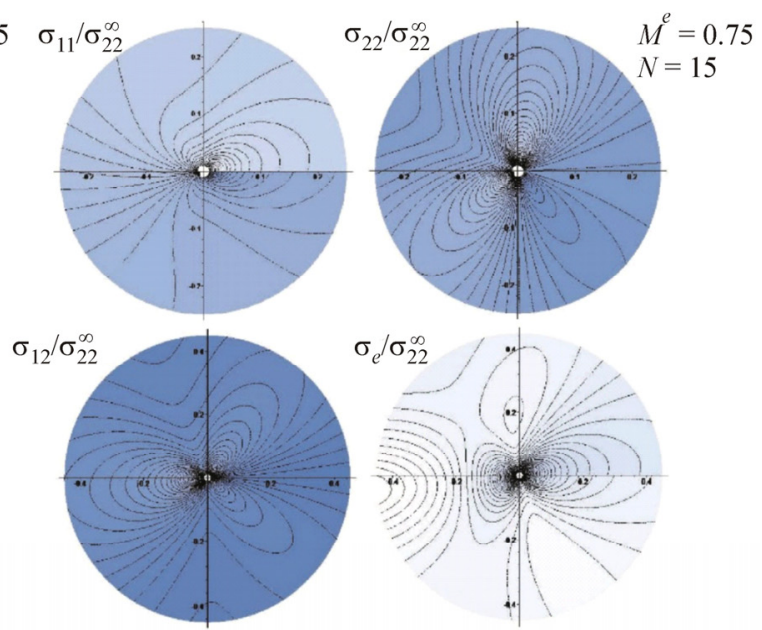

$\sigma_{e} / \sigma_{22}^{\infty}$

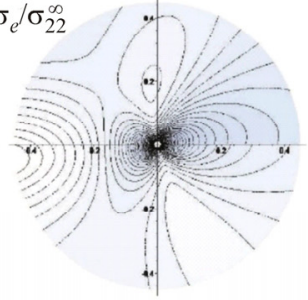

$b$

Fig. 19. Level lines of the stress tensor components in the vicinity of the crack tip $z=a$ I $\mathrm{n}$ the case of mixed mode loading, built with mononomial asymptotic expansions $(a)$ and by means of fifteen-nomial asymptotic expansions $(b)$

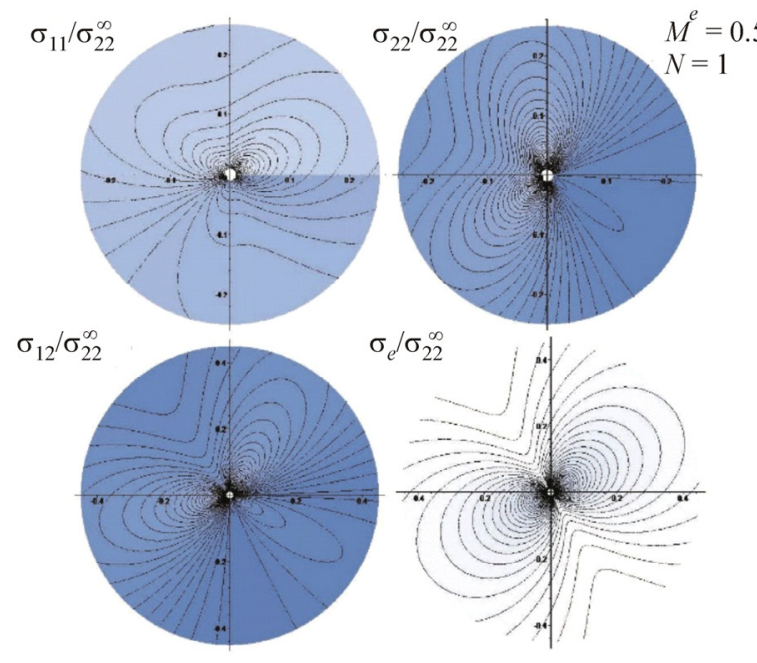

$a$

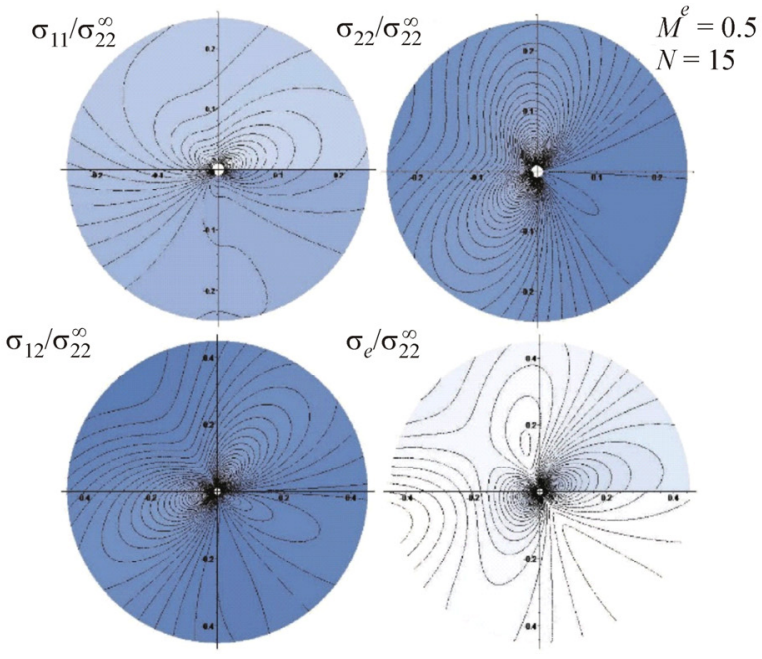

$b$

Fig. 20. The level lines of the stress tensor components in the vicinity of the crack tip $z=a$ in case of mixed mode loading conditions for different values of the loading promiscuity parameter: $M^{e}=0.5$, built with the mononomial asymptotic expansions $(a)$ and by means of the fifteen-term asymptotic expansions $(b)$

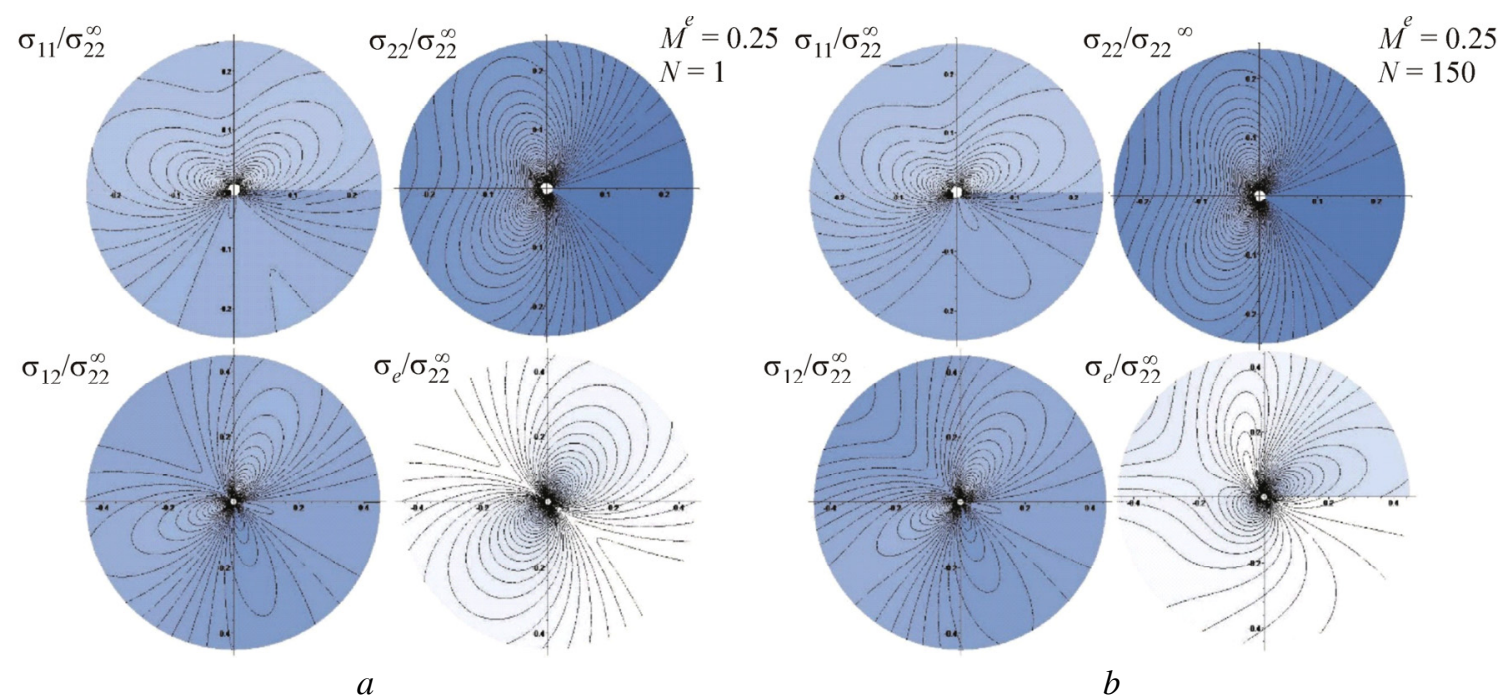

Fig. 21. The level lines of stress in the vicinity of the tip $z=a$ for the mononomial and binomial asymptotic expansions for the loading promiscuity parameter $M^{e}=0.25$, built with the mononomial asymptotic expansions $(a)$ and by means of the asymptotic expansions holding 150 terms $(b)$ 
revealed that holding the T-stresses only helps clarifying the stress intensity. Building the level lines in Fig. 21, b, 150 terms were held in the asymptotic expansion. It is seen that consideration of the higher approximations increases the calculation precision of the mechanic values of the crack tip. Fig. 22-25 demonstrate the angular distributions of the component $\sigma_{22}$ in the vicinity of the crack tip under mixed mode loading conditions applied in different distances from the crack tip. The figures show that the expansion of the asymptotic scope determined the need for holding the higher-order terms.
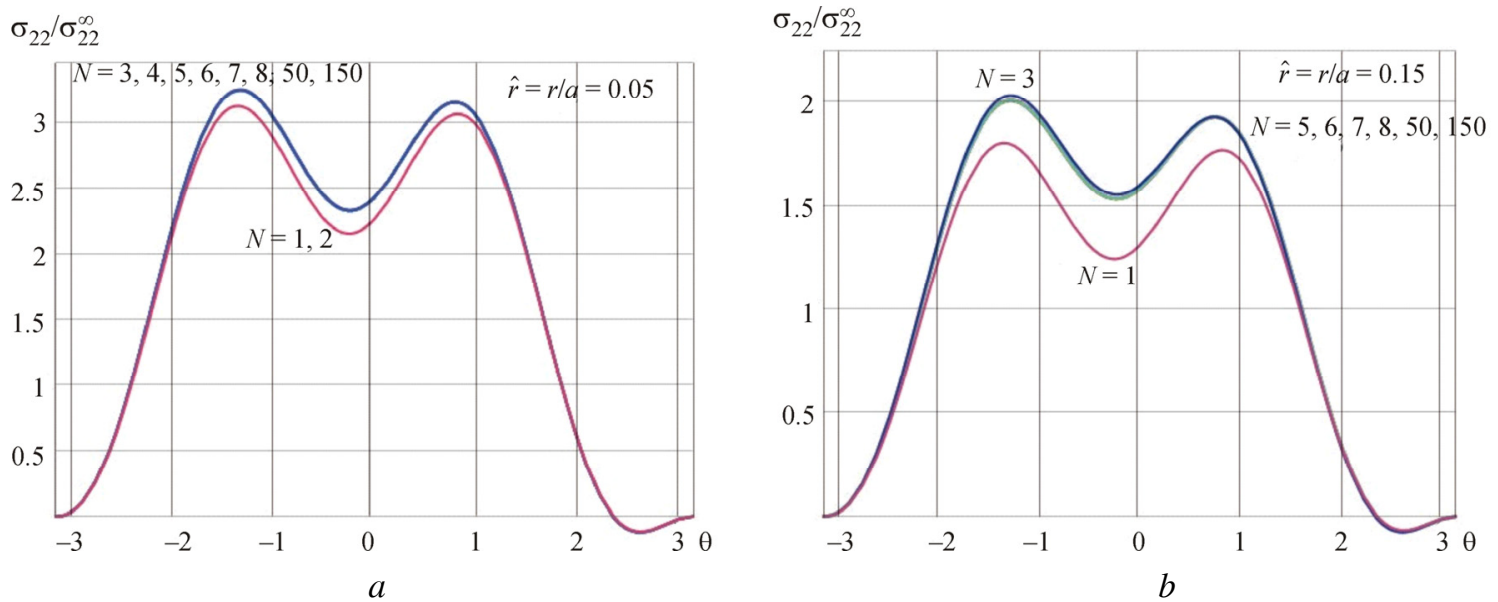

Fig. 22. The angular distribution of the stress tensor component $\sigma_{22}$ under mixed mode loading conditions $\left(\sigma_{11}^{\infty}, \sigma_{12}^{\infty}, \sigma_{22}^{\infty}\right)=(0,0.75,1) \sigma_{22}^{\infty}$ in different distances from the crack tip: $a$ ) for $\hat{r}=r / a=0.05 ; b)$ for $\hat{r}=r / a=0.15$
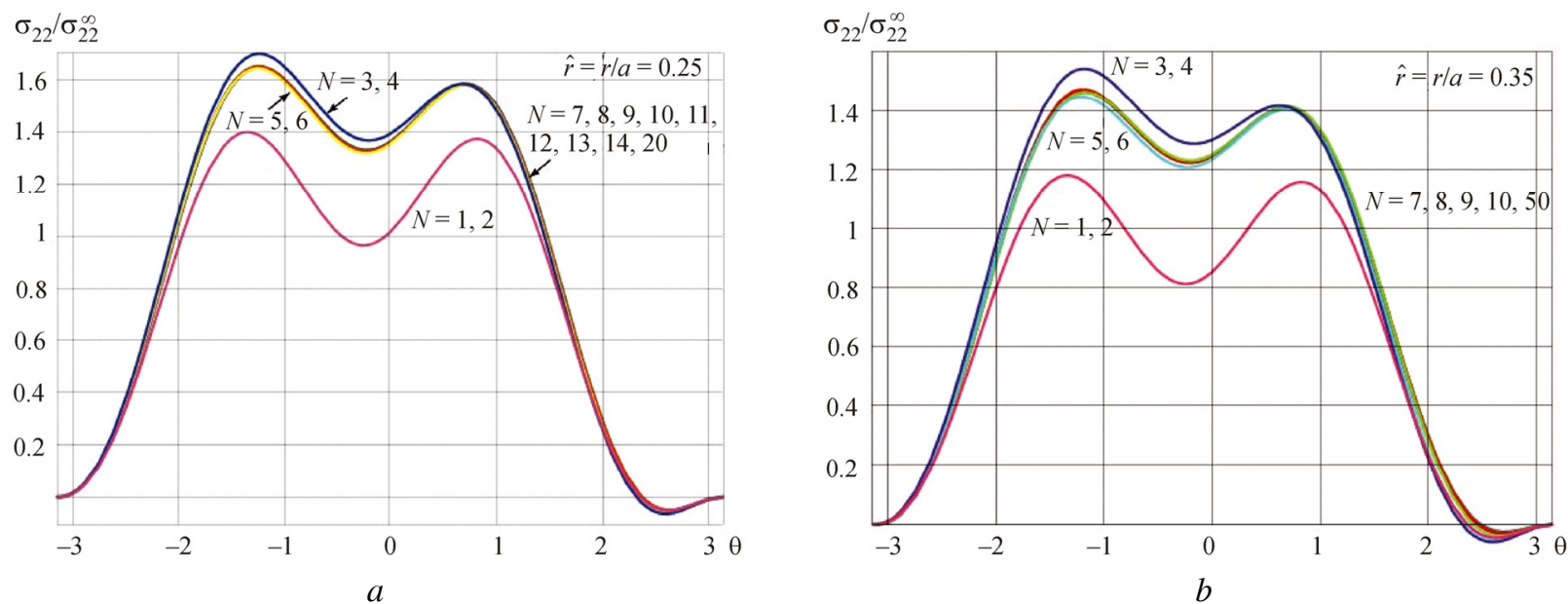

Fig. 23. The angular distribution of the stress tensor component $\sigma_{22}$ under mixed mode loading conditions $\left(\sigma_{11}^{\infty}, \sigma_{12}^{\infty}, \sigma_{22}^{\infty}\right)=(0,0.75,1) \sigma_{22}^{\infty}$ in different distances from the crack tip: $a$ ) for $\hat{r}=r / a=0.25 ; b)$ for $\hat{r}=r / a=0.35$
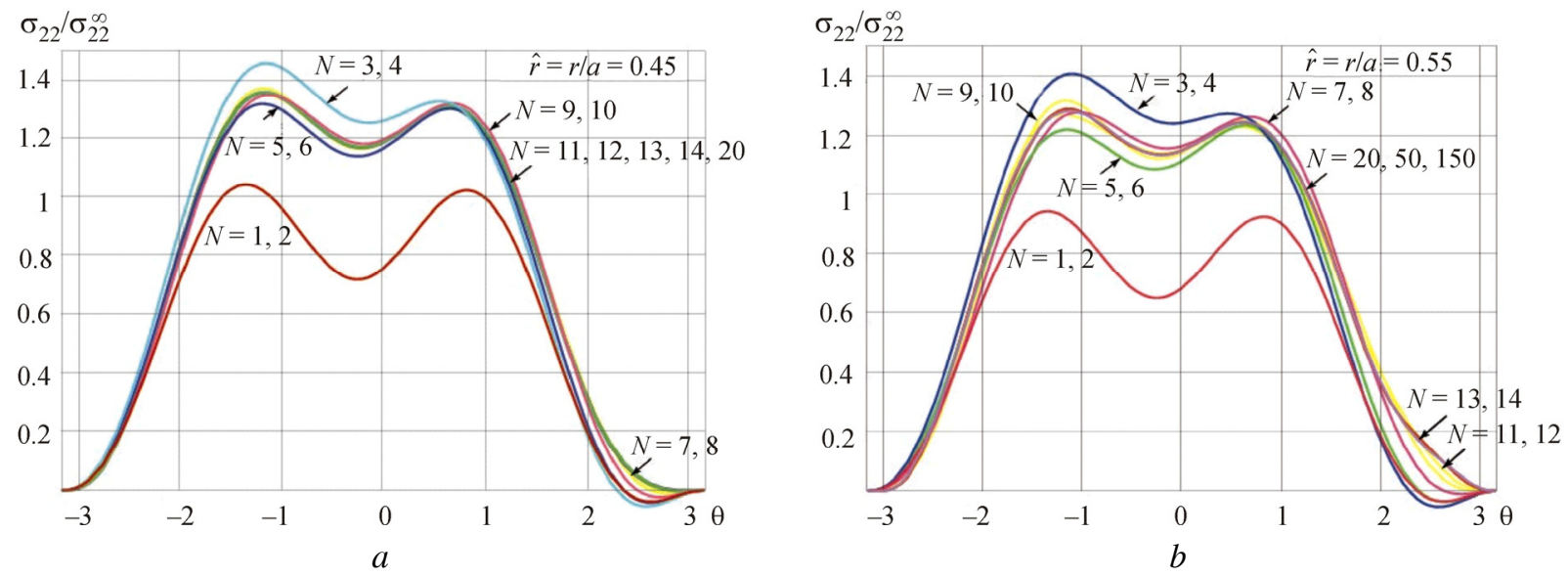

Fig. 24. The angular distribution of the stress tensor component $\sigma_{22}$ under mixed mode loading conditions $\left(\sigma_{11}^{\infty}, \sigma_{12}^{\infty}, \sigma_{22}^{\infty}\right)=(0,0.75,1) \sigma_{22}^{\infty}$ in different distances from the crack tip: $a$ ) for $\hat{r}=r / a=0.45 ; b)$ for $\hat{r}=r / a=0.55$ 


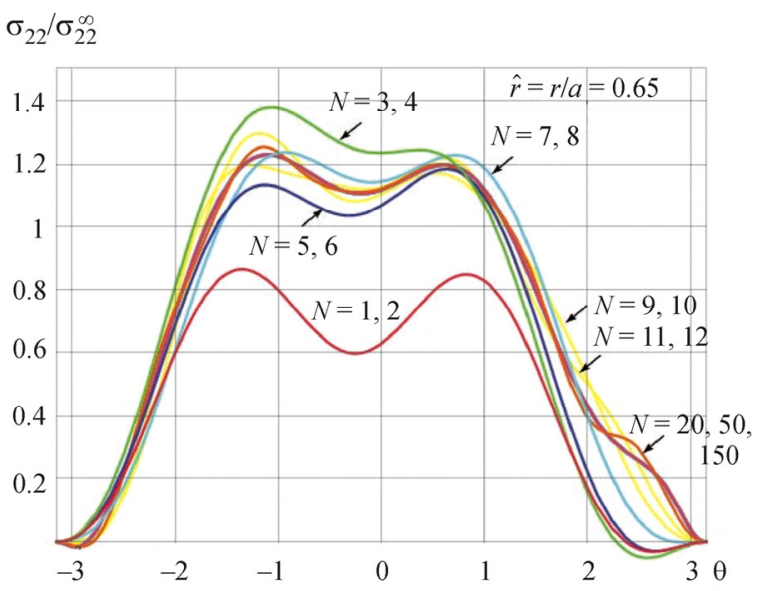

$a$

$$
\sigma_{22} / \sigma_{22}^{\infty}
$$

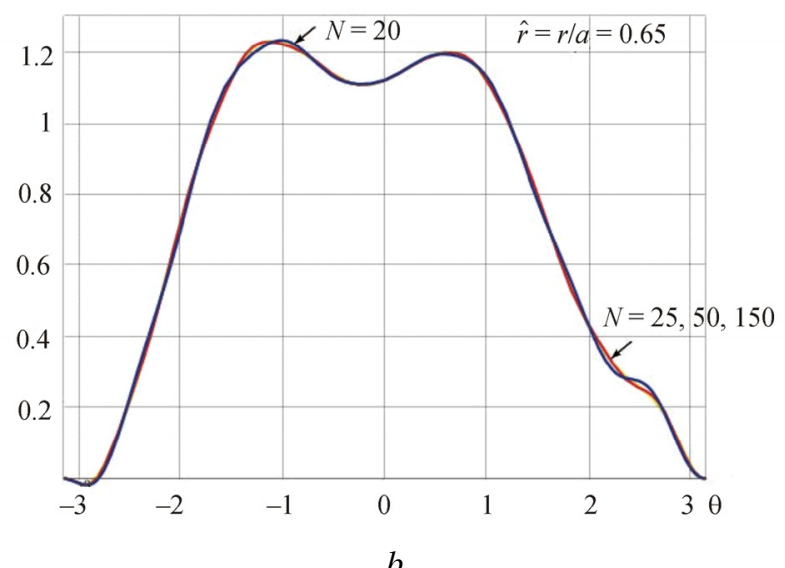

$b$

Fig. 25. The angular distributions of the stress tensor component $\sigma_{22}$ under mixed mode loading conditions $\left(\sigma_{11}^{\infty}, \sigma_{12}^{\infty}, \sigma_{22}^{\infty}\right)=(0,0.75,1) \sigma_{22}^{\infty}$, built with different numbers of held terms in asymptotic expansion
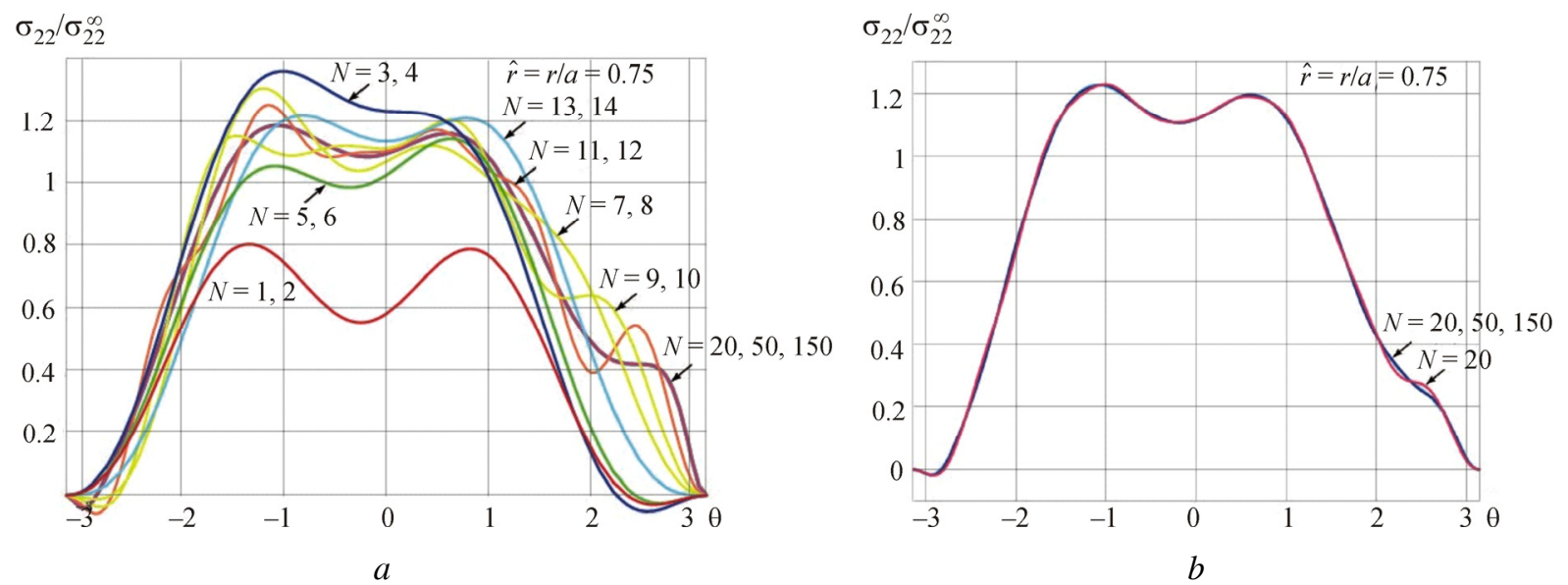

Fig. 26. The angular distributions of the stress tensor component $\sigma_{22}$ under mixed mode loading conditions $\left(\sigma_{11}^{\infty}, \sigma_{12}^{\infty}, \sigma_{22}^{\infty}\right)=(0,0.75,1) \sigma_{22}^{\infty}$, built with different numbers of held terms in asymptotic expansion
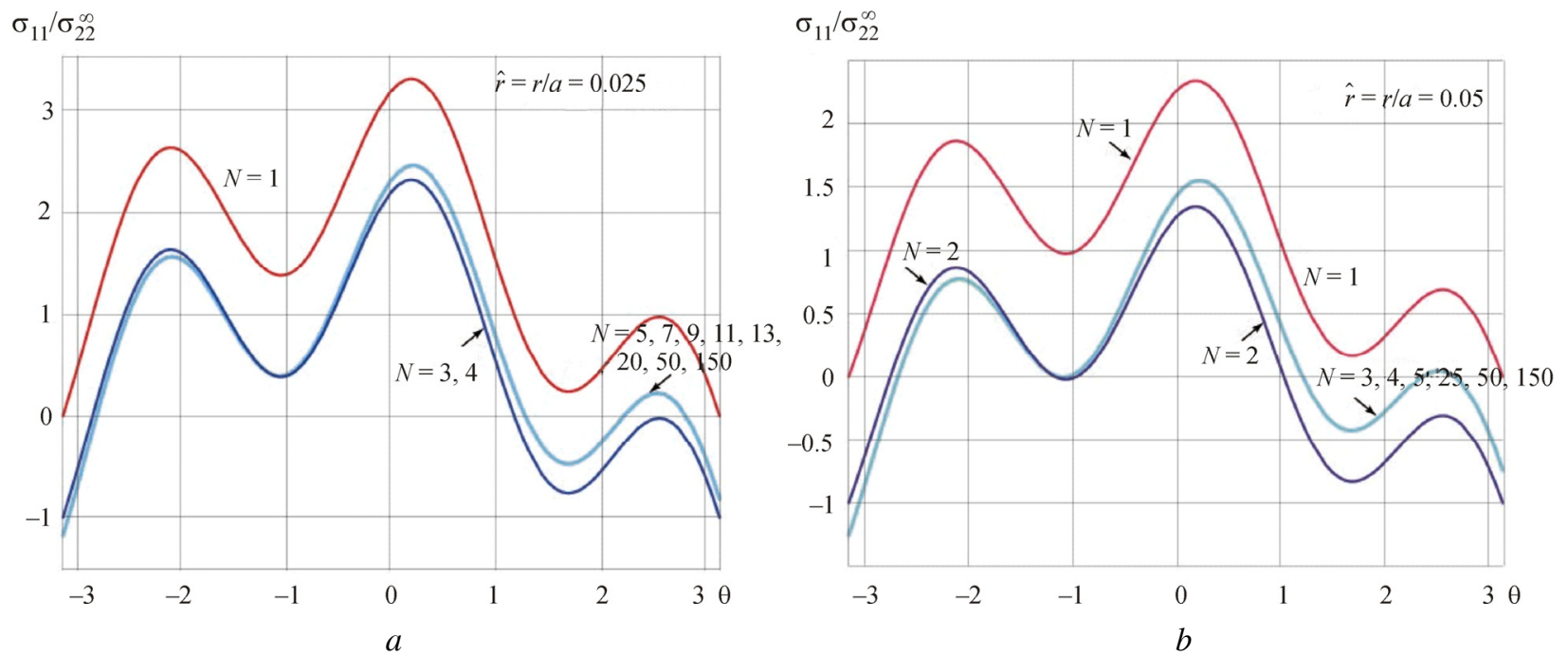

Fig. 27. The angular distribution of the stress tensor component $\sigma_{11}$ under mixed mode loading conditions $\left(\sigma_{11}^{\infty}, \sigma_{12}^{\infty}, \sigma_{22}^{\infty}\right)=(0,0.75,1) \sigma_{22}^{\infty}$ in different distances from the crack tip: $a$ ) for $\hat{r}=r / a=0.025 ; b)$ for $\hat{r}=r / a=0.05$ 

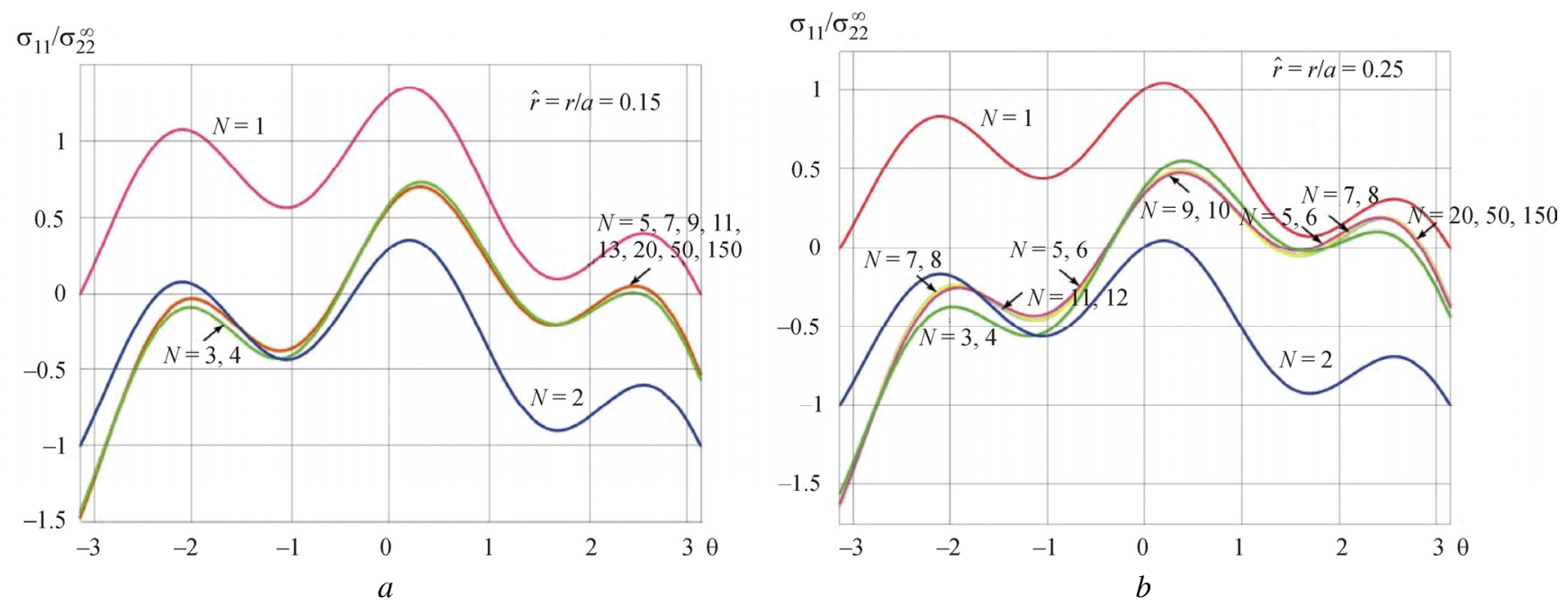

Fig. 28. The angular distribution of the stress tensor component $\sigma_{11}$ under mixed mode loading conditions $\left(\sigma_{11}^{\infty}, \sigma_{12}^{\infty}, \sigma_{22}^{\infty}\right)=(0,0.75,1) \sigma_{22}^{\infty}$ in different distances from the crack tip: $a$ ) for $\hat{r}=r / a=0.15 ; b)$ for $\hat{r}=r / a=0.25$

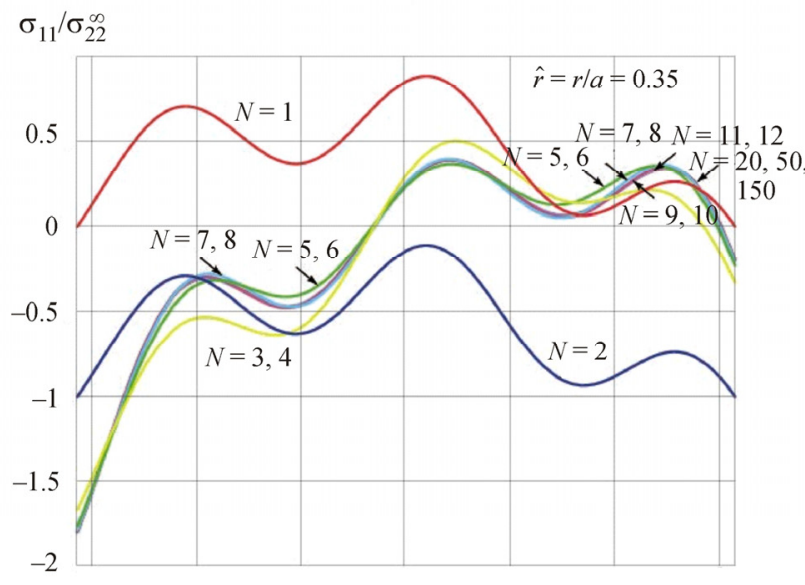

$a$

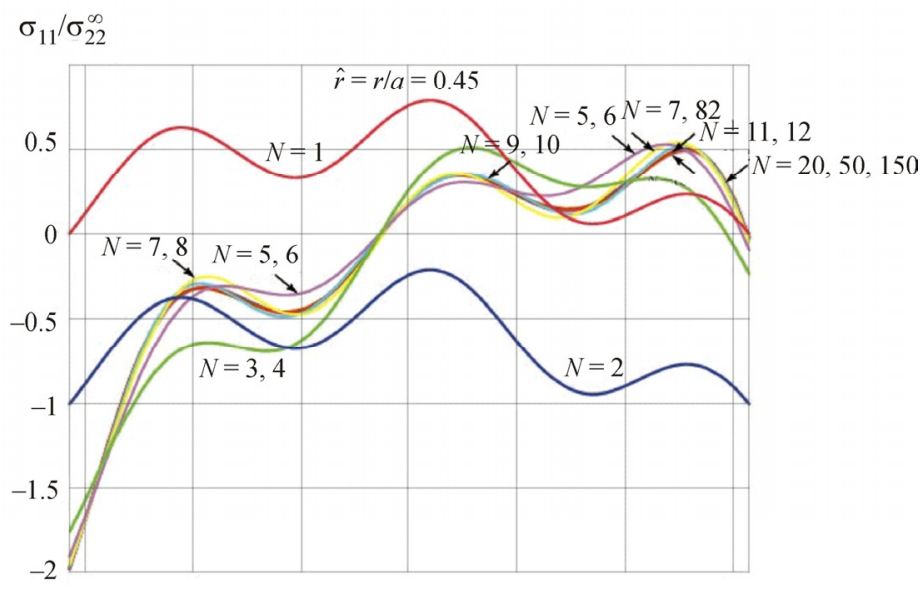

$b$

Fig. 29. The angular distribution of the stress tensor component $\sigma_{11}$ under mixed mode loading conditions $\left(\sigma_{11}^{\infty}, \sigma_{12}^{\infty}, \sigma_{22}^{\infty}\right)=(0,0.75,1) \sigma_{22}^{\infty}$ in different distances from the crack tip: $a$ ) for $\hat{r}=r / a=0.35 ; b)$ for $\hat{r}=r / a=0.45$

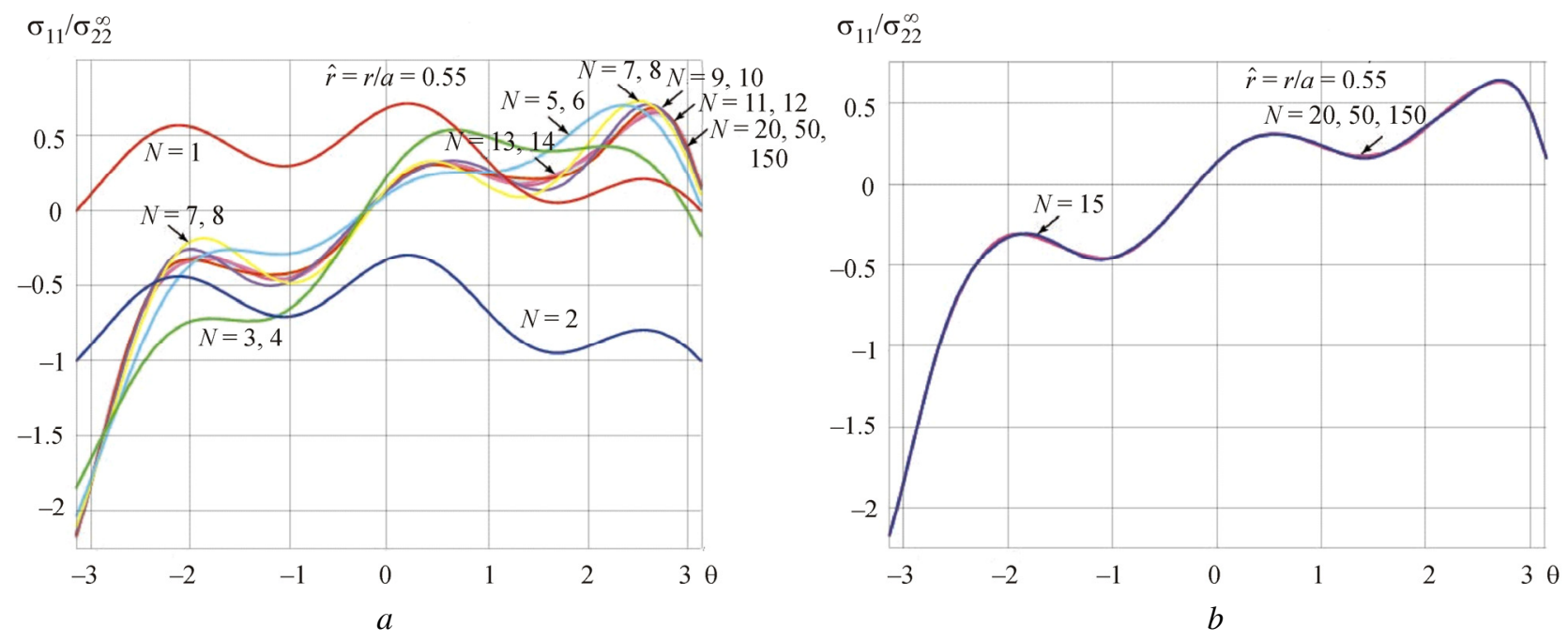

FIg. 30. The angular distributions of the stress tensor component $\sigma_{11}$ under mixed mode loading conditions $\left(\sigma_{11}^{\infty}, \sigma_{12}^{\infty}, \sigma_{22}^{\infty}\right)=(0,0.75,1) \sigma_{22}^{\infty}$, built with different numbers of held terms in asymptotic expansion 

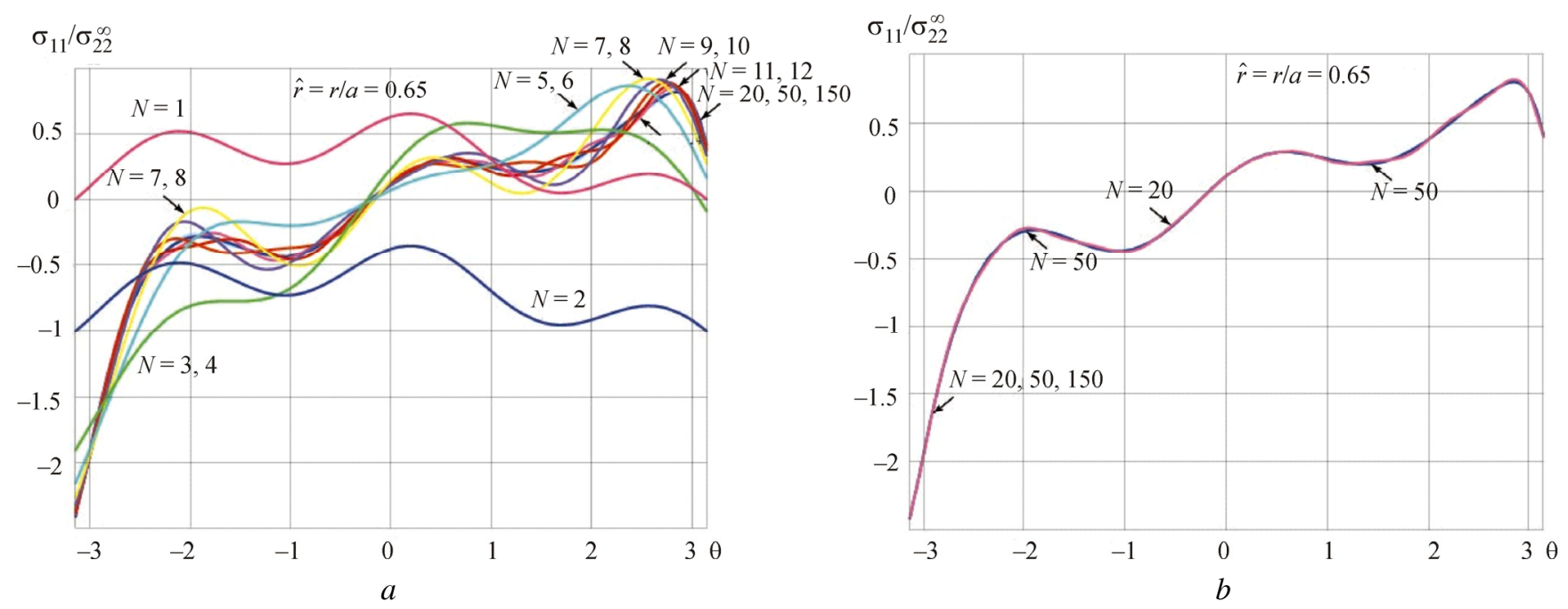

Fig. 31. The angular distributions of the stress tensor component $\sigma_{11}$ under mixed mode loading conditions $\left(\sigma_{11}^{\infty}, \sigma_{12}^{\infty}, \sigma_{22}^{\infty}\right)=(0,0.75,1) \sigma_{22}^{\infty}$, built with different numbers of held terms in asymptotic expansion

Fig. 27-31 demonstrate the angular distributions of the stress tensor components $\sigma_{22}$ and $\sigma_{11}$ under mixed mode loading conditions $\left(\sigma_{11}^{\infty}, \sigma_{12}^{\infty}, \sigma_{22}^{\infty}\right)=(0,0.75,1) \sigma_{22}^{\infty}$ in different distances from the crack tip. The figures clearly present that for more precise description of a stress field it is necessary to hold not only the T-stresses, but also the higher approximations in the complete asymptotic expansion in the vicinity of the crack tip.

\section{Conclusion and Results Discussion}

The work acquires analytic expressions for the amplitude coefficients of the complete stress field asymptotic expansion near the tips of two collinear cracks of finite length in the infinite plate medium in the conditions of 1) pure strain; 2) pure transverse shear; 3) mixed mode loading. It demonstrates that along with the main member of the asymptotic expansion and the T-stress, the higher approximations are major fracture mechanic parameters of the complete asymptotic expansion, the consideration of which is essential for precise evaluation of the stress fields near the fault tip, and, consequently, for more precise evaluation of the bearing capacity and the life duration of the specimen. The analytical expressions of the stress field asymptotic expansion coefficients for any previously given number of the held terms are only available for the plate medium with one crack of a finite length [17]; for this reason it is important to expand the class of the specimens providing analytical dependences of the amplitude coefficients on the applied load and the geometric parameters of specimens. The asymptotic solution found in the present paper for an infinite plate medium with two cracks of equal length may be used for: 1) checking the numerical processing of the experimental data obtained with polarization-optic methods of the deformed solid body mechanics for cracked specimens; 2) checking the numerical algorithms actively developed today for calculation of the multiparameter stress field amplitude coefficients $[6,9,37,43]$.

The project is developed with the financial support of the Russian Foundation for Basic Research (Grant No. 13-01-97009).

\section{References}

1. Wei R.P. Fracture Mechanics. Integration of Mechanics, Materials Science and Chemistry. Cambridge: Cambridge University Press, 2014. 232 p.

2. Voyiadjis G.Z. Handbook of damage mechanics: nano to macro scale for materials and structures. Berlin: Springer, 2015. $1577 \mathrm{p}$.

3 Gupta M., Alderliesten R.C., Benedictus R. A review of $\mathrm{T}$-stress and its effects in fracture. Engineering Fracture Mechanics, 2015, vol. 134, pp. 218-241.

4. Weibgraeber P., Becker W. Crack initiation at weak stress singularities - Finite Fracture Mechanics approach. Procedia Materials Science, 2014, no. 3, pp. 153-158.

5. Shlyannikov V.N., Zakharov A.P. Multiaxial crack growth under variable T-stress. Engineering Fracture Mechanics, 2014, vol. 123, pp. 86-99.

6. Berto F., Lazzarin P. Multiparametric full-field representations of the in-plane stress fields ahead of cracked components under mixed mode loading. International Journal of Fatigue, 2013, vol. 46, pp. 16-26.

7. Lu K., Meshii T. A systematic investigation of T-stresses for a variety of center-cracked tension specimen. Theoretical and Applied Fracture Mechanics, 2015, no. 2, pp. 74-81.

8. Akbardoost J., Rastin A. Comprehensive date for calculating the higher order terms of crack tip stress field in disk type specimens under mixed-mode loading. Theoretical and Applied Fracture Mechanics, 2015, vol. 76, pp. 75-90.

9. Akbardoost J., Ayatollahi M.R. Experimental analysis of mixed mode crack propagation in brittle rocks: The effect of nonsingular terms. Engineering Fracture Mechanics, 2014, vol. 129, pp. 77-89.

10. Berto F., Lazzarin P. On higher order terms in the crack tip stress field. International Journal of Fracture, 2010, vol. 161, pp. 221-226. 
11. Vesely V., Frantik P., Sobek J., Malikova L., Seitl S. Multi-parametric crack tip stress state description for evaluation of nonlinear zone width in silicate composite specimens in component splitting/ bending test geometry. Fatigue and Fracture of Engineering Materials and Structures, 2015, vol. 38, no. 2, pp. 200-214.

12. Vesely V., Sobek J., Sestakova L., Frantik P. Multiparametric crack tip stress state description for estimation of fracture process zone extent in silicate composite WST specimens. Frattura ed Intergrita Strutturale, 2013, vol. 25, pp. 69-78.

13. Malikova L., Vesely V. Williams expansion terms and their importance for accurate stress field description in specimens with a crack. Transaction of the VSB- Technical University of Ostrava, Mechanical Series, 2013, no. 2, vol. LIX, pp. 109-114.

14. Ayatollahi M.R., Nejati M. An over-deterministic method for calculation of coefficients of crack tip asymptotic field from finite element analysis. Fatigue and Fracture of Engineering Materials and Structures, 2010, vol. 34, pp. 159-176.

15. Sevecek O., Bermejo R., Profant T., Kotoul M. Influence of the T-stress on the crack bifurcation phenomenon in ceramic laminates. Procedia Materials Science, 2014, vol. 3, pp. 1062-1067.

16. Malikova L., Vesely V. Significance of higher-order terms of the Williams expansion for plastic zone extent estimation demonstrated on a mixed-mode geometry. Procedia Materials Science, 2014, vol. 3, pp. 1383-1388.

17. Hello G., Tahar M.B., Roelandt J.-M. Analytical determination of coefficients in crack-tip stress expansions for a finite crack in an infinite plane medium. International Journal of Solids and Structures, 2012, vol. 49, pp. 556-566.

18. Sestakova L. Using the multi-parameter fracture mechanics for more accurate description of stress and displacement crack tip fields. Key Engineering Materials, 2013, vol. 586, pp. 237-240.

19. Sestakova L. How to enhance efficiency and accuracy of the over-deterministic method used for determination of the coefficients of the higher-order terms in Williams expansion. Applied Mechanics and materials, 2013, vol. 245, pp. 120-125.

20. Stepanova L.V., Fedina M.Ye. Self-similar solution of a tensile crack problem in a coupled formulation. Journal of Applied Mathematics and Mechanics, 2008, vol. 72(3), pp. 360-368.

21. Stepanova L.V., Igonin S.A. Perturbation method for solving the nonlinear eigenvalue problem arising from fatigue crack growth problem in a damaged medium. Applied Mathematical Modelling, 2014, vol. 38 (14), pp. 3436-3455.

22. Stepanova L.V., Adylina E.M. Stress-strain state in the vicinity of a crack tip under mixed loading. Journal of Applied Mechanics and Technical Physics, 2014, vol. 55(5), pp. 885-895.

23. Beliakova T.A., Kulagin V.A. The eigenspectrum approach and T-stress at the mixed - mode crack tip for a stress state dependent material. Procedia Materials Science, 2014, vol. 3, pp. 147-152.

24. Stepanova L.V., Yakovleva E.M. Mixed-mode loading of the cracked plate under plane stress conditions. PNRPU Mechanics Bulletin, 2014, no. 3, pp. 129-162. DOI: 10.15593/perm.mech/2014.3.08

25. Stepanova L., Yakovleva E., Mironova E. Asymptotic self-similar solution of the creep crack problems in damaged materials under mixed mode loading. Applied Mechanics and Materials, 2015, vol. 784, pp. 145-152.
26. Stepanova L.V. Eigenspectra and orders of stress singularity at a mode I crack tip for a powerlaw medium. Comptes Rendus - Mecanique, 2008, vol. 336 (1-2), pp. 232-237.

27. Stepanova L.V. Eigenvalue analysis for a crack in a power-law material. Computational Mathematics and Mathematical Physics, 2009, vol. 49(8), pp. 1332-1347.

28. Shlyannikov V.N., Tumanov A.V., Zakharov A.P. The mixed mode crack growth rate in cruciform specimens subject to biaxial loading. Theoretical and Applied Fracture Mechanics, 2014, vol. 73, pp. 68-81.

29. Profant T., Klusak J., Sevecek O., Kotoul M., Hrstka M., Marcian P. An effect of the first nonsingular term of the Williams asymptotic expansion to the stability of the bi-material orthotropic notch. Key Engineering Materials, 2014, vol. 592-593, pp. $745-748$

30. Matvienko Yu.G. Nesinguliarnye T-napriazheniia $\mathrm{v}$ problemakh dvukhparametricheskoi mekhaniki razrusheniia [Nonsingular T-stress in problems of two-parameter fracture mechanics]. Zavodskaia laboratoriia. Diagnostika materialov, 2012, vol. 78, no. 2, pp. 51-58.

31. Matvienko Yu.G. Nesinguliarnye T-napriazheniia v kriteriiakh mekhaniki razrusheniia tel $\mathrm{s}$ treshchinami [The nonsingular T-stress in fracture mechanics criteria of solids with notches]. Vestnik Nizhegorodskogo universiteta, 2011, no. 4-5, pp. 2651-2652.

32. Litvinov I.A., Matvienko Yu.G., Razumovsky I.A. O tochnosti opredeleniia nesinguliarnykh komponent tenzora naprjazhenij $\mathrm{v}$ vershine treshhiny $\mathrm{s}$ primeneniem metoda jekstrapoljacii [On the accuracy of determination of nonsingular component in stress field at crack tip using extrapolation method]. Mashinostroenie $i$ inzhenernoe obrazovanie. 2014, no. 2 (39), pp. 47-52.

33. Matvienko Y.G., Pochinkov R.A. Effect of nonsingular T-stress components on the plasticdeformation zones near the tip of a mode I crack. Russian metallurgy (Metally), 2013, vol. 2013, no. 4, pp. 262-271.

34. Pisarev V.S., Matvienko Y.G., Odintsev I.N. Opredelenie parametrov mekhaniki razrusheniia pri malom prirashchenii dliny treshchiny [Determination of fracture Mechanics Parametera at a small increment of the crack length]. Zavodskaia laboratoriia. Diagnostika materialov, 2012, vol. 78, no. 4, pp. 45-51.

35. Matvienko Y.G. [Two approaches to accounting the nonsingular T-stress in fracture mechanics criteria for cracked bodies]. Problemy mashinostroeniia $i$ nadezhnosti mashin, 2011, no. 5, pp. 104-110.

36. Matvienko Y.G. Dvuhkparametricheskaia mekhanika razrusheniia $\mathrm{v}$ sovremennykh problemakh prochnosti [Two parametric fracture mechanics in actual reliability problems]. Problemy mashinostroeniia i nadezhnosti mashin, 2013, no. 5, pp. 37-46.

37. Matvienko Y.G., Chernyatin A.S., Razumovsky I.A. Chislennyi analiz nesinguliarnykh sostavliaiushchikh trekhmernogo polia napriazhenii $\mathrm{v}$ vershine treshchiny smeshannogo tipa [Numerical analysis of non-singular stress tensor components in the vicinity of the mixed-mode crack tip]. Problemy mashinostroeniia i nadezhnosti mashin, 2013, no. 4, pp. 40-48.

38. Matvienko Yu. G. The effect of the non-singular T-stress components on crack tip plastic flow zone under Mode I. Procedia Materials Science, 2014, vol. 3, pp. 141-146. 
39. Williams M.L. On the stress distribution at the base of a stationary crack. Journal of Applied Mechanics, 1957, vol. 24, pp. 109-114.

40. Kolosoff G. Primenenie kompleksnoi peremennoi k teorii uprugosti [Application of the complex variable to the elasticity theory]. Moscow, Leningrad: 1935, 224 p.

41. Muskhelishvili N.I Nekotorye osnovnye zadachi matematicheskoi teorii uprugosti [Some basic problems of mathematical problems of elasticity theory]. Moscow: Nauka, 1966, 708 p.
42. Mirsayar M.M., Aliha M.R.M., Samaei A.T. On fracture initiation angle near bi-material notches - Effects of first nonsingular terms. Engineering fracture mechanics, 2014, vol. 119, pp. 124-131.

43. Kotousov A., Lazzarin P., Berto F., Pook L.P. Threedimensional stress state at crack tip induced by shear and antiplane loading. Engineering Fracture Mechanics, 2013, vol. 108, pp. 65-74.

Original Russian Text:

Stepanova L.V., Roslyakov P.S. Complete asymptotic expansion M. Williams near the crack tips of collinear cracks of equal lengths in an infinite plane medium. PNRPU Mechanics Bulletin. 2015, no. 4, pp. 188-225. DOI: 10.15593/perm.mech/2015.4.12 


\title{
PNRPU MECHANICS BULLETIN
}

\author{
№ 3-4, 2018
}

http://vestnik.pstu.ru/mechanics/about/inf/

DOI: 10.15593/perm.mech/eng.2018.3.13

UDC 539.3

\section{SERRATED YIELDING: PHYSICAL MECHANISMS, EXPERIMENTAL DATA, MACROPHENOMENOLOGICAL MODELS}

\author{
P.V. Trusov, E.A. Chechulina \\ Perm National Research Polytechnic University, Perm, Russian Federation
}

\section{ARTICLE INFO}

Received: 24.05.2014

Accepted: 15.06 .2014

Published: 25.12.2018

\section{Keywords:}

review, the Portevin-Le Chatelier effect, serrated yielding, physical mechanisms, strain aging, negative strain-rate sensitivity, instability, experimental studies, phenomenological models.

\begin{abstract}
Jump-like deformations as a phenomenon of plastic deformation instability is found for a wide range of ductile materials within certain temperature and strain rate ranges. It is known that temperature and strain rate are the most important parameters of inelastic deformation. For most polycrystals, in the absence of phase transitions, the increase of temperature and decrease of deformation speed leads to a reduction of stresses of inelastic deformation resistance. At the same time there is an inverse dependence of the flow stress for a great number of alloys in some ranges of temperatures and strain rates. Many researchers think that the main reason of this anomalous behaviour is a diffusion process and interaction of dislocations with solute atoms. The Portevin-Le Chatelier effect is one of the best known manifestations of the influence of diffusion processes on the behaviour of deformable materials. At the moment it is an urgent problem to identify ranges of actions, within which serrated yielding is implemented in order to exclude them from manufacturing modes of metal processing.

It is preferable to use methods and approaches based on mathematical modelling for the analysis of serrated yielding, determination of optimal processing modes and design of new materials, as experimental methods are very resource intensive and applicable only for existing materials. It is not possible to build mathematical models of the studied processes with a required degree of sufficiency without a thorough study of available empirical data and establishment of leading physical mechanisms.

In the first part of the review we consider the works devoted to the description of physical mechanisms and experimental studies of serrated yielding. The main mechanism is considered to be dislocations pinning with solute atoms during delays of motion of dislocations with barriers of different nature. Three main types of the Portevin-Le Chatelier effects have been allocated based on the experimental data of uniaxial loading, in real experiments, different combinations of these three types can be found. Different approaches and models (macrophenomenological, structural mechanical, physical) are used for the theoretical description of serrated yielding; only phenomenological models are analyzed in the present review.
\end{abstract}




\section{Introduction}

Serrated yielding (SY), also called jump-like deformation, is a phenomenon of plastic deformation instability which is found almost in all alloys at certain temperature and strain rate ranges. Serrated yielding is revealed on deformation curves in the form of repeating inhomogeneities, i.e. steps or teeth of different types, and has a number of common factors for different materials and temperatures. In the majority of works in this area, SY is connected to macro- and mesolocalization of deformation, which is revealed in the form of shear bands for mono- and polycrystalline metals and alloys. Traces of shear bands on surfaces of ready-made products significantly increase roughness of surfaces, decrease fatigue strength and corrosion resistance. Therefore, it is important to solve the problem of specifying ranges of actions, within which serrated yielding is implemented, in order to eliminate them in technological modes of metal processing (at least during finishing operations).

Competitive nonequilibrium processes related to hardening and softening are active during deformation of materials at high temperatures. The increase of dislocations density in a metal, their interaction with each other and with other defects of the crystalline lattice make the greatest contribution to hardening. Without phase transitions, alloy softening occurs due to dynamic recovery, polygonization and recrystallization (however, these processes can be considered as types of phase transitions, from the point of mechanics).

Loss of monotonicity of temperature dependence and sensitivity to rate of mechanical properties (flow stress, in particular) during inelastic deformation under simple and complex loadings is found in ferrum-based alloys, i.e. alloy steels, intermetalic metals and other alloys. Experimental methods of studying the considered phenomenon are extremely resource-intensive (especially for complex loading tests) and applicable only for existing materials. It is preferable to use methods and approaches based on mathematical modelling for the analysis of serrated yielding, determination of optimal processing modes and design of new materials. It is not possible to construct mathematical models of the studied processes with a required degree of sufficiency without a thorough study of available empirical data and specifying leading physical mechanisms; and the main part of this review is devoted to it.

According to the available experimental data, it is well known that temperatures and strain rates significantly influence deformation processes. For most polycrystals, in the absence of phase transitions, the increase of temperature and decrease of strain rate lead to a reduction of stresses of inelastic deformation resistance. The influence of strain rate and temperature on materials behavior are presented in the following works [47, 71, 72, 73 etc.] The influence of temperature and strain rate on material response depends largely on a mode of their changing, type of a crystalline lattice, and defect structure.
Holding polycrystals after preliminary plastic deformation at high temperatures $\left(0.1-0.2 \mathrm{~T}_{\mathrm{r}}, \mathrm{T}_{\mathrm{r}}\right.$ is the homological temperature equal to the ratio of the process temperature to the material melting temperature in Kelvin degrees) leads to a significant increase of flow stress during subsequent plastic deformation; this phenomenon is called aging and caused by "fixing" dislocations with atoms of "solutes" diffusing to them.

Among the effects related to static strain aging (SSA) and dynamic strain aging (DSA) we will mention the following ones: occurrence of a "yielding tooth" on a deformation curve, its repeated occurrence, a qualitative dependence of a "tooth" from the rigidity of the loading system and serrated yielding, which is associated with the Portevin-Le Chatelier effect (sensitivity) in the majority of works.

Physical processes causing SSA and DSA in alloys lead to microstructure changes, which affects macroproperties of products. That is why it is necessary to know thermomechanical conditions initiating SSA and DSA, relations between physical mechanisms of aging with other mechanisms of hardening and softening in order to understand and model processes taking place in the course of material deformation.

\section{Aging and Diffusion Defects}

A significant difference of alloys behaviour from the reaction of pure metals on different interactions are well known, they are already used by the mankind for centuries. Most alloys used in industry are formed based on some main metal (for example, in ferrum steels), other components may amount from tenth (and hundredth) up to tens of percent of atomic weight; later the atoms of the latter will be called "solute" ones. A great variety of alloy properties is generated not only due to a variety of physical and chemical interactions and microstructure at the stage of a material formation (e.g., crystallization from alloys), but also due to processes occurring at stages of a subsequent thermomechanical processing of workpieces. Diffusion processes are most important for the considered serrated yielding; they are studied and described in a great number of works, including classical monographs in solid mechanics $[14,16]$. A significant part of works in this area is devoted to different aspects and results of experimental studies.

The paper in [75] is about methods and results of experimental studies of static strain aging of specimens made from eutectoid steel drawn with high degrees of reduction (more than 3) [75]. Differential scanning calorimetry and thermoelectric methods are used for the experimental analysis. Based on the experimental results it is stated that the aging process can be divided into two stages. At first, in the neighbourhood of dislocations in the ferrite phase carbon atoms located in the interstices of the iron lattice are moving, but because of a small concentration of carbon in the ferrite this process quickly exhausts itself. It is noted here that the local equilibrium concentration 
depends on the dislocation density which increases with an increase of dislocations density. At the second stage dissociation of martensite and diffusion of carbon atoms in the neighbourhood of dislocation cores until they reach a locally equilibrium concentration.

Results of thermomechanical tests of the specimens from titanium-base alloy (Ti-Al) can be found in [56]. The specimens were pre-reduced by $0.6-3.4 \%$ with strain rates of $10^{-5}-10^{-4} \mathrm{~s}^{-1}$, after it, they were unloaded until they reached different values of stresses (from $2 / 3$ to $1 / 10$ of flow stress) and were exposed at temperatures ranging from 200 to $500{ }^{\circ} \mathrm{C}$. During further loading there was a considerable increase of flow stress with a subsequent sharp fall of the latter, which can be explained with static strain aging effects. It is shown that the holding temperature and time highly affect the value of stress increase, while the level of stresses maintained in the process of aging has practically no influence on the value of the flow stress increase.

[67] discusses mechanical testing results of uniaxial symmetric cyclic deformation of cylindrical specimens made from stainless steel $316 \mathrm{~L}(\mathrm{~N})$, which give an idea of how dynamic strain aging influences fatigue strength. The experiments are given for wide ranges of strain amplitudes $(0.25-1.0 \%)$, strain rates $3 \cdot 10^{-5}-3 \cdot 10^{-2} \mathrm{~s}^{-1}$ and temperatures $(298-873 \mathrm{~K})$. The results of the experiments prove that dynamic strain aging taking place at temperatures ranging within 673-873 K significantly decreases fatigue strength. The results of similar studies with regard to austenitic stainless steel (15Cr-15Ni-2.5 Mo) modified with titanium are presented in [64].

[68] provides data of experimental mechanical and microstructural (using electron microscopy) studies on how temperature, holding time and cooling rate influence the process of static strain aging. The experiments were carried out using four grades of ultra low-carbon (with $0.0032-0.0052 \%$ of carbon) steels at annealing temperatures of $750-920{ }^{\circ} \mathrm{C}$. The influence of aging on mechanical properties was estimated by an increase of yield stress (a "yielding tooth"). Results of similar studies performed with specimens from Al-Mg are given in [28]. Special attention is paid to an influence of alloy additives of boron on viscosity and plasticity of alloys.

Results of detailed experimental studies of Luders bands in tubular specimens from steel 1045 (C - 0.487, $\mathrm{Si}-0.28, \mathrm{Mn}-0.74 \%$ ) under stretching, torsion and combined loading (ray trajectories and trajectories with a break/rupture by $90^{\circ}$ ) at room temperature are outlined in [81]. The formation of Luders bands is explained with a release of dislocations from Cottrell atmospheres and a sharp increase of their density. Distribution characteristics of bands are described depending on types of deformation trajectories.

The work in [36] suggests using experiments of simple cyclic loading at different temperatures $\left(-20,20\right.$ and $\left.60{ }^{\circ} \mathrm{C}\right)$ and different methods of preliminary heat treatment of specimens to study the effects of strain aging on behaviour of aluminium alloys. Some part of specimens has been prepared to have a maximum preliminary aging at high temperatures, when solute atoms create discretely distributed particles of the secondary phase. Another series of specimens was subject to the so called natural aging at room temperature. Later specimens of both groups were subject to cyclic loading at fixed strain amplitude $( \pm 0.6 \%)$. It is shown that the specimens of the first group show a fast initial increase of amplitude values of stresses with their subsequent steady decrease. The authors explain softening as cutting of particles of a rigid phase with moving dislocations and formation of shear bands. Specimens of the second group showed a monotonic increase in the amplitude stresses (up to the formation of cracks), the higher the test temperature, the greater the amplitude stresses. This hardening is explained by the effect of dynamic strain aging due to diffusion of solute atoms uniformly distributed in the material (solid solution).

The results of the experimental study of the effect of dynamic strain aging on features of texture formation of various layers of a rolled sheet of low-alloyed chromium (the content of alloying elements of $\mathrm{La}, \mathrm{Ti}, \mathrm{Nb}, \mathrm{Ta}$ is in the range of $0.2-0.5 \%$, and $0.008-0.01 \%$ of solute atoms $\mathrm{C}, \mathrm{O}$, N) [59]. A significant change in the texture distribution along the thickness of the sheet is shown, depending on reduction modes, which the authors explain by the influence of the latter on the diffusion flows of solute atoms, which, in turn, lead to a difference in the realization of the conservative and nonconservative modes of motion of dislocations.

Work [3] provides an experimental study of the influence of dynamic strain aging alloy $\mathrm{AMg} 6$ on resistance of plastic deformation in the range of temperatures $300-500{ }^{\circ} \mathrm{C}$ and strain rates $0.1-4 \mathrm{~s}^{-1}$. Metallographic studies of AMg6 alloy have been carried out with the purpose of revealing the main mechanisms of hardening and softening in the investigated temperature and strain rate range. Metallographic methods of studies showed that in AMg6 alloy, dynamic strain aging takes place during deformation, which leads to extraction of intermetallides from the solid solution matrix at a test temperature of $400{ }^{\circ} \mathrm{C}$. It is established that in AMg6 alloy, a partial dissolution of the intermetallide precipitates occurs at a temperature of $400{ }^{\circ} \mathrm{C}$.

The results of mechanical tests for monotonic and cyclic uniaxial loading of stainless steel specimens at constant and cyclically varying temperatures are given in [78]. Testing temperature varied within the range of 293-823 K, strain rates varied within $10^{-5}-10^{-3} \mathrm{~s}^{-1}$. It follows from the analysis of the experimental results that at low temperatures the material exhibits a high sensitivity to strain rate, which decreases with an increase of temperature when temperatures of serrated yielding in a certain temperature range occur. If temperature increases, an increase in cyclic hardening is also observed. It is noted 
that the specified effects express (among other mechanisms) the influence of dynamic strain aging. A macrophenomenological thermoviscoplastic model with a combined hardening law is used for the description; here isotropic hardening takes into account strain aging, and two components of residual microstresses ("back stresses") are available in the law of kinematic hardening responsible for close and far acting stress fields.

The methods and results of investigating the influence of formations (the second phase) on mechanical characteristics and the anisotropy of plastic properties in the uniaxial stretching of the aged Al-Mg-Si alloy are presented in [19]. During the model construction, previously obtained results of other researchers are widely used, in particular, the analytical solutions to problems of nucleation and growth of inclusions. To describe deformation, the elastoviscoplastic model with the power law of flow is used. The influence of inclusions and solute atoms of alloying elements ( $\mathrm{Mg}$ and $\mathrm{Si}$ for the considered alloy) is taken into account in the ratio for critical shear stresses along sliding systems (SS); hardening is determined by the density of dislocations, the evolution equation also includes the dependence of the equation parameters on the concentration of the atoms of alloying of solutions and inclusions. A direct model (of the $2^{\text {nd }}$ type) [13], is built into the ABAQUS package was used for implementation. The theoretical results show a satisfactory compliance with the data of the experiments performed by the authors.

\section{The Portevin-Le Chatelier Effect}

Based on models of solid mechanics and available experimental data, it can be stated that all deformation processes, in which diffusion processes (diffusion of point defects, nonconservative motion ("creeping") of dislocations, etc.) play a great role, are sensitive to strain rate and temperature [13]. The Portevin-Le Chatelier (Savart-Masson) effect is one of the best known manifestations of the influence of diffusion processes on the behaviour of deformable materials.

It is worth reminding that, depending on the applied loading method, there are two types of mechanical tests, i.e. "rigid" (kinematic) and "soft" force loading. In the first case, the traverse speed is set, and the force response of the system is measured. In the second case, external force factors are set (for example, the stress value necessary for the implementation of the prescribed deformation) and the kinematic response of the material is measured.

From the point of view of macroexperiments on uniaxial loading, the Portevin-Le Chatelier effect occurs in certain cases, such as at low strain rates and elevated temperature, diagram $\sigma-\varepsilon$ acquires a sawlike shape ("teeth") under "rigid" loading; under "soft" loading the diagram becomes steplike (Fig. 1) [1, 2].

Initially the discovery of this effect belongs to F. Savart (1837) and A. Masson (1841) [1, 2], but the work of these researchers was not given due attention and later (1923) the effect was "rediscovered" by A. Portevin and F. Le Chatelier [61], whose names denote this effect in most modern works. For the sake of justice, it is important to note that, unlike Savar and Masson, Portevin and Le Chatelier originally intended to study just serrated yielding. To solve this problem, they used specimens from alloys (aluminum + $4.5 \%$ of copper) and (aluminum $+4.5 \%$ of copper $+0.5 \%$ of magnesium); the tests were carried out in a kinematic type machine (rigid loading) at deformation rates of $0.08 \mathrm{~min}^{-1}$.

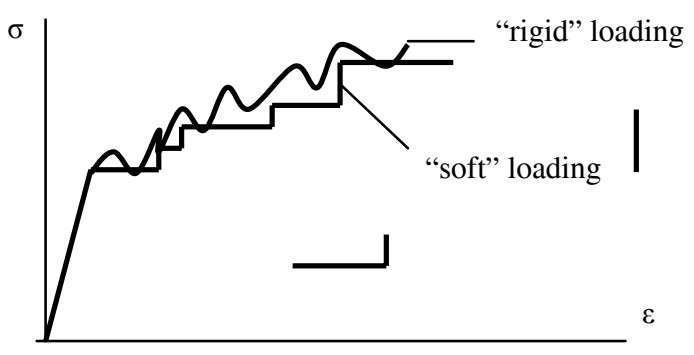

Fig.1. Diagrams of uniaxial "rigid" and "soft" loadings

This effect has been studied by many researchers (K. Elam, T. Sutoki, E.A. MacReynolds, O.V. Dillon, U.N. Sharp and others). The experimental studies showed a dependence of the amplitude of the teeth on temperature and temperature prehistory (Sutoki), the effect of the metals purity on the Portevin-Le Chatelier effect, and the wave-like character of the movement along the specimen of the deformation step (McReinolds). At the moment there are several explanations of the Portevin-Le Chatelier effect. One of the first ones was given by A.G. Cottrell [30] and explained the effect with a diffusion of solute atoms to dislocations and their "pinning" due to the interaction with the solute atoms $[14,16]$. It is worth mentioning that this point of view is shared by many researchers of the PortevinLe Chatelier effect today (for example, [22, 33, 39, 45, 50, $53,57,58,62,70]$ and longs lists of their references. B.M. Lempriere (1962) denoted the effect as instability of strain rate for some materials and fluctuations of the test machine; the need in taking account of the experimental set-up is also noted in [53]. At present, none of these hypotheses is prevailing and proven experimentally, so there are no models that adequately describe this effect for various materials and loading conditions.

Materials showing serrated creep can be divided into two groups by the scale of this phenomenon. The first group includes materials exhibiting macroscopic serrated creep. The most well-known example of localization of deformation at a macroscopic level is the appearance of a neck at the final stage of stretching the specimen $[10,12$, 15], the Luders-Chernov bands. Macroscopic serrated creep is found in metals and alloys prone to the Portevin-Le Chatelier effect [61], i.e. polycrystalline alloys of systems $\mathrm{Al}-\mathrm{Cu}, \mathrm{Al}-\mathrm{Mg}$ [1, 2, 52], Ni-Cr, Ni-Fe-Cr [40-42].

The second group includes materials demonstrating mesoscopic serrated creep associated with the dynamics of 
dislocation clusters at the mesoscopic structural level (lines and slip bands, twins, etc.). In this case serrated creep occurs in the form of a sequence of jumps of deformation on creep curves. This group of materials includes single crystals of zinc, ice, alkali-halide single crystals, polycrystalline brass, copper, lead, and a number of polymers.

Usually the effect of the Portevin-Le Chatelier effect is observed in a number of dilute solutions of introduction and substitution (aluminum, copper, soft steel alloys), some metallic composites [11, 31], and for each material the effect manifests itself in a certain temperature-rate region $[6,7]$. These temperature-rate regions of the Portevin-Le Chatelier effect correspond to the inverse high-speed and anomalous temperature of the flow stress dependency, i.e. if the strain rate increases, the flow stress does not increase but decreases, and as the temperature increases, the flow stresses remain either independent of its increase or increase.

\section{Experimental Studies}

Experimental data indicating a nonmonotonic response in the case of monotonic inelastic deformation or loading of specimens were discovered long time ago. Earlier we have already mentioned the works of Savart [65], Masson [49], Portevin-Le Chatelier [61], peculiar curves of deformation are shown in the experiments of Montel [55].

For small and large deformations, this effect has been studied for the last two centuries by many experimenters and theoreticians (K. Elam, T. Sutoki, E.A. MacReynolds, O.V. Dillon, U.N. Sharp and others), but a satisfactory explanation and description to date has not been received.

Irregularities of the stress-strain diagram for tensile metallic specimens were first described by Dulot in 1813 [2]. Stepwise relations in case of "soft" loading are known since 1837 as the Savar-Masson effect.

Masson described a steep, almost vertical (in the $\sigma-\varepsilon$ diagram) stress increase, accompanied by very small deformation, up to the value at which a sudden sharp increase in deformation at constant stress occurred (ladder effect).

In 1923 Portevin and Le Chatelier tested specimens from alloys (aluminum $+4.5 \%$ of copper) and (aluminum + $+4.5 \%$ of copper $+0.5 \%$ of magnesium) in a kinematic type machine ("rigid" loading) at strain rates of $0.08 \mathrm{~min}^{-1}$. They found serrated yielding and occasionally clear sounds associated with the appearance of each step of yielding [2].

In 1949 McRainolds found [52] that the formation of each horizontal domain of the graph is due to the passage of a slow "wave" pattern along the specimen.

A.G. Cottrell considered the effect of sensitivity in solid substitutional solutions (by the example of V-C) in [77]. Estimates are obtained for the intervals of strain rates and temperatures, in which the effect of sensitivity appears on the basis of a qualitative analysis of the interaction of solute atoms with dislocations.
An interest to experimental studies of the Portevin-Le Chatelier effect is still great among present time researchers. It should be noted that most of the experiments are implemented for the case of uniaxial loading of flat or cylindrical (with circular cross section) specimens. Three main types of the Portevin-Le Chatelier effects have been allocated based on the experimental data of uniaxial loading: 1) Type A. The appearance and movement of a single (solitary) wave along the axis of the specimen, which can occur many times; 2) Type B. Deformation bands appear and disappear in an oscillating or intermittent mode, propagating along the sample (stop-and-go); 3) Type C. Bands arise (and disappear) randomly along the length of the specimen. Like every classification, the above is somewhat conditional; in real experiments there can be a different combination of these three types.

Results of the experimental studies of inelastic deformation of titanium alloys ( $\mathrm{Ti}-15 \% \mathrm{Mo}$ and $\mathrm{Ti}-25 \% \mathrm{Mo}$ ) in a wide range of temperatures and strain rates are presented in [20]. Serrated yielding was observed in the experiments on uniaxial tension at temperatures of $575-775 \mathrm{~K}$ and strain rate $1.31 \cdot 10^{-4} \mathrm{~s}^{-1}$ for the Ti alloy of $15 \% \mathrm{Mo}$; the structure was studied at different stages of deformation of the specimens with the use of electron microscopy. At different scale levels (from tens of $\mathrm{nm}$ to $\mathrm{mm}$ ) deformation processes are described in detail, which are responsible for serrated yielding. For the alloys under consideration, the main mechanism of serrated yielding is the alternating occurrence and destruction (by shifting bands) of the $\omega$-phase particles in the environment of a stable $\beta$-phase. It is noted that in the alloy $\mathrm{Ti}-25 \% \mathrm{Mo}$, not prone to the formation of $\omega$-phase, deformation is realized monotonically throughout the temperature-strain rate range under consideration.

By analyzing the results of numerous experiments aimed at investigating serrated yielding, it can be concluded that the source of discontinuous, irregular response of the material under monotonous influences is the presence of inhomogeneities in the properties of the material and the features of the motion of large dislocation arrays (i.e. their coordinated motions) at various scale levels, from nanosizes to values commensurate with the dimensions of macrospecimens. In this case, these inhomogeneities themselves can arise and disappear due to the processes of motion and interaction of defects of various nature and dimensions occurring in a material.

Methods and analysis of results related to the experimental studies of serrated yielding in specimens from titanium aluminides are presented in [60]. Uniaxial compression tests are carried in vacuum at temperatures of $20-500{ }^{\circ} \mathrm{C}$ and strain rate $2 \cdot 10^{-3} \mathrm{~s}^{-1}$ for alloy TiAlNb, $20-900{ }^{\circ} \mathrm{C}$ and $5 \cdot 10^{-4} \mathrm{~s}^{-1}$ for alloys TiAlMo and TiAlMoNb. On the basis of studying various quantitative compositions of alloys, it is established that the sensitivity effect is observed in alloys in which the stoichiometric ratio for Ti atoms is violated, in which (or with a smaller number of titanium atoms) titanium atoms occupy quite definite 
places in the crystal lattice. Excess titanium atoms form solute clouds around dislocations, interaction with which determines the irregular nature of deformation.

Results of the experimental studies of how specimens made from $\mathrm{Al}-2.03 \% \mathrm{Mg}-1.13 \% \mathrm{Cu}-0.95 \% \mathrm{Zn}$ alloy behave are given in [80]. The experiments were carried using flat specimens of 20 and 50 millimetre long under uniaxial stretching, at room temperature, in a wide range of loading rate alterations $\left(7.6 \cdot 10^{-4} \div 10.5 \mathrm{MPa} \mathrm{s}^{-1}\right)$. The authors connect the Portevin-Le Chatelier effect with formation and distribution of shear bands. There is a significant effect on the kinetics of the shear bands of the presence of stress concentrators, loading rate, and the length of the specimen.

The results of systematic studies of specimens behaviour from $\mathrm{Cu}+\mathrm{Al}$ and $\mathrm{Cu}+\mathrm{Mn}$ alloys under uniaxial loading over a wide range of temperatures and strain rates are given in [57, 58]. Based on the analysis of uniaxial stretching diagrams (curves $\sigma-\varepsilon$ ), the diagrams of regions of stable and unstable (serrated) inelastic deformation are constructed; the presence of three characteristic regions of the process parameters is noted, where the Portevin-Le Chatelier effect occurs. According to the authors, the difference in the processes of dynamic strain aging in the three indicated regions is due to the difference in diffusion mechanisms ("lattice" (normal) and "tunnel" diffusion).

Results of the experimental studies related to the influence on serrated yielding of the nitrogen content in austenitic stainless steel 316L are given in [39]. The tests were made using cylindrical specimens under uniaxial tension with constant strain rates within the range $\left(2 \cdot 10^{-4} \div 10^{-2}\right) \mathrm{s}^{-1}$ at $293,373,573,673,773,883$ and $973 \mathrm{~K}$. The contents of nitrogen was changing within the range of $0.01-0.15 \%$. It is shown that the region of serrated yielding shifts toward higher temperatures with an increasing content of nitrogen. An increase in the nitrogen concentration up to $773 \mathrm{~K}$ also leads to an increase in the critical accumulated deformation of the start of serrated yielding; at higher temperatures the increase in the nitrogen content does not affect the critical deformation. It is also observed that the energy of dynamic strain aging starts to activate as the nitrogen concentration starts to increase.

The anisotropy of sensitivity for aluminum sheet alloys was demonstrated by results of the experimental studies given in [29]. The tests were carried out on samples of Al-Mg, of AA5182 alloy, obtained by continuous casting (CC) and casting into moulds (CIM), followed by hot and cold rolling and various types of heat treatment. The specimens obtained for testing differed significantly in microstructure, i.e. samples from a CC alloy had an approximately equiaxed grain without a clear texture, whereas CC samples had an elongated grain shape in the direction of rolling and texture. The experiments were carried out on specimens cut in the rolling direction, in the transverse direction and at an angle of $45^{\circ}$ to the rolling direction under kinematic stretching (rigid loading). The distribution law of amplitude of the stresses jumps (the share of jumps having a certain amplitude value) was used as the main characteristic of the discontinuous flow. It is shown that for CC samples, the distribution laws of amplitude of the stress jumps are almost the same for different specimens, whereas for CC specimens, these laws are significantly different. The authors explain the anisotropy effect by the concentration of solute atoms predominantly along the grain boundaries, which creates easier conditions for dislocations' slip along the direction of grains elongation.

The results of experimental tension studies of the specimens from polycrystals of $\mathrm{Al}-\mathrm{Mg}$ alloy and singlecrystal $\mathrm{Cu}-\mathrm{Al}$ alloy are presented and analyzed in [24]. The experiments were carried out at room temperature in a wide range of strain rates $\left(5.56 \cdot 10^{-6} \div 1.39 \cdot 10^{-2}\right) \mathrm{s}^{-1}$. Polycrystalline samples had a different structure, i.e. in the state of delivery (after rolling), obtained after annealing and deep annealing. In the whole range of the studied strain rates, modes of discontinuous plasticity were implemented. In order to process the measurement results, the methods of chaotic dynamics and fractal analysis were used. It was found that at medium speeds, the deformation has a chaotic character (shear bands of type $\mathrm{C}$ ), and at high speeds a transition to self-organized criticality (slip bands of type B and A) is observed.

[43] shows the results of tests on indentation and stretching of samples from aluminum alloy $(3.6 \mathrm{Mg}$, $0.39 \mathrm{Mn}, 0.30 \mathrm{Fe}, 0.16$, Si, 0.076 Cu, 0.072 Cr, 0.031 Zn, $0.018 \mathrm{Ti}, 0.014 \mathrm{Zr}$ in mass percent) at room temperature. Indenters of conical, pyramidal and cylindrical shapes are used. A satisfactory agreement of the results in all the experiments was shown. The transition to a "stationary" mode of discontinuous plasticity (that is, approximately same stress jumps with a continued monotonic loading) with large deformations is noted.

The work in [69] is of a considerable interest (especially from the point of view of identification and verification of models of the sensitivity effect), where the results of the experimental study of behaviour of $\mathrm{Al}-\mathrm{Cu}$ alloy specimens subjected to uniaxial stretching at low speeds $\left(10^{-4}, 10^{-3}, 5 \cdot 10^{-3} \mathrm{~s}^{-1}\right)$ are presented. The specimens were heat-treated until a solid solution (heating and aging for 3 hours at a temperature of $500{ }^{\circ} \mathrm{C}$, cooling in an oven and holding at temperatures of $500{ }^{\circ} \mathrm{C}, 400{ }^{\circ} \mathrm{C}, 300^{\circ} \mathrm{C}$, $200{ }^{\circ} \mathrm{C}$ and $100{ }^{\circ} \mathrm{C}$ followed by aging). As a comparison, one of the series of specimens was annealed (holding for 2 hours at a temperature of $500{ }^{\circ} \mathrm{C}$ and slow cooling in a furnace). An increase in the treatment temperature leads to an increase in the $\mathrm{Cu}$ concentration in the solid solution, a decrease in temperature contributes to the formation of local zones of $\mathrm{Cu}$ precipitates and the formation of $\mathrm{CuAl}_{2}$ inclusions, which affects the behaviour of macrospecimens. It is shown that with an increase in the treatment temperature, a transition is observed from type $\mathrm{C}$ shear bands to type $\mathrm{B}$ bands with a simultaneous increase in the amplitude of stresses of serrated yielding. 
The tension experimental results shown in [74] of cylindrical specimens from magnesium alloy $(94.7 \% \mathrm{Mg}$, $4.32 \% \mathrm{Li}, 0.97 \% \mathrm{Al}$ ) at strain rates $3.33 \cdot 10^{-4}, 6.66 \cdot 10^{-4}$, $3.33 \cdot 10^{-3}, 6.66 \cdot 10^{-3} \mathrm{~s}^{-1}$, and room temperature have a negative rate sensitivity and serrated yielding for the specified parameters of deformation. The authors explained the alloy behaviour peculiarities with a diffusion of $\mathrm{Li}$ and $\mathrm{Al}$ atoms to dislocation clusters at various dislocation barriers.

The technique and results of the experimental study of samples from alloy $3033(\mathrm{Al}-\mathrm{Mn})$ under uniaxial compression to true (logarithmic) deformation values of 80 $\%$ are presented in [33]. The tests were conducted in wide ranges of strain rates (from $10^{-3}$ up to $10^{4} \mathrm{~s}^{-1}$ ) and temperatures (from $77 \mathrm{~K}$ to $800 \mathrm{~K}$ ). A significant influence on the material microstructure and behaviour, the history of temperature effects, accumulated plastic deformation and strain rate are noted. It is shown that serrated yielding, the manifestation of which is associated with strain aging, can occur even at high strain rates at elevated temperatures. Based on the physical analysis and review of the experimental data, a modification of the relation aimed at determining the flow stress was proposed, in which, however, the effect of strain aging was not explicitly reflected.

In $[8,9,17,18]$, it was established that the jump-like deformation of AMg6 alloy is a structural-sensitive effect. In $[8,9]$, the dependence of the initial deformation of jumps on the grain size after severe plastic deformation was revealed. The characteristics of jump-like deformation, especially the number of jumps, the mobility and morphology of the first deformation strips, change dramatically after annealing in the vicinity of the temperature of the limited solubility of magnesium in aluminum $\mathrm{TSV} \approx 275^{\circ} \mathrm{C}[17,18]$.

A detailed presentation of the methodology and results of carefully performed experiments (including electron microscopy studies) on uniaxial stretching of magnesium alloy specimens containing an additive of rare-earth $(0.2 \%$ $\mathrm{Nd})$ material at room temperature with $3.3 \cdot 10^{-5}, 1.1 \cdot 10^{-4}$, $1.1 \cdot 10^{-3}, 3.3 \cdot 10^{-3}$ and $1.1 \cdot 10^{-2} \mathrm{~s}^{-1}$ strain rates are given in [54]. The paper notes the distinction of serrated yielding associated with the Luders bands and the Portevin-Le Chatelier effect, both in kinematic characteristics (geometrical dimensions, motion rate) and in mechanisms. In materials with a hexagonal lattice, a significant contribution (about $50 \%$ ) to deformation caused by Luders bands is made by twins, the latter, when approaching the grain boundaries, can generate twins in neighbouring grains. The Portevin-Le Chatelier effect is connected to the dislocation mechanism of deformation and the inhibition of dislocations by impurities diffusing to them.

In [13], it was suggested that the sensitivity effect may be a macroscopic manifestation of the instability of inelastic deformation by various mechanisms at micro- and mesolevels arising in different ranges of impact values. These can include dislocation depinning from the Cottrell atmospheres, grain-boundary shifts, the emergence of mesobands and cooperative shear bands, and destruction, the restoration of particles of rigid inclusions, and sharp rearrangements of dislocation substructures. Each of these phenomena has been confirmed in experimental studies at the meso- and microlevels, and in modelling using models of different scale levels.

\section{Models for the Portevin-Le Chatelier Effect Description}

Plastic (inelastic) deformation of any materials and in any ranges of effects can be interpreted as a combination of a huge number of abrupt changes of parameters of various nature and dimension, from point defects to conglomerates of grains. In other words, inelastic deformation can be considered as a series of multiscale instabilities. When these unstable processes are implemented on microscales ("hopping" of dislocations in the energy relief of Peierls, breakthroughs of dislocation clusters through barriers of different nature, etc.), then on macro, and even on mesoscales, they are observed as monotonic, smooth changes in body configuration, since these unstable processes are realized by large sets of physical carriers of inelastic deformation, they are disordered, inconsistent neither in time nor in space. However, if the movement of various carriers or their groups begins to be carried out in a coordinated, self-organized manner, the unstable nature of the deformation becomes observable at the meso- and macrolevel. This is manifested in the "response-effect diagrams" in the form of non-monotonic response curves for monotonically varying effects, and in such cases they are referred to as "noncontinuous", "sawtooth" or "serrated" plastic deformation.

At the moment the processes of plastic deformation development is considered at all scale levels, such as micro, meso- and macroscopic structural levels. The study of the "subtleties" of the evolution of dislocation substructures and point defects, especially in the internal regions of the specimens, with the help of the experimental methods, is associated with enormous difficulties and high costs. Therefore in the recent 20 years mathematical models of different scale levels have been intensively developing.

Mathematical models allow studying the phenomenon of plasticity of crystals, including the conditions of deformation defect occurrence, their movement, interaction, annihilation, which are difficult or impossible to observe in a real physical experiment.

\section{Macrophenomenological Models}

One of the well-known phenomenological models focused on the description of the sensitivity effect under uniaxial loading was proposed in [44]. The rate sensitivity of the material is determined by the sum of two components 
which of them is independent and dependent on strain aging; the latter is established using a dislocation submodel that includes two evolution equations (ordinary first-order differential equations) for scalar densities of mobile and forest (immobile) dislocations. The implementation region of the regime of serrated yielding corresponds to a negative rate sensitivity, the boundaries of this region are determined by the zero rate sensitivity. It is noted that the model makes it possible to determine the critical values of the accumulated deformations (the beginning and the end of serrated yielding), which are actually observed in the experiments.

In work [53], two types of plastic flow instability are associated with diffusion aging: the propagation of Luders bands and the Portevin-Le Chatelier effect (PLC), focusing on the description of the sensitivity effect. The movement of dislocations is considered as a process of a very fast free movement and a long-term stop on obstacles of various natures. During stops on obstacles to the nuclei and in the vicinity of dislocations, solute atoms flow together, thus forming "clouds" (atmospheres) of atoms, interacting with dislocations and hindering their movement. With a further increase in stresses, the dislocations are split and they move to the next obstacle; it is assumed that the dislocations do not "pull" the atmosphere after them. The latter assumption does not seem to be sufficiently substantiated the hypothesis about dragging a part of the atoms of the atmosphere by moving dislocations after them seems to be more plausible, as a result of which the viscous resistance to the movement of dislocations surrounded by solute atoms should increase. A brief review of works devoted to experimental and theoretical studies of the sensitivity effect is given.

The model modification proposed by McCormick in 1988 was used as a basic equation:

$$
\dot{\varepsilon}=\dot{\varepsilon}_{0} e^{\frac{-\Delta \mathrm{G}}{\mathrm{k} \theta}},
$$

where $\dot{\varepsilon}$ is deformation speed, $\Delta \mathrm{G}$ is Gibbs free energy, $\kappa$ is the Boltzmann constant, $\theta$ is the absolute temperature, $\dot{\varepsilon}_{0}$ is the so called deformation speed (equal to the shear rate at zero Gibbs free energy). It is assumed that $\Delta \mathrm{G}$ is a function of the effective stress (the difference between the effective stresses and the yield stress at $0 \mathrm{~K}$ ) and the solute concentration. The solute concentration is determined by the function of the delay of dislocations on obstacles, referred to the characteristic diffusion time; shows the phenomenological relationship to determine the delay proposed earlier by other researchers. Ultimately, a determining relation was obtained (the dependence of stress on strain rate and temperature) for uniaxial loading. It is noted that during the quasistatic deformation mode, the rate sensitivity of the material, according to the model, turns out to be negative, and therefore, the deformation is unstable. For a number of authors, the occurrence of a mode of alternating rate sensitivity is associated with dynamic processes, with a possible change of the sign of rate sensitivity and a transition to the "sawtooth" nature of the response. For a multiaxial stress-strain state (SST), the defining relation is generalized by a commonly used technique, i.e. replacing uniaxial measures of stress and strain rate with corresponding deviators.

Most of the articles aredevoted to studying the system deformation stability including the deformable specimen and a loading system, considered as an elastic rod. For analysis, the apparatus of linear perturbation theory is used. Stability conditions for spatial and temporal perturbations are obtained; a significant effect on the deformation stability and the nature of the unstable behaviour of the rigidity of the loading system and the characteristics of hardening of the material were shown. It is noted that the proposed material model allows us to describe both the "sharp yield point" and the effect of the sensitivity.

Another mechanism of serrated yielding which was called by the authors of the pseudo sensitivity effect, observed in ordered solid solutions, is considered in [26]. During thermomechanical effects under inelastic deformation, a decrease in ordering takes place, which can be restored due to diffusion mechanisms. A constitutive model is considered for the case of uniaxial loading. A kinetic equation is proposed for the order parameter, varying from 0 (completely unordered) to 1 (fully ordered solid solution). As a defining relation, we used the equation of a nonlinear viscous fluid with a power dependence of stresses on strain rate, in which the flow stress depends on the order parameter. An analytical solution of the system of constitutive model equations is obtained, the analysis of which made it possible to determine the presence of limits of temperature and strain rate in which serrated yielding mode can be implemented.

The statistical analysis results of stress-strain curves for uniaxial loading of single-crystal specimens from Al-4.5\% Mg alloy are given in [46]. The experiments were carried out for two orientations of the crystallite with respect to the axis of tension $(<111>$ and $<100>)$ at temperatures of 300,350 , and $400 \mathrm{~K}$ and strain rates in the range of $\left(3.2 \cdot 10^{-6} \div 1.3 \cdot 10^{-3}\right) \mathrm{s}^{-1}$. In order to describe the sensitivity effect, a uniaxial deformation model was used, in which the flow stress is determined by the sum of terms depending on the accumulated deformation and on the current strain rate (both terms depend on temperature), with the dependence of stress on the strain rate $\left(2^{\text {nd }}\right.$ term in the additive representation) has a $\mathrm{N}$-shaped view. To consider the spatial inhomogeneity of deformations, which reflects the formation and propagation of shear bands observed in the experiments, a simple rod model is proposed, according to which a one-dimensional specimen is represented as a set of a finite number of layers. In each elementary rod (layer), the flow stress, in addition to the two components mentioned above, contains an additional additive term, which depends on the difference of stresses in the layer under consideration and two adjacent ones. It is shown that the model under consideration allows to qualitatively 
describe the space-time distribution of strain localization and the sensitivity effect.

A stochastic model for describing the sensitivity effect at meso- and macrolevels was proposed in [35]. This effect is explained by the collective interaction of dislocations by long-range stress fields. A stochastic differential equation (of the Fokker-Planck-Kolmogorov type) is obtained, which describes the evolution of the distribution function of the probability of deviation of local deformation from the mean one by a given value. The model is used to describe the behaviour of a single-crystal specimen deformed by a single shear; a comparison of theoretical and experimental results demonstrates a satisfactory conformity.

A brief review of papers that propose various mechanisms responsible for the sensitivity effect and the models for their description can be found in [34]. The author proposes a constitutive model which is considered for the case of uniaxial loading which allows to properly reproduce the mode of serrated yielding. For this, an additional term with an internal variable responsible for the dynamic aging process is introduced into the evolution equation for the flow stress. A careful analysis of the linear stability of the constitutive material model was carried out, estimates of the limits of the stable (monotonic) response and the region of serrated yielding in material state values (temperature, strain rate and strain) were obtained.

In [82], a macrofenomenological viscoelastic model was used in combination with the finite element method (FEM) in a 3-dimensional formulation to describe the PLC effect. The ratio for the rate of inelastic deformations includes the dependence on the concentration of solutions. A phenomenological equation for the concentration of impurities, depending on the accumulated inelastic deformation and aging time, was also proposed. Numerical experiments were performed for specimens with rectangular and circular cross sections (Al-Mg-Si alloy) subjected to stretching with a constant strain rate. As an initial perturbation, a deviation was introduced either in one finite element, or with the help of deviations randomly distributed over the entire volume within $(0 \div 10) \mathrm{MPa}$. It is shown that the model makes it possible to qualitatively describe the sensitivity effect implemented due to the formation and movement of the neck along the sample axis.

A similar model was used in [32] to analyze the deformation of $\mathrm{Al}-\mathrm{Li}$ and $\mathrm{Al}-\mathrm{Cu}$ alloys. For the numerical study, samples with rectangular cross-sections with flat edges, with $\mathrm{V}$-shaped cuts (with angles of 60 and 90 ) and with flat cuts simulating cracks were applied. The generation and propagation of shear bands, the effect on the kinetics of changing the shape of the notch and taking into account strain aging are analyzed in detail.

[27] describes the application of the cellular automation method in a two-dimensional formulation for the analysis of the sensitivity effect. The motion of dislocations in a field of randomly distributed barriers on which dislocations can temporarily linger is considered. During the delay, solute atoms flow to the hindered dislocations, which increases the necessary activation energy for further movement. The activation of delayed dislocations occurs under the action of applied stresses, long-range interaction forces, and random temperature fluctuations. It is shown that the sensitivity effect is observed only with a simultaneous consideration of long-range forces between dislocations and dynamic strain aging.

An extensive list of works devoted to experimental studies and theoretical models of the sensitivity effect is given in [62]. Just like in most other works, the main mechanism is considered to be dislocations pinning with solute atoms by solute atoms during delays in the movement of dislocations by barriers of a different nature. It is noted that the sensitivity effect should be distinguished from other types of plastic deformation instability (for example, Luders bands), first of all with repetitiveness, in a certain sense with "renewability" of mechanisms and driving forces of the sensitivity effect. The analysis of existing models reveals a number of their significant disadvantages, in particular, the inability to determine main parameters of unstable deformation (width, propagation velocity and deformation value in localization bands), and the difficulty of using them within continual models.

According to the authors, a distinctive feature of the proposed model is considered to be the introduction of two characteristic time scales, one of which is associated with dynamic strain aging, and the second one is associated with the mobility of dislocations. The McCormick model is used as a base one, according to which the rate of plastic deformation is determined by an Arrhenius-type law, i.e. by the exponential law on the activation energy of the dislocation motion, the process temperature, the current rate sensitivity of the material and effective stress equal to the difference between the applied and internal stresses. Internal stresses are associated with strain hardening and are considered to be linearly dependent on plastic deformations. An additional additive term, proportional to the concentration of solute atoms, deposited on dislocations, is introduced into the activation energy. An evolutionary equation is proposed to describe the change in this "addition" to the activation energy, which is an ordinary differential equation (ODE). A detailed qualitative analysis of the evolution equation was carried out (stationary mode, bifurcations, critical points, etc.). In the future, this evolutionary equation is supplemented by a diffusion term. The defining equation itself is expanded by the inclusion of a term describing the behaviour of the loading system. The qualitative analysis of the resulting system of two differential equations (ODE and partial differential equation (PAE)) was carried out using the numerical procedure. It is shown that the proposed one-dimensional and essentially macrophenomenological model qualitatively and satisfactorily describes the sensitivity effect.

To analyze the motion of dislocations and their interactions with solute atoms in [37], the phase field model was used, into which the diffusion of solute equations were introduced. The resolving equations of the model are 
obtained on the basis of the thermodynamic approach, relations for the elastic, chemical, and dislocation components of the free energy are proposed. The interaction of solute atoms with a Frank-Reed source, fixed and moving dislocations is considered. It is shown that the model qualitatively and correctly describes both long-range interactions (stress fields of dislocations) and short-range order interactions (with solute atoms).

A detailed review of the methods and results of the study of the instability of plastic deformation (including sharp yield point and serrated yielding) is given in $[4,5]$. Low-temperature (at temperatures of liquid hydrogen, helium, or nitrogen) and high-temperature (at 0.3-0.7 homologous temperature) serrated yielding are distinguished. Low-temperature serrated yielding is associated with twinning processes and phase transformations. There is a significant impact of size and surface condition of the specimens on the process. Hightemperature serrated yielding is caused with the deformation localization with the formation of shear bands. Based on the results analysis of uniaxial stretching of specimens from different materials, various natures of formation and evolution of shear bands at a constant rate of stress or strain changing are noted. Based on the analysis of known experimental data, conclusions are drawn about the general patterns of serrated yielding. It is emphasized that this effect is determined by the processes of the mesolevel, and not the microlevel [4]. The second part of the [5] review contains a detailed analysis of the theoretical principles and models proposed to describe serrated yielding. The author believes that the main disadvantage of the reviewed papers is the lack of analysis of the processes occurring at higher than the microlevels in most of them.

The results of experimental studies of serrated yielding of smooth and notched cylindrical, prismatic and flat aluminum alloy specimens subjected to single-axis loadinguniaxial loading at room temperature in the range of strain rates from $10^{-5}$ up to $10^{3} \mathrm{~s}^{-1}$ are presented in [21, 22]. The macrofenomenological elastic-viscoplastic model based on experimental data under single-axis loading was considered in [21]. According to the model, the flow stress is determined by the sum of the yield strength, the value of the resistance increased due to plastic hardening and the term depending on the rate of inelastic deformation ("viscous resistance"). It is assumed that the last term in a certain range of strain rates may have a negative derivative ("negative rate sensitivity"). A qualitative analysis of the model for the case of uniaxial loading was performed. A considerable attention is paid to the analysis of the stability of inelastic deformation, for which the method of small perturbations is used. The model under consideration is generalized to the case of a three-dimensional stress-strain state (SSS) and is used in the LS-DYNA finite element package to study the deformation of cylindrical specimens (smooth and with an annular undercut with different rounding radii) of aluminum alloy 5083-H116. The characteristics of the evolution of the SSS are given and analyzed for specimens of various configurations and at different strain rates. The results indicate the implementation of serrated yielding in a wide range of strain rates. The influence on the results of computations of the finite-element lattice and the integration step over time is investigated. The paper [22], which contains the results of carefully performed and processed experimental studies on "single-axis" loading of specimens of circular and rectangular cross-sections, is closely related to the aboveconsidered paper.

A macrophenomenological model for the analysis of serrated yielding was proposed in [76]. The uniaxial loading of a polycrystalline specimen under plane stress and plane deformed state is considered. It is assumed that inelastic deformation is implemented by a shear along one and/or two slip systems. The shear rate on each slip system is determined by a viscous-plastic law of power type, which also includes the dependence on the concentration of solutes in this system. To determine the concentration of solutes in the slip system, an evolutionary relationship has been proposed, according to which the concentration increases when the accumulated shear increases and the shear rate decreases along this system. To determine the position of shear bands, the linear bifurcation approach is used. A satisfactory agreement of the computation results with the experimental data is noted.

In [23], a geometrically nonlinear macrofenomenological viscoelastic model was used in combination with the finite element method (FEM) in a 3-dimensional formulation to describe the sensitivity effect. The constitutive model is based on the the Neo-Hookean law, and the Almancy strain tensor, determined from the elastic component of the placement gradient, is taken as a measure of elastic deformation. The rate of inelastic deformations is determined by the relations of the theory of plastic flow, in which the flow stress depends on the concentration of solute atoms; the latter is determined by the phenomenological evolutionary equation (a function of accumulated plastic deformation and aging time). The values of material parameters were experimentally determined on the basis of tensile tests. Polycrystalline flat specimens with $((5.1 \cdot 1.5 \cdot 21) \mathrm{mm}$ dimensions were made of $\mathrm{Al}-\mathrm{Mg}$ alloy (AA5754). All specimens were cut from sheet materials with a stretching axis in the direction of rolling. After grinding and polishing, the specimens were subjected to annealing (exposure for 2 hours at a temperature of $400{ }^{\circ} \mathrm{C}$ ) and quenched in water. Tension tests were carried out at room temperature at constant strain rates from $2 \cdot 10^{-3}$ to $6 \cdot 10^{-3} \mathrm{~s}^{-1}$. The comparison of the theoretical results with the data from the experiments conducted by the authors reveals a satisfactory conformity.

The results of the experimental and theoretical studies of a single-axis loading of specimens (aluminum alloy Al-4 \% Cu (A2017)) are presented in [38]. The main goal of the work is to study the space-time features of three types (bands A, B, and C) of the manifestation of the sensitivity effect. A brief description of the experimental procedure is 
given. In order to reduce residual stresses, the specimens were annealed (for 4 hours at a temperature of $723 \mathrm{~K}$ with a slow cooling in the furnace). The average grain size of the specimen was determined using an optical microscope and was $30 \mu \mathrm{m}$. All the tests were carried out on uniaxial tension at constant strain rates in the range of $10^{-5} \div 5 \cdot 10^{-3} \mathrm{~s}^{-1}$. It is shown that as the strain rate decreases, a change in the type of the $\mathrm{A} \rightarrow \mathrm{B} \rightarrow \mathrm{C}$ shift bands is observed.

For the theoretical description of the sensitivity effect, a macrofenomenological one-dimensional viscoplastic model is used, taking into account the effect on the strain rate of the concentration of solutes. An evolution equation to determine the change in the latter is proposed. A description of the difference scheme for the analysis of the rod deformation, which takes into account the rigidity of the loading system, is given. A comparison of theoretical and experimental results for the three types of curves demonstrates a satisfactory agreement.

The results of experimental and theoretical studies of single-axis loading of samples (aluminum alloy 2024) cut from rolled sheet billets at angles of $0^{\circ}, 45^{\circ}$ и $90^{\circ}$ to the direction of rolling are presented in [25]. All tests were carried out at room temperature, the strain rate was from $1 \cdot 10^{-5}$ to $7 \cdot 10^{-1} \mathrm{~s}^{-1}$. In the range of low strain rates $\left(1 \cdot 10^{-4} \div 1 \cdot 10^{-3}\right) \mathrm{s}^{-1}$, there is a "reverse" high-speed hardening (decrease in the flow stress with the increasing strain rate), accompanied by a serrated flow pattern. At strain rates exceeding $1 \cdot 10^{-2} \mathrm{~s}^{-1}$, the flow stress increases with an increase in the strain rate and the strain is monotonically implemented. For the theoretical description of the deformation process, the macrofenomenological theory of elastic-viscous plasticity is used, in which the additive decomposition of the strain rate into elastic, plastic, and viscous components is adopted. The flow stress is represented by the sum of the components depending on the accumulated plastic deformation, the strain rate and the process of strain aging. A generalization of geometrically linear defining relations for the case of large gradients of displacements is proposed. A considerable attention is paid to the statistical analysis of theoretical and experimental data, on the basis of which the conditions for the transition from the nonlinear chaotic mode (type $\mathrm{C}$ bands) to the "selforganized criticality" mode (type A bands) are established.

Modifications of the macrophenomenological model proposed earlier (2001) by the first author of the paper below (together with J.R.Klepazcko), allowing to describe the effects of dynamic strain aging (negative velocity sensitivity of the material), are given in [63]. Modifications of the model are focused on the description of behaviour of aluminum alloys (with magnesium, manganese, silicon, zinc and other components) in wide ranges of strain rates $\left(10^{-4}-10^{4}\right) \quad \mathrm{s}^{-1}$ and temperatures $(223-500 \mathrm{~K})$. Determining relations are formulated for the case of uniaxial loading; flow stresses in the proposed ratios are assumed to be equal to the sum of the components responsible for strain hardening, viscous resistance, and decrease in strain resistance in a certain range of strain rates; each component is temperature dependent. The evolution equations for the material parameters included in the relations are given. A satisfactory agreement between the simulation results and the experimental data was shown both in the area of the negative rate sensitivity (strain rate $\left.\left(10^{-4} \div 10^{2}\right) \mathrm{s}^{-1}\right)$ and the transition to positive rate sensitivity at higher strain rates). The paper does not consider the application of the proposed ratios to describe the sensitivity effect, however, they are suitable for such an analysis.

The numerical analysis results of flat and cylindrical, smooth and notched samples of the nickel super alloy subjected to uniaxial tension at temperature of $500{ }^{\circ} \mathrm{C}$ and strain rates $\left(10^{-6} \div 10^{-2}\right) \mathrm{s}^{-1}$ are given in [50]. The MacCormic model was used to describe strain aging. The model was implemented using the finite element method in two-dimensional and three-dimensional settings. It is shown that at low strain rates $\left(10^{-6} \mathrm{~s}^{-1}\right.$ order $)$, the instability of plastic flow corresponds to the formation of type $\mathrm{C}$ bands, in the intermediate region $\left(10^{-4} \mathrm{~s}^{-1}\right.$ order) corresponds to the formation of type $\mathrm{B}$, and at relatively high strain rates $\left(10^{-2} \mathrm{~s}^{-1}\right.$ order) corresponds to the formation of type A. A considerable attention is paid to the integration procedure (in time) of constitutive equations, an algorithm is proposed that significantly reduces the cost of computing time while maintaining stability and accuracy. The influence of the used lattices on the calculation results has been thoroughly studied.

In [48], based on the physical analysis of strain hardening, it is assumed that the dependence of the flow stress on the strain rate can be represented as two components: the contribution from the viscous resistance to dislocation motion and through the dependence of strain hardening due to clusters of immobile dislocations. At low strain rates and an elevated temperature, solute atoms "flock" to dislocation clusters, fixing these dislocation barriers; an increase in the strain rate contributes to the activation of a part of immobile dislocations and reduces the influx of solute atoms to dislocation clusters. These mechanisms make strain hardening sensitive to strain rate and temperature, leading to the appearance of ranges of these parameters in which negative rate sensitivity and serrated deformation occur. It is noted that taking into account these mechanisms allows us to explain the experimentally observed fact of the occurrence of intermittent plasticity only after reaching some critical accumulated plastic deformation. Using the proposed model based on the linear analysis of stability, a criterion is proposed that establishes the time when the Portevin-Le Chatelier effect appears for uniaxial loading depending on the accumulated plastic deformation, temperature and strain rate.

The macrophenomenological model, which is a modification of the MacCormick model and focused on the description of the behaviour of metastable stainless steel of the austenitic class, was considered in [45]. In the equation 
of the yield surface, the flow stress depends on the terms responsible for dynamic and static strain aging, martensitic transformation of a part of the material and speed hardening, i.e. softening. A considerable attention is paid to the identification procedure, for which the results of the authors' own experiments are used. A brief description of the experimental procedure and the results obtained are given. Tests were carried out at constant and stepwise varying strain rates, with unloading and holding (from 3 to 56 days) between two stages of monotonic deformation. The qualitative agreement of the theoretical results with the experimental data is noted.

As already noted above, in a number of studies on the sensitivity effect, the manifestation of the latter is associated with the appearance of shear bands. Since the shear band is a region of localized deformations, attempts to use gradient plasticity theories to describe them are reasonable. In [79], a simplified rigid-plastic gradient model is considered, in which an additional term proportional to the second gradient of the intensity of the accumulated plastic deformation is introduced into the hardening law. The variants with plasticity independent and dependent on the strain rate are investigated. For the test problem of a simple shear, the features of the origin and evolution of the shear bands are considered. The physical reasons of possible fluctuations of the yield stress and their connection with the diffusion of solute atoms are not analyzed in the work.

The gradient elastoplastic model, in which the second gradients of the displacement vector are introduced and the moment stresses associated with them, are presented in [66]. The results of applying the model to studying the localization of plastic deformations (formation of shear bands) are considered; as an example, the pure shear problem is used. The flow stress is assumed to depend on the invariants of the small strain tensor and the 3rd rank tensor, a measure of the strain generated by the second gradients of the displacement vector. The deformation resistance is approximated by a piecewise linear function of a strain measure containing a softening region. Although this model is not directly oriented on the description of the sensitivity effect, it seems possible to use it for this purpose, for which it is necessary to introduce the dependence on the strain rate and temperature in the stress-strain diagram, which can be done using the parametric dependence of the coefficients in the fitting yield curve as a function of process parameters.

In [51], to study the Luders bands and serrated yielding, it is proposed to use a simple version of the macrophenomenological gradient theory, in which the intensity gradient of accumulated plastic deformation is introduced as an additional internal variable. Using the example of the numerical solution of plane problems of stretching a band (with different thicknesses), it is shown that the results obtained using the classical theory of plastic flow substantially depend on the approximation of a region by finite elements. The proposed model allows to exclude a similar dependence.

\section{Conclusion}

A brief overview is proposed concerning the work aimed at describing physical mechanisms and results of the experimental studies of alloys deformation in the temperature-speed ranges, in which diffusion processes have a significant influence on the behaviour of materials. Special attention is paid to the consideration of serrated yielding, the occurrence of which most authors associate with the formation of shear bands and the interaction of dislocations with the atmospheres of solute atoms. The experimental data given in the cited papers confirm the validity of this point of view. The study of the "subtleties" of the evolution of dislocation substructures and point defects, especially in the internal regions of the specimens, with the help of the experimental methods, is associated with enormous difficulties and high costs. Therefore in the recent 20 years mathematical models of different scale levels have been intensively developing. It should be noted that mathematical models cannot completely replace experimental studies, the latter need to be developed and improved, since without new empirical data it is hardly possible to create new in-depth models with a high predictive potential. In this paper the authors consider only well-known macrophenomenological models, therefore, this review does not pretend to be overwhelming. It should be noted that this class of models is based on experimental studies, that is why macrophenomenological models do not have universality, nor can they be used to predict the properties of designed materials. To a large extent, in the considered models, the correctly understood physics of the processes is "directly" introduced into the defining relations, without using parameters describing the indicated mechanisms and their carriers. The paper did not consider approaches based on physical theories of plasticity and multilevel models, which will be considered in the next publication. According to the authors, multilevel models do not have many of the disadvantages noted above.

The work was performed at Perm National Research Polytechnic University with the financial support of the Ministry of Education and Science of the Russian Federation (the basic part of the PNRPU State Assignment, project No. 9.7434.2017/8.9), the Russian Foundation for Basic Research (project No. 17-01-00379-a).

\section{References}

1. Bell J.F. Eksperimental'nye osnovy mekhaniki deformiruemykh tverdykh tel. Ch. 1. Malye deformatsii [The experimental foundations of solid mechanics. Part 2. Small deformations]. Moscow, Nauka, 1984, 600 p.

2. Bell J.F. Eksperimental'nye osnovy mekhaniki deformiruemykh tverdykh tel. Ch. 2. Konechnye deformatsii [The experimental foundations of solid mechanics. Part 2. Finite deformation]. Moscow, Nauka, 1984, 432 p.

3. Konovalov A.V., Smirnov A.S. Vliianie dinamicheskogo deformatsionnogo stareniia splava $\mathrm{AMg} 6$ na soprotivlenie 
deformatsii [Effect of dynamic strain aging alloy AMg6 on the resistance strain]. Fiziko-khimicheskaia kinetika $v$ gazovoi dinamike, 2011, vol. 12, pp. 1-6.

4. Krishtal M.M. Neustoichivost' i mezoskopicheskaia neodnorodnost' plasticheskoi deformatsii (analiticheskii obzor). Chast' I. Fenomenologiia zuba tekuchesti i preryvistoi tekuchesti [Instability and mesoscopic inhomogeneity of plastic deformation (analytical review). Part I. Phenomenology of the sharp yield point and discontinuous flow]. Fizicheskaia mezomekhanika, 2004, vol. 7, no. 5, pp. 5-29.

5. Krishtal M.M. Neustoichivost' i mezoskopicheskaia neodnorodnost' plasticheskoi deformatsii (analiticheskii obzor). Chast' II. Teoreticheskie predstavleniia o mekhanizmakh neustoichivosti plasticheskoi deformatsii [Instability and mesoscopic inhomogeneity of plastic deformation (analytical review). Part II. Theoretical understanding of the mechanisms of instability plastic deformation]. Fizicheskaia mezomekhanika, 2004, vol. 7, no. 5, pp. 31-45.

6. Krishtal M.M. Vzaimosviaz' neustoichivosti i neodnorodnosti plasticheskoi deformatsii: Zakonomernosti i osobennosti preryvistoi tekuchesti na primere Al-Mg splavov [The relationship between instability and inhomogeneities of plastic deformation: Laws and features of discontinuous flow on the example of Al-Mg alloys]. Tol'iattinskii gosudarstvenniy universitet, 2003, $330 \mathrm{p}$.

7. Lebedkin M.A. Samoorganizatsiia i kollektivnye effekty pri neustoichivoi plasticheskoi deformatsii kristallov [Selforganization and collective effects instability of plastic deformation in crystals]. Diss. dokt. fiz.-mat. nauk. Chernogolovka: Institut Fiziki Tverdogo Tela RAN, 2002, 248 p.

8. Markushev M.V., Murashkin M.Iu. Struktura i mekhanicheskoe povedenie aliuminievogo splava $\mathrm{AMg} 6$ posle intensivnoi plasticheskoi deformatsii i otzhiga. 1. Osobennosti zerennoi struktury i tekstury [Structure and mechanical behavior of aluminum alloy $\mathrm{AMg} 6$ after plastic deformation and annealing. Part 1. Features of the grain structure and texture]. Fizika tverdogo tela, 2001, vol. 91, no. 5, pp. 97-102.

9. Markushev M.V., Murashkin M.Iu. Struktura i mekhanicheskoe povedenie aliuminievogo splava AMg6 posle intensivnoi plasticheskoi deformatsii i otzhiga. 2. Mekhanicheskie svoistva [Structure and mechanical behavior of aluminum alloy AMg6 after severe plastic deformation and annealing. Part 2. Mechanical properties]. Fizika tverdogo tela, 2001, vol. 92, no. 1, pp. 90-98.

10. Nadai A.N. Plastichnost' i razrushenie tverdykh tel. [Ductility and destruction in solids]. Moscow, Mir, 1969, vol. 2, $863 \mathrm{p}$.

11. Panin V.E., Deriugin E.E. Mezomekhanika formirovaniia polosovykh struktur na mezo- i makromasshtabnykh urovniakh [Mesomechanics formation of stripe structures at the meso-and macroscale levels]. Fizika metallov i metallovedenie, 2003, no. 6. pp. 1-15.

12. Tomas T. Plasticheskoe techenie i razrushenie v tverdykh telakh [Plastic flow and destruction in solids]. Moscow, Mir, 1964, $308 \mathrm{p}$.

13. Trusov P.V., Shvejkin A.I. Teoria plastichnosti [Crystal plasticity]. Permskiy natsionalniy issledovatelskiy polytekhniskiy universitet, 2011, 419 p.

14. Fridel' J. Dislokatsii [Dislocations]. Moscow, Mir, 1967, $644 \mathrm{p}$.

15. Fridman Ia.B. Mekhanicheskie svoistva metallov [Mechanical properties of metals]. Moscow, Gosudarstvennoe izdatel'stvo oboronnoi promyshlennosti, 1952, $555 \mathrm{p}$.
16. Hirt D., Lote I. Teorija dislokacij [Theory of Dislocations]. Moscow, Atomizdat, 1972, 600 p.

17. Shibkov A.A., Mazilkin A.A., Protasova S.G., Mikhlik D.V., Zolotov A.E., Zheltov M.A., Shuklinov A.V. Vliianie sostoianiia primesei na skachkoobraznuiu deformatsiiu splava AMg6 [Effect of impurities on the instability of plastic deformation of AMg6 alloy]. Deformation and fracture of materials, 2008, no. 5, pp. 24-32.

18. Shibkov A.A., Zolotov A.E., Mikhlik D.V., Zheltov M.A., Shuklinov A.V., Averkov V.A., Denisov A.A. Kinetika i morfologiia polos deformatsii na nachal'noi stadii poteri ustoichivosti plasticheskogo techeniia splava AMg6 [Kinetics and morphology the deformation bands in the initial stages of buckling plastic flow]. Deformation and fracture of materials, 2009, no. 8, pp. 23-30.

19. Anjabin N., Karimi Taheri A., Kim H.S. Crystal plasticity modeling of the effect of precipitate states on the workhardening and plastic anisotropy in an $\mathrm{Al}-\mathrm{Mg}-\mathrm{Si}$ alloy. Computational Materials Science, 2014, vol. 83, pp. 78-85, available at: http://dx.DOI.org/10.1016/j.commatsci.2013.09.031

20. Banerjee S., Naik U.M. Plastic instability in an omega forming Ti - 15\% Mo alloy. Acta Mater, 1996, vol. 44, no. 9, pp. 3667-3677.

21. Benallal A., Berstad T., Børvik T., Clausen A.H., Hopperstad O.S. Dynamic strain aging and related instabilities: experimental, theoretical and numerical aspects. Eur. J. Mechanics A/Solids, 2006, vol. 25, pp. 397-424.

22. Benallal A., Berstad T., Børvik T., Hopperstad O.S., Koutiri I., Nogueira de Codes R. An experimental and numerical investigation of the behaviour of AA5083 aluminium alloy in presence of the Portevin-Le Chatelier effect. Int. J. Plasticity, 2008, vol. 24, pp. 1916-1945.

23. Bertram A., Böhlke T., Brüggemann C., Estrin Y., Lebyodkin M. Modeling and Simulation of the Portevin-Le Chatelier Effect. Proc. Appl. Math. Mech, 2006, vol. 6, pp. 353-354. DOI: 10.1002/pamm.200610158

24. Bharathi M.S., Lebyodkin M., Ananthakrishna G., Fressengeas C., Kubin L.P. The hidden order behind jerky flow. Acta Materialia, 2002, vol. 50, pp. 2813-2824.

25. Böhlke T., Bondár G., Estrin Y., Lebyodkin M.A. Geometrically non-linear modeling of the Portevin-Le Chatelier effect. Comput. Materials Science, 2009, vol. 44, pp. 1076-1088.

26. Brechet Y., Estrin Y. Pseudo-Portevin-Le Chatelier effect in ordered alloys. Scripta materiali, 1996, vol.35, no. 2, pp. 217-223.

27. Bross S., Hähner P., Steck E.A. Mesoscopic simulations of dislocation motion in dynamic strain ageing alloys. Computational Materials Science, 2003, vol. 26, pp. 46-55.

28. Cheng T.T., Bate P.S., Botten R.R., Lipsitt H.A. Strain ageing and yield plateau phenomena in $\gamma$-TiAl based alloys containing boron. Scripta materialia, 1999, vol. 40, no. 3. pp. 283-288.

29. Cheng X.-M., Morris J.G. The anisotropy of the PortevinLe Chateliereffect in aluminum alloy. Scripta mater, 2000, vol. 43, pp. 651-658.

30. Cottrell A.H. A note on the Portevin - Le Chatelier effect. Philosophical Magazine, Ser. 7, 1953, vol. 44, iss. 355, pp. 829-832.

31. Deryugin Ye.Ye., Panin V.E., Shmauder S., Soppa E. The effects of macrolocalization of deformation in Al-based composites with $\mathrm{Al}_{2} \mathrm{O}_{3}$ inclusions. Fatigue Fract Engng Mater Struct, 2003, vol. 26, pp. 295-304.

32. Graff S., Forest S., Strudel J.-L., Prioul C., Pilvin P., Béchade J.-L. Finite element simulations of dynamic strain ageing 
effects at V-notches and crack tips. Scripta Materialia, 2005, vol. 52, pp. 1181-1186.

33. Guo W.G., Zhang X.Q., Su J., Su Y., Zeng Z.Y., Shao X.J. The characteristics of plastic flow and a physicallybased model for 3003 Al-Mn alloy upon a wide range of strain rates and temperatures. Eur. J. Mechanics / A Solids, 2010. DOI:10.1016/ j.euromechsol.2010.09.001

34. Hähner P. On the critical conditions of the Portevin-Le Chatelier effect. Acta mater, 1997, vol. 45, no. 9, pp. 3695-3707.

35. Hähner P., Zaiser M. From mesoscopic heterogeneity of slip to macroscopic fluctuations of stress and strain. Acta mater, 1997, vol. 45, no. 3, pp. 1067-1075.

36. Hörnqvist M., Karlsson B. Dynamic strain ageing and dynamic precipitation in AA7030 during cyclic deformation. Procedia Engineering, 2010, vol. 2. pp. 265-273.

37. Hu S.Y., Li Y.L., Zheng Y.X., Chen L.Q. Effect of solutes on dislocation motion - a phase-field simulation. Int. J. Plasticity, 2004, vol. 20, pp. 403-425.

38. Huifeng J., Qingchuan Z., Xuedong Ch., Zhongjia Ch., Zhenyu J., Xiaoping W., Jinghong F. Three types of Portevin-Le Chatelier effects: Experiment and modeling. Acta Materialia, 2007, vol. 55. pp. 2219-2228.

39. Kim D.W., Ryu W.-S., Hong J.H., Choi S.-K. Effect of nitrogen on the dynamic strain ageingbehaviour of type $316 \mathrm{~L}$ stainless steel. J. Mater. Sci., 1998, vol. 33, pp. 675- 679.

40. Klueh R.L., King J.F., Unusual creep behavior in a commercial nickel-chromium alloy. Scripta Metallurgica, 1979, vol. 13, pp. 205-209.

41. Klueh R.L., King J.F., Creep and creep rupture of ERNiCr-3 weld metal. J. of Nuclear Materials, 1981, vol. 98, pp. 173-189.

42. Klueh R.L., Discontinuous creep in short-range order alloys. Mater. Sci. and Engineer, 1982, vol. 54, pp. 65-80.

43. Kovács Zs., Chinh N.Q., Lendvai J., Vörös G. PortevinLe Châtelier type plastic instabilities in depth sensing macro-indentation. Mat. Sci. and Engineering, 2002, vol. A325, pp. 255-260.

44. Kubin L.P., Estrin Y. Evolution of dislocation densities and the critical conditions for the Portevin-Le Chatelier effect. Acta metall. Mater, 1990, vol. 38, pp. 697-708.

45. Larsson R., Nilsson L. On the modelling of strain ageing in a metastable austenitic stainless steel. Journal of Materials Processing Technology, 2012, vol. 212, pp. 46-58. DOI: 10.1016/j.jmatprotec.2011.08.003

46. Lebyodkin M., Brechetz Y., Estrin Y. and Kubin L.Statistical behaviour and strain localization patterns in the Portevin-Le Chatelier effect. Acta mater, 1996, vol. 44, no. II, pp. 4531-4541.

47. Lennon A.M, Ramesh K.T. The influence of crystal structure on the dynamic behavior of materials at high temperatures. Int. J. Plasticity, 2004, vol. 20, pp. 269-290.

48. Van Liempt P., Sietsma J. A reviesed criterion for the Portevin - Le Chatelier effect based on the strain-rate sensitivity of the work-hardening rate. Metallurgical and Materials transactions A, 2011, vol. 42 A, pp. 4008-4014. DOI: 10.1007/s11661-011$0850-5$

49. Masson A. Sur elasticite des corps solides. Annales de Chimie et de Physique. Troisieme serie, 1841, vol. 3, pp. 451-462.

50. Mazière M., Besson J., Forest S., Tanguy B., Chalons H., Vogel F. Numerical aspects in the finite element simulation of the Portevin-Le Chatelier effect. Comput. Methods Appl. Mech. Engrg., 2010, vol. 199, pp. 734-754.

51. Mazière M., ForestS. Strain gradient plasticity modeling and finite element simulation of Lüders band formation and propagation. Continuum Mech. Thermodyn, 2013. DOI: 10.1007/s00161-013-0331-8

52. McReynolds A.W. Plastic deformation waves in aluminum. Metals Transact, 1949, no.1, pp. 32-45.

53. Mesarovic S. Dj. Dynamic strain aging and plastic instabilities. J. Meeh Phys. Solids, 1995, vol. 43, no. 5, pp. 671-700.

54. Min J., Hector Jr. L.G., Lin J., Carter J.T., Sachdev A.K. Spatio-temporal characteristics of propagative plasticinstabilities in a rare earth containing magnesium alloy. Int. J. Plasticity, 2014, vol. 57, pp. 52-76.

55. Montheillet F., Cohen M., Jonas J.J., Axial stresses and texture development during the torsion testing of $\mathrm{Al}, \mathrm{Cu}, \mathrm{a}-\mathrm{Fe}$. Acta Metallurgica, 1984, vol. 32, pp. 2077-2089.

56. Morris M.A., Lipe T., Morris D.G. Strain-ageing, strainrate sensitivity, and flow stress variations at intermediate temperatures in a two-phase Ti-Al alloy. Scripta materialia, 1996, vol. 34, no. 8, pp. 1337-1343.

57. Nortmann A., Schwink Ch. Characteristics of dynamic strain ageing in binary f.e.c. copper alloys - I. Results on solid solutions of CuAl. Acta mater, 1997, vol. 45, no. 5, pp. 2043-2050.

58. Nortmann A., Schwink Ch. Characteristics of dynamic strain ageing in binary f.e.c. copper alloys - II. Comparison and analysis of experiments on CuAl and CuMn. Acta mater, 1997, vol. 45, no. 5, pp. 2051-2058.

59. Perlovich Yu., Isaenkova M. Effects of dynamical deformation ageing on structureand texture of hot-rolled sheetsfrom alloyed bcc metals. Int. J. Mater. Form, 2010, vol. 3, iss. 1 supplement, pp. 1143-1146. DOI: 10.1007/s12289-010-0974-y

60. Popille F., Kubin L.P., Douin J. and Naka S. Portevin-Le Chatelier instabilities and stoichiometric effects in B2 titanium aluminides. Scripta materialia, 1996, vol. 34, no.6, pp. 977-984.

61. Portevin A., Le Chatelier F. Sur un phenomene observe lors de l'essai de traction d'alliages en cours de transfor-mation. Compt. Rend. Acad. Sci. Paris, 1923, vol. 176, pp. 507-510.

62. Rizzi E., Hähner P. On the Portevin-Le Chatelier effect: theoretical modeling and numerical results. Int. J. Plasticity, 2004, vol. 20, pp. 121-165, DOI: 10.1016/S0749-6419(03)00035-4

63. Rusinek A., Rodríguez-Martínez J.A. Thermoviscoplastic constitutive relation for aluminium alloys, modeling of negative strain rate sensitivity and viscous drag effects. Materials and Design, 2009, vol. 30, pp. 4377-4390.

64. Sandhya R., K. Bhanu Sankara Rao, Mannan S.L. The effect of temperature on the low cycle fatigue properties of a $15 \mathrm{Cr}-15 \mathrm{Ni}$, Ti modified austenitic stainless steel. Scripta materialia, 1999, vol. 41, no. 9, pp. 921-927.

65. Savart F. Recherches sur les vibration longitudinales. Ann. Chim. Phys., 1837, vol. 65, pp. 337-402.

66. Shi M.X., Huang Y., Hwang K.C. Plastic flow localization in mechanism-based strain gradient plasticity. Int. J. Mech. Sciences, 2000, vol. 42, pp. 2115-2131.

67. Srinivasan V.S., Sandhya R., Valsan M., K. Bhanu Sankara Rao, Mannan S.L., Sastry D.H. The influence of dynamic strain ageing on stress response and strain-life relationship in low cycle fatigue of $316 \mathrm{~L}(\mathrm{~N})$ stainless steel. Scripta materialia, 1997, vol. 37 , no. 10 , pp. 1593-1598.

68. Starling J., Saimoto S., Boyd J.D. Strengthening of low-interstitial steels by strain-ageing treatments. Scripta materialia, 1998, vol. 39, iss. 4/5, pp. 487-492.

69. Sun L., Zhang Q., Jiang H. Effect of solute concentration on Portevin-Le Chateliereffect in Al-Cu alloys. Front. Mater. Sci. China, 2007, vol. 1(2), pp. 173-176. DOI: 10.1007/s11706-007-0031-z 
70. Varadhan S., BeauDOIn A.J., Fressengeas C. Lattice incompatibility and strain-aging in single crystals. J. Mech. Phys. Solids, 2009, vol. 57, pp. 1733-1748.

71. Voyiadjis G.Z., Abed F.H. Microstructural based models for bcc and fcc metals with temperature and strain rate dependency. Mechanics of Materials, 2005, vol. 37, pp. 355-378.

72. Voyiadjis G.Z., Abed F.H. A coupled temperature and strain rate dependent yield function for dynamic deformations of bcc metals. Int. J. Plasticity, 2006, vol. 22, pp. 1398-1431.

73. Voyiadjis G.Z., Almasri A.H. A physically based constitutive model for fcc metals with applications to dynamic hardness. Mechanics of Materials, 2008, vol. 40, pp. 549-563.

74. Wang C., Xu Y., Han E.Portevin - Le Chatelier effect of LA41 magnesium alloys. Front. Mater. Sci. China, 2007. vol. 1. iss. 1. pp. 105-108. DOI: 10.1007/s11706-007-0019-8

75. Watté P., Van Humbeeck J., Aernoudt E., Lefever I. Strain ageing in heavily drawn eutectoid steel wires. Scripta materialia, 1996, vol. 34, no. 1, pp. 89-95.

76. Yang S.-Y., Tong W. A perturbation analysis of the unstable plastic flow pattern evolution in an aluminum alloy. Int. J. Solids and Structures, 2006, vol. 43, pp. 5931-5952. DOI: 10.1016/j.ijsolstr.2005.07.041
77. Yoshinaga H., Morozumi S. A Portevin - Le Chatelier effect expected from solute atmosphere dragging. Philosophical Magazine, 1971, vol. 23, iss. 186, pp. 1351-1366. DOI: $10.1080 / 14786437108217007$

78. Yu D., Chen X., Yu W., Chen G. Thermo-viscoplastic modeling incorporating dynamic strain aging effecton the uniaxial behavior of Z2CND18.12N stainless steel. Int. J. Plasticity, 2012, vol. 37, pp. 119-139. available at: http://dx.DOI.org/10.1016/j.ijplas.2012.05.001

79. Zbib H.M., Aifantis E.C. On the gradient-dependent theory of plasticity and shear banding. Acta Mechanica, 1992, vol. 92, pp. 209-225.

80. Zeghloul A., Mliha-Touati M., Bakir S. Propagation mode of Portevin-Le Chatelier plastic instabilities in an aluminium - magnesium alloy. Scripta materialia. 1996, vol. 35, no. 9, pp. 1083-1087.

81. Zhang J., Jiang Y. Lüders bands propagation of 1045 steel under multiaxial stress state. Int. J. Plasticity. 2005. vol. 21. pp. 651-670.

82. Zhang S., McCormick P. G. and Estrin Y. The morphology of Portevin-Le Chatelier bands: finite element simulation for Al-Mg-Si. Acta mater, 2001, vol. 49, pp. 1087-1094.

Original Russian Text:

Trusov P.V., Chechulina E.A. Serrated yielding: physical mechanisms, experimental dates, macro-phenomenological models. PNRPU Mechanics Bulletin, 2014, no. 3, pp. 186- 232. DOI: 10.15593/perm.mech/2014.3.10 


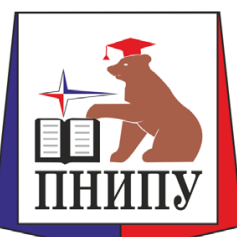

\title{
PNRPU MECHANICS BULLETIN
}

№ 3-4, 2018

http://vestnik.pstu.ru/mechanics/about/inf/

\section{CONTACT INTERACTION OF PLATES AND BEAMS UNDER THE INFLUENCE OF WHITE NOISE}

\author{
T.V. Yakovleva ${ }^{1,2}$, V.G. Bazhenov', V.A. Krysko², E.Yu. Krylova ${ }^{1,3}$ \\ ${ }^{1}$ Mechanics Research Institute of N.I. Lobachevsky State University of Nizhny Novgorod, \\ Nizhny Novgorod, Russian Federation \\ ${ }^{2}$ Yuri Gagarin State Technical University of Saratov, Saratov, Russian Federation \\ ${ }^{3}$ Saratov State University, Saratov, Russian Federation
}

\section{ARTICLE INFO}

Received: 14.02 .2017

Accepted: 15.03 .2017

Published: 25.12.2018

\section{Keywords:}

micromechanical systems, contact interaction, nonlinear dynamics of beams and plates, phase transitions induced by white noise, wavelet analysis.

\begin{abstract}
This paper deals with contact interaction of a multi-layer structure in the form of a plate reinforced by beams. There are small gaps between the plate and beams. Such systems are integral elements of modern devices. The created mathematical model is based on the following hypothesis: the system has a multi-layer structure; materials are isotropic. We used the kinematic model of the first approximation (the Kirchhoff model for the plate, the Euler-Bernoulli model for beams). To solve the problem we used the finite difference method with approximation 0 (h2), 0 (h4) and the Faedo-Galerkin method in higher approximations of spatial coordinates, as well as the Runge-Kutta method 0 (h4), 0 (h6), 0 (h8) in time. When solving problems associated with chaotic vibrations, it is necessary to solve the issue of error and realness of chaos, so we need to use different numerical methods at each stage of the study to validate the results in order to distinguish chaos from the numerical error. For the analysis of chaotic dynamics we have applied all methods of qualitative analysis. We have investigated the spatiotemporal chaos based on wavelet analysis. We have studied the influence of white noise on the contact interaction of elements of the multilayer structure. Also, the analysis of the complex vibrations of plates and beams depending on different intensities of noise and types of applied load has been made. It was found that by using an external additive white noise, it is possible to control chaotic oscillations and transfer the system from a chaotic state to a harmonious one and enable or disable the contact interaction.
\end{abstract}

(๔) Tatyana V. Yakovleva - CSc in Physical and Mathematical Sciences, Junior Researcher, e-mail: yan-tan1987@mail.ru

Valentin G. Bazhenov - Doctor of Physics and Mathematics, Professor, e-mail: bazhenov@mech.unn.ru

Vadim A. Krysko - Doctor of Technical Sciences, Professor, e-mail: tak@san.ru

Catherine Y. Krylova - CSc in Physical and Mathematical Sciences, Junior Researcher, e-mail: kat.krylova@bk.ru 


\section{Introduction}

The structures of modern devices and equipment are complex multi-layer systems of beams and plates with small gaps between them. Such structures are affected by extreme conditions caused by deterministic external influence of various kinds and random fluctuations in the environment properties which causes modification of modes of dynamic systems [1]. It is necessary to take into account the contact interaction of layers which is the reason of constructive nonlinearity [2]. A gap between the elements (plate-beam, plate-plate, beam-beam, shell-beam and other combinations), as well as the imperfection of the device, even if there are small deflections comparable with the gap between the elements, can cause the studied object to be in a state of chaotic oscillations [3-4]. Therefore, it is important to study influence of control parameters, and different kinds of external load on performance of the system. Such systems have a wide application to electronics, in particular, to gyroscopes (multi-layered flat micromechanical accelerometers (MMA)), described in articles [5-6], but these works do not deal with the contact interaction of layers. When modeling behavior of structures of modern devices, the type of the chaotic state is important. This phenomenon can be studied from the perspective of analysis of the variety of signs of Lyapunov exponents [7-9], Fourier analysis and wavelet analysis [10]. An important matter is the control of chaos and complex nonlinear oscillations that lead to various performance errors of sensors of measuring instruments. Such errors can be studied by taking into account the mathematical model of white noise. The problem of increasing the accuracy and structural strength of modern devices is currently relevant. This problem can be solved by using new technical solutions and new technologies, as well as by creating new mathematical models that describe nonlinear dynamics of distributed systems. At the moment, both foreign and Russian scientific schools have increased interest in effects associated with the influence of external noises on the behavior of dynamic systems. In such areas as physics, chemistry, and biology it has already been proved that random influences play a very significant role in the behavior of dynamic systems [11-12]. External noise can cause not only fluctuations in the properties of dynamic systems, but also a qualitative modification of their modes [13-15]. Using the example of the Anishchenko-Astakhov oscillator, T.E. Vadivasova [16] has proved that the effect of noise signal causes a shift of doubling bifurcations towards the increase of the control parameter. In the work by V.D. Potapov [17] it is shown that the deterministic parametric system which is unstable according to Lyapunov, can be stabilized by applying random noise to the parametric load. The work [18] reports on the results of the sample study of a beam-impact system under Gaussian noise disturbances. It is proved that when taking into account several forms of oscillations, the reaction of a nonlinear model differs greatly from that of the calculation model with one degree of freedom. The article
[19] shows that by taking into account the number of degrees of freedom we can significantly affect reliability of the results. The work [20] presents calculations of vibrations and radiation of sound of reinforced plates covered with a damping layer under harmonic load and load of the white noise type. The solution is obtained by natural decomposition of oscillations. S.I. Denisov [21] examines noise-induced transitions in one-dimensional systems that cause their stationary distribution functions to change qualitatively with the change of noise intensity. When fluctuations are modeled by Gaussian white noise, the necessary condition for such transitions is multiplicity of noise. The authors of the article [22] suggest a theoretical static model of equilibrium of a liquid drop on a rough flat surface. The surface is described using a random stationary function of the white noise type in a limited frequency range. A generalization of the model for surface topography in the form of a set of random functions was carried out. However, in the literature that we know about, there are no works devoted to the matter of external influence of the environment on nonlinear oscillations of multi-layer systems in the form of beams and plates as systems with a variety of degrees of freedom.

\section{Setting the Problem}

The authors of this work have created a mathematical model of complex vibrations of a multi-layer system consisting of a plate and three beams, which is subjected to external load of different types (Fig. 1). The upper layer is a plate described by equation of the Germain-Lagrange type, and the lower layer is a set of parallel beams. Each beam is described by the Euler-Bernoulli equation. The contact interaction is taken into account by the Winkler model. The plate and beams are isotropic and connected by the boundary conditions, there is a small gap between them. The mathematical model is described by a following system of equations:

$$
\left\{\begin{array}{l}
\frac{1}{12\left(1-\mu^{2}\right)}\left(\frac{1}{\lambda^{2}} \frac{\partial^{4} w_{1}}{\partial x^{4}}+\lambda^{2} \frac{\partial^{4} w_{1}}{\partial y^{4}}+2 \frac{\partial^{4} w_{1}}{\partial x^{2} \partial y^{2}}\right)+ \\
+\frac{\partial^{2} w_{1}}{\partial t^{2}}+\varepsilon \frac{\partial w_{1}}{\partial t}-q_{1}(x, y, t)-K\left(w_{1}-w_{2}-h_{k}\right) \Psi_{1}- \\
-K\left(w_{1}-w_{3}-h_{k}\right) \Psi_{2}-K\left(w_{1}-w_{4}-h_{k}\right) \Psi_{3}=0 \\
\frac{1}{12} \frac{\partial^{4} w_{2}}{\partial x^{4}}+\frac{\partial^{2} w_{2}}{\partial t^{2}}+\varepsilon \frac{\partial w_{2}}{\partial t}-q_{2}(x, t)+ \\
+K\left(w_{1}-w_{2}-h_{k}\right) \Psi_{1}=0 \\
\frac{1}{12} \frac{\partial^{4} w_{3}}{\partial x^{4}}+\frac{\partial^{2} w_{3}}{\partial t^{2}}+\varepsilon \frac{\partial w_{3}}{\partial t}-q_{3}(x, t)+ \\
+K\left(w_{1}-w_{3}-h_{k}\right) \Psi_{2}=0 \\
\frac{1}{12} \frac{\partial^{4} w_{4}}{\partial x^{4}}+\frac{\partial^{2} w_{4}}{\partial t^{2}}+\varepsilon \frac{\partial w_{4}}{\partial t}-q_{4}(x, t)+ \\
+K\left(w_{1}-w_{4}-h_{k}\right) \Psi_{3}=0
\end{array}\right.
$$


where functions $\quad \psi_{1}=\frac{1}{2}\left[1+\operatorname{sign}\left(w_{1}-h_{k}-w_{2}\right)\right]$, $\psi_{2}=\frac{1}{2}\left[1+\operatorname{sign}\left(w_{1}-h_{k}-w_{3}\right)\right], \quad$ and $\quad \psi_{3}=$ $=\frac{1}{2}\left[1+\operatorname{sign}\left(w_{1}-h_{k}-w_{4}\right)\right]$.

The ratio $K\left(w_{1}-w_{i}-h_{k}\right) \Psi_{i-1}$ (where $i=2 ; 3 ; 4$ is the beam number) is the contact pressure between the layers. In the contact problems of the theory of plates and beams this ratio is the Winkler connection between compression and contact pressure.

$$
\nabla_{\lambda}^{4}=\frac{1}{\lambda^{2}} \frac{\partial^{4}}{\partial x^{4}}+\lambda^{2} \frac{\partial^{4}}{\partial y^{4}}+2 \frac{\partial^{4}}{\partial x^{2} \partial y^{2}} ; \quad \Psi_{i-1}=1, \quad \text { if }
$$

$\mathrm{w}_{1}>w_{i}+h_{k}$ is the contact between the plate and the beam, otherwise $\Psi_{i-1}=0 ; \quad w_{1}, w_{i}$ are functions describing deflections of the plate and beams, respectively, $K$ is the stiffness coefficient of transversal compression of the structure in the contact zone, $h_{k}$ is the gap between the layers. Adhesion zones are unlikely to occur, since the contact pressure between the layers is low. The conditions of contact between the layers may depend on coordinates and include all kinds of the imperfect one-side contact [23].

The system of equations (1.1) has the following dimensionless form: $x=a \bar{x}, \quad y=a \bar{y} ; \quad q=\bar{q} \frac{E(2 h)^{4}}{a^{2} b^{2}}$, $\tau=\frac{a b}{2 h} \sqrt{\frac{\gamma}{E g}}, \lambda=\frac{a}{b}$, where $a, b$ are dimensions of the plate regarding $x$ and $y$, respectively, $t$ is the time, $\varepsilon$ is the damping coefficient, $w$ is the deflection function, $2 h$ is the thickness of the plate, $\mu=0.3$ is the Poisson's ratio, $g$ is the gravity acceleration, $E$ is the modulus of elasticity, $q_{1}(x, y, t)$ is the transverse load applied to the plate, $q_{i}(x, t)$ are transverse loads applied to the beams, $\gamma$ is the specific weight of the material.

The multi-layer system can be subjected to different external loads: transverse loads with or without additive noise.

The general form of transverse loads can be written as follows:

$$
\begin{gathered}
q_{1}(x, y, t)=q_{0} \sin \left(\omega_{p} t\right)+a^{0} \times \frac{2 \text { rand }}{\text { rand_max }+1}-1 ; \\
q_{i}(x, t)=q_{i}^{0} \sin \left(\omega_{p} t\right)+a_{i}^{0} \times \frac{2 \text { rand }}{\text { rand_max }+1}-1, \\
(i=2, \ldots, 4) ;
\end{gathered}
$$

The additive noise is a form of deterministic input, whereby the noise is used only by applying the external load and expressed by the formula $a^{0} \times \frac{2 \text { rand }}{\text { rand_max }+1}-1$, where $a^{0}$ is the noise intensity, the function rand is the random number generator of a random value.
For simplicity sake, bars over dimensionless parameters in the system of equations (1.1) can be omitted.

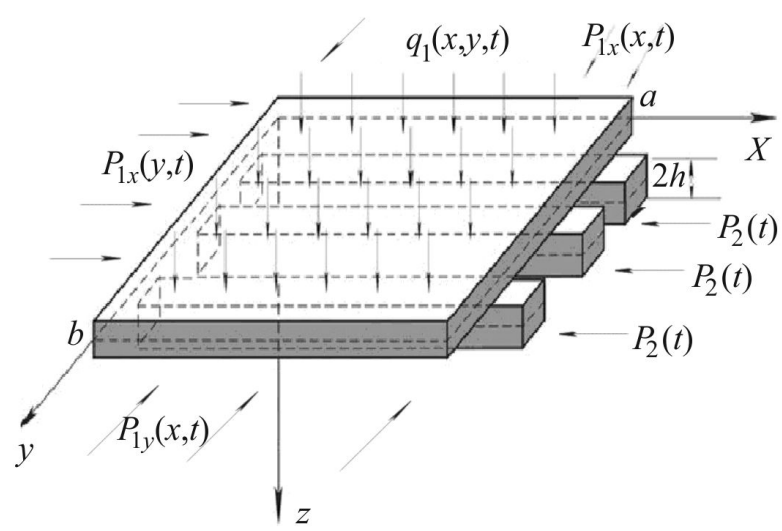

Fig. 1. Schematic view of a multi-layer structure consisting of a plate and three beams

The boundary conditions (hinge support along the contour and zero initial conditions) should be added to the initial equations:

$$
\begin{gathered}
w_{m}=0 ;\left.\quad w_{m}^{\prime \prime}\right|_{x}=0 ; \text { at } x=0 ; 1 ; \\
w_{m}=0 ;\left.\quad w_{1}^{\prime \prime}\right|_{y}=0 ; \text { at } y=0 ; 1 ;
\end{gathered}
$$

$m=1,2,3,4$ is the index corresponding to the plate and beams,

$$
\begin{gathered}
\left.w_{1}(x, y)\right|_{t=0}=0,\left.\quad w_{2}(x)\right|_{t=0}=0,\left.\quad w_{3}(x)\right|_{t=0}=0, \\
\left.w_{4}(x)\right|_{t=0}=0,\left.\quad \dot{w}_{m}\right|_{t}=0, m=1,2,3,4 .
\end{gathered}
$$

These conditions and conditions of nonpenetration of one system into the body of another one should be attached. Obtained system of nonlinear PDEs (1.1) is reduced to second order ODEs (1-3) by the Faedo-Galerkin higher approximation order method [24]. Functions $w_{1}$ and $w_{i}$ $(i=2, . ., 4)$, being solutions to (1.1), are approximated by the following functions that depend on time and coordinates:

$$
\begin{gathered}
w_{1}=\sum_{k=1}^{N} \sum_{j=1}^{N} A_{k j}(t) \varphi_{k j}(x, y), \\
w_{i}=\sum_{k=1}^{N} A_{i}^{k}(t) \varphi^{k}{ }_{i}(x) \quad(i=2, . ., 4), N=6 .
\end{gathered}
$$

The functions $\kappa_{k j}(x, y)$ and $\varphi^{k}{ }_{i}(x)$ are chosen in such a way that they are linearly independent, continuous together with their differential derivatives up to fourth order, and satisfy boundary and initial conditions. In this regard the equation is written as follows:

$$
\begin{gathered}
\varphi_{k j}(x, y)=\sin (k \pi x) \sin (j \pi y), \quad \varphi^{k}{ }_{i}(x)=\sin (k \pi x), \\
(i=2, . ., 4) .
\end{gathered}
$$

The coefficients $A_{k j}(t)$ и $A_{i}^{k}(t)$ are the required functions of time. The system of second order with respect to functions of time is obtained by the Faedo-Galerkin 
method. The number of equations in the system depends on the number of beams. The system of equations of second order is reduced to first order system by the variable replacement method. Cauchy problems for the nonlinear system of first-order equations is solved by the Runge-Kutta method in time.

When solving problems associated with chaotic vibrations, it is necessary to solve the issue of error, so we need to use different numerical methods to validate the results. For this purpose, we reduced the obtained differential equations to the Cauchy problems by the finite difference method with approximation $0(\mathrm{~h} 2)$ and $0(\mathrm{~h} 4)$ and the Faedo-Galerkin method in higher approximations, studied convergence of the method for different numbers of terms of the order $N=1, \ldots, 6$, and checked the accuracy by the Runge rule. Obtained ODEs were solved by the 4th, 6th, 8th order Runge-Kutta method in time, a comparative analysis of the results was carried out $[1,4]$. Since the system of equations is nonlinear, it is not possible to solve it analytically.

Based on this algorithm, a complex solution was created that allows to study a multi-layer system of a plate and three beams described by a system of equations (1.1). The obtained results are analyzed using the methods of nonlinear dynamics and qualitative theory of differential equations: each layer is studied using such techniques as construction of signals, phase portraits, Poincaré maps, Fourier spectra, use of wavelet transforms as well as analysis of the Lyapunov exponents. Various wavelets are used: Morlet, Mexican hat, and Gaussian derivatives wavelets (from 1st to 8th order inclusive). 8th order Gaussian wavelet and the Morlet wavelet give similar results, however, the Morlet wavelet is preferable, because it allows to better localize the frequency in time, i. e. it is more informative [25-26].

\section{Numerical Experiment}

Let us study complex vibrations of a multi-layer system consisting of a plate and three parallel beams positioned at an asymmetric distance from the center of the plate ( $y=0.2, y=0.4$ and $y=0.7)$, the gap between the plate and each of the beams is $h_{k}=0.01$. Let us study the contact interaction depending on three types of load:

1) external distributed transverse load $q_{1}(x, y, t)=q_{0} \sin \left(\omega_{p} t\right)$ is applied only to the upper plate, the beams are at standstill, i. e. $q_{i}(x, t)=0$;

2) external distributed transverse load with the noise component $q_{1}(x, y, t)=q_{0} \sin \left(\omega_{p} t\right)+a^{0} \times \frac{2 \text { rand }}{\text { rand_max }+1}-1$, is applied only to the upper plate, the beams are at standstill $\left(q_{i}(x, t)=0\right)$;

3) external distributed transverse load $q_{1}(x, y, t)=$ $=q_{0} \sin \left(\omega_{p} t\right)$ is applied to the upper plate, all three beams are subjected to the additive white noise, i. e. the load is defined as $q_{i}(x, t)=a_{i}^{0} \times \frac{2 \text { rand }}{\text { rand_ } \max +1}-1$.

Let us discuss the first type of the load. The upper plate is subjected to an external distributed transverse load $q_{1}(x, y, t)=q_{0} \sin \left(\omega_{p} t\right)$ with the intensity $q_{0}<0.065$ and excitation frequency $\omega_{p}=5$, close to the natural-vibration frequency of the plate. The plate executes harmonic vibrations, and the beams are at standstill. When the external load amplitude is $q_{0}=0.065$, there is a contact between the plate and beams, which causes short time damped vibrations of the beams. When $q_{0}=0.07$, vibration behavior of the plate and beams changes. the system goes into chaos state, the period triples (see Fig. 2, b1, b2), while the second and third beams are at standstill. Figure 2 shows the graphs of the Fourier power spectra (b1, b2), 2D Morlet wavelet-spectra $(\mathrm{c} 1, \mathrm{c} 2)$ of the plate and the first beam, respectively, as well as the graph of coupled vibrations of the plate and the first beam $(y=0.2)(a)$, a continuous line is the plate, a dotted line is the beam.

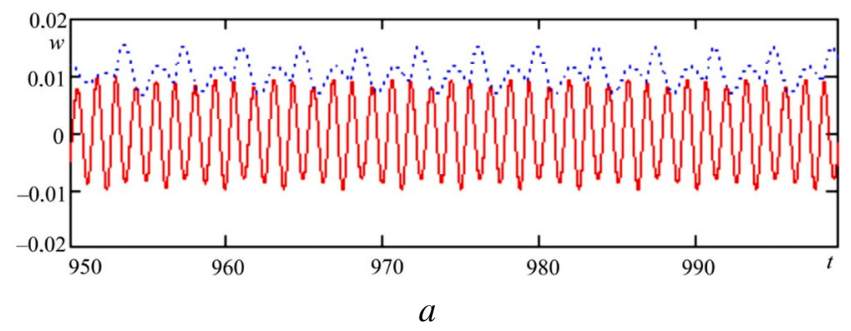

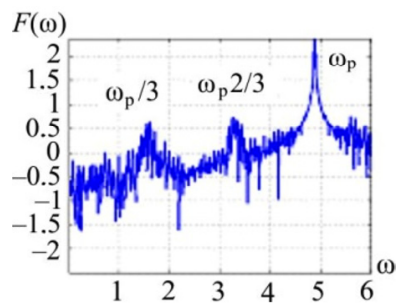

b1

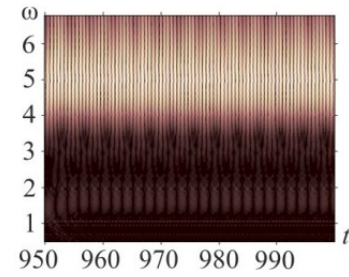

c1

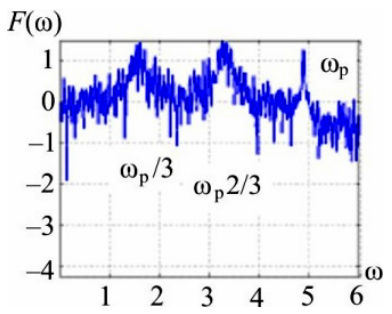

b2

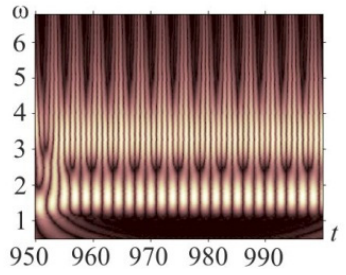

c2
Fig. 2. Contact interaction of the plate and three asymmetric beams at the load amplitude $q_{0}=0.07$ with the gap $h_{k}=0.01$

With an increase of the external load amplitude, the plate executes chaotic vibrations during period tripling with each of the end beams at a time. When the load amplitude is 
in the range $q_{0} \in[0.074 ; 0.09]$, each element of the twolayer beam-plate system (plate and all three beams) executes vibrations. The graphs of 2D Morlet waveletspectra show that the vibrations are executed at different frequencies at different time intervals (see Fig. 3 b1-b4), unlike the Fourier power spectra (see Fig. 3, a1-a4), which show frequencies of vibrations for the entire period of time. This analysis allows us to draw a conclusion about the presence of intermittency zones and areas of enabling/disabling frequencies. With increase of the load, the plate once again executes vibrations with each of the beams at a time. And finally, starting with the load amplitude $q_{0}=0.31$, the plate interacts simultaneously with two end beams ( $y=0.2, y=0.7)$, the vibration behavior is chaotic.

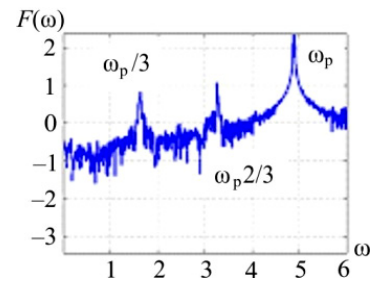

a1

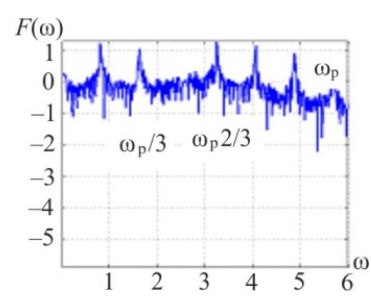

a3

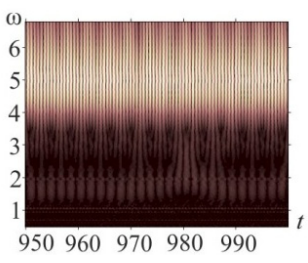

b1

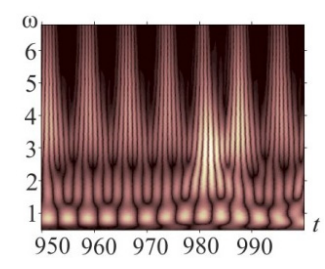

b3

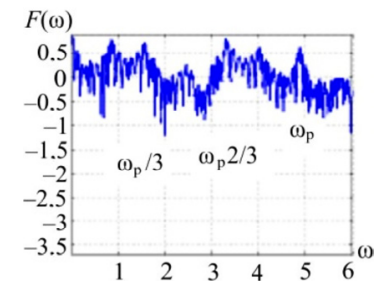

a2

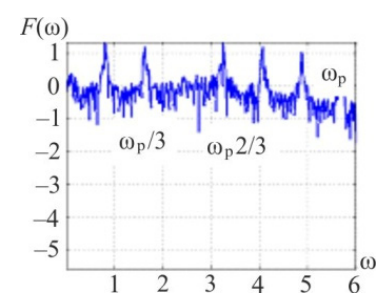

a4

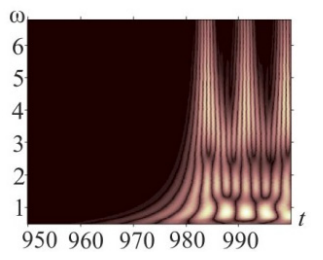

b2

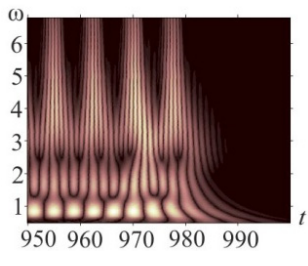

b4
Fig. 3. Contact interaction of the plate and three asymmetric beams at the load amplitude $q_{0}=0.077$ with the gap $h_{k}=0.01$

Let us discuss the second type of the load. The upper plate is subjected to an external distributed transverse load with the amplitude $q_{0}=0.07$. Let us study the influence of additive noise added to the external transverse load applied to the plate, on the complex vibrations of the multi-layer system. The noise intensity from the range of $a^{0} \in\left[1 \cdot 10^{-6} ; 6.6 \cdot 10^{-3}\right]$ has absolutely no influence on the vibration behavior (see Fig. 4 a1, b1, c1, d1). The system is still deterministic, chaotic vibrations are captured during period tripling of the plate and the first beam $(y=0.2)$. Figure 4 shows graphs of Fourier power spectra and 2D Morlet wavelet-spectra of the plate $w_{1}(0.5 ; 0.5, t)$ (a1-a4 and $\mathrm{b} 1-\mathrm{b} 4)$, first beam $w_{2}(0.5 ; t)$ (c1-c4 and d1-d4), second beam $w_{3}(0.5 ; t)(\mathrm{e} 3-\mathrm{e} 4$ and $\mathrm{f} 3-\mathrm{f} 4)$ and third beam $w_{4}(0.5 ; t)$ (g3-g4 and h3-h4), respectively, for different noise intensities. When increase of the noise intensity $a^{0}=6.7 \cdot 10^{-3}$, the vibration behavior of the entire system has changed. The vibrations of the plate became harmonic at the excitation frequency of the external load $\omega_{p}=5$, and the beams are at standstill. Thus, there is no contact interaction with the presence of additive noise $a^{0}=6.7 \cdot 10^{-3}$ in the external load (see Fig. 4, a2, b2). With the noise intensity of $a^{0} \in\left[6.7 \cdot 10^{-3} ; 5 \cdot 10^{-2}\right]$ and amplitude of the external transverse load of $q_{0}=0.07$, the vibrations of the system are harmonic, the phase portrait has the form of a ring. When the noise intensity is increased up to $a^{0}=6 \cdot 10^{-2}$ at the previous values of other control parameters, the system changes and tripling of orbits is shown in the phase plate portrait. The beams execute vibrations due to the contact as a result of the contact interaction of layers (see Fig. 4, c3, d3, e3, f3, g3, h3). The Fourier power spectrum of the plate shows localization of frequencies around a frequency, which will occur with a further increase of the noise intensity (see Fig. 4, a3, b3).

When the noise intensity is $a^{0}=7 \cdot 10^{-2}$, the system executes chaotic vibrations during period tripling. When the noise intensity is increased up to $a^{0}=1 \cdot 10^{-1}$, the multilayer system executes complex chaotic vibrations during period tripling. At different time intervals, the plate interacts with each of the beams at a time. The contact interaction of the plate with the second $(y=0.4)$ and third $(y=0.7)$ beams occurs only for a short period of time (see Fig. 4, a4, b4, c4, d4, e4, f4, g4, h4).

Now, let us discuss the third type of the load. The upper plate is subjected to an external distributed transverse load with the amplitude $q_{0}=0.07$ and excitation frequency $\omega_{p}=5$. Let us study the contact interaction under the influence of additive noise applied to all three beams, i. e. the load on the beams is defined as $q_{i}(x, t)=a_{i}^{0} * \frac{2 \text { rand }}{\text { rand_max }+1}-1$.

When there is no external white noise $\left(a_{i}^{0}=0\right)$, there is a contact between the plate and the first beam $(y=0.2)$, the 


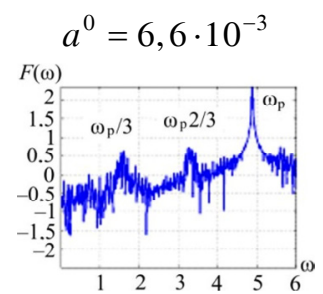

a1

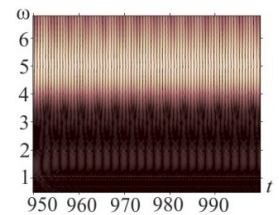

b1

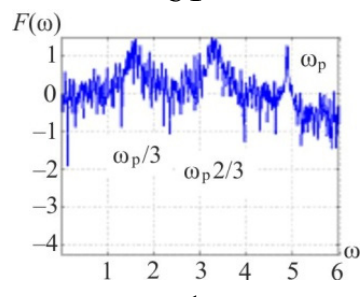

c1

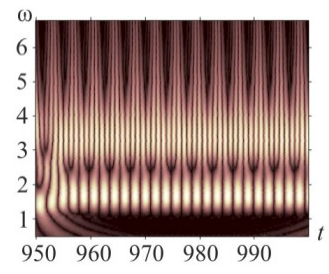

d1

at standstill

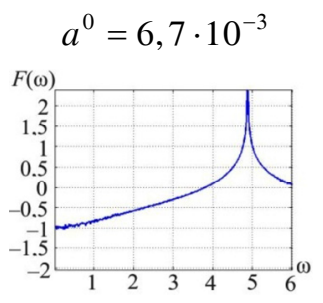

a2

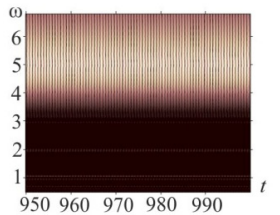

b2

at standstill

at standstill

at standstill

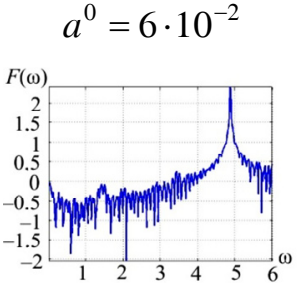

a3

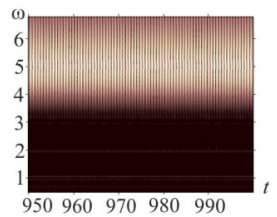

b3

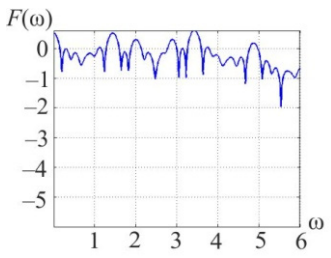

c3

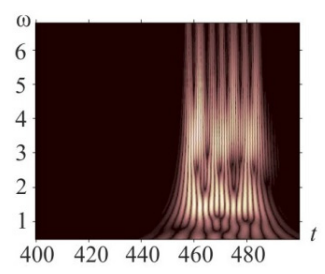

d3

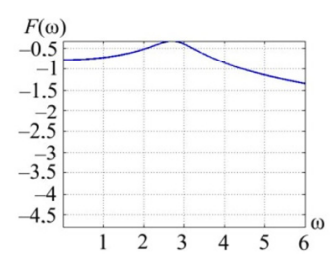

e3

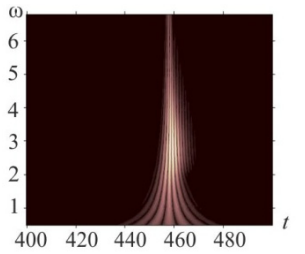

f3

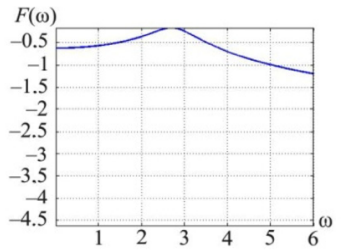

g3

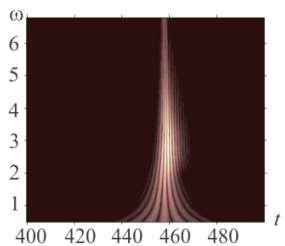

h3

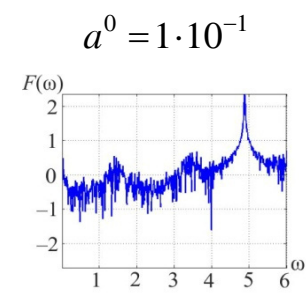

a4

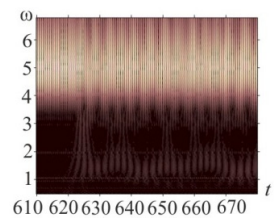

b4

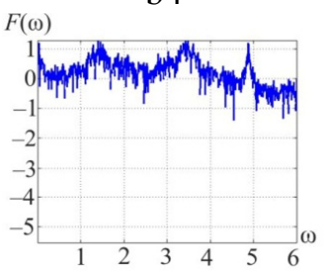

c4

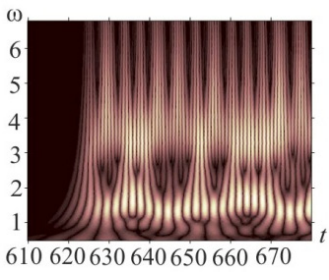

d4

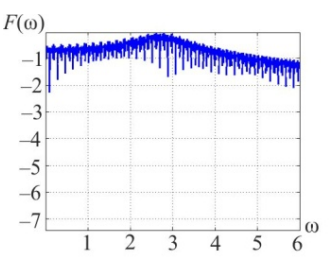

e4

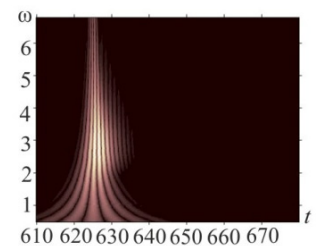

$\mathrm{f} 4$

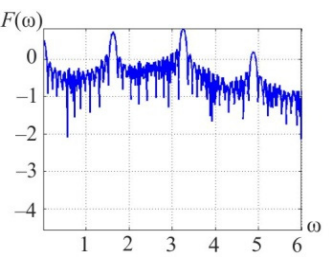

g4

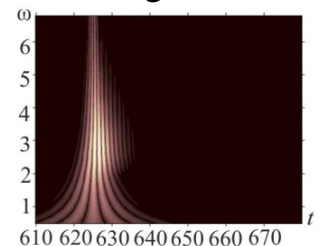

h4

Fig. 4. Study of the influence of white noise on vibrations of a multi-layer system using the Fourier method and wavelet analysis 


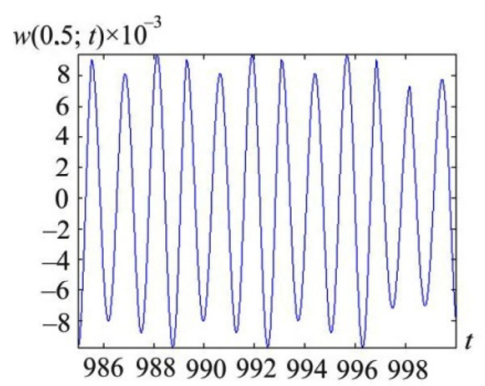

a1

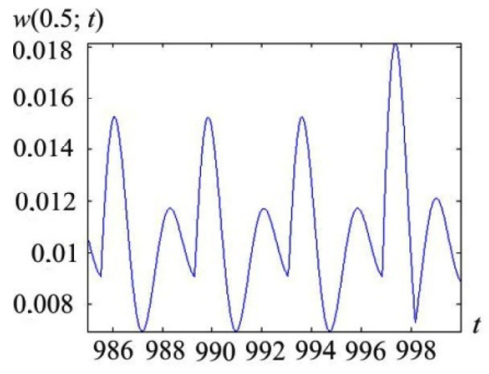

a2
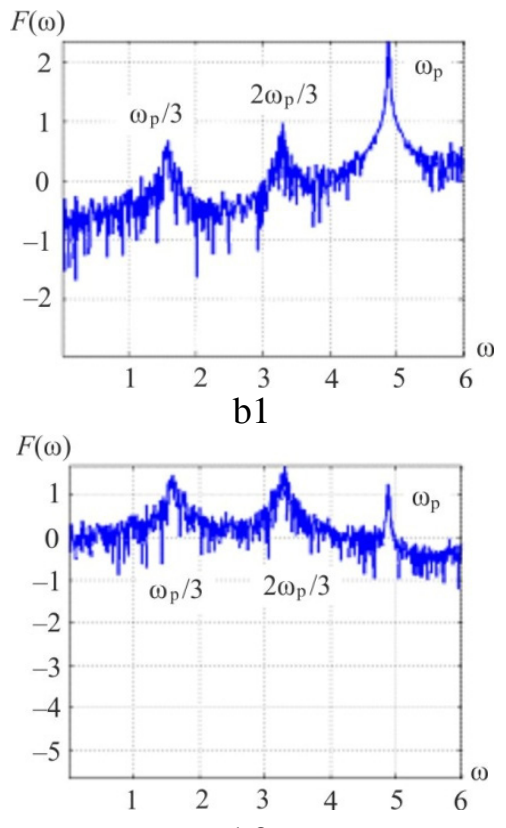

b2
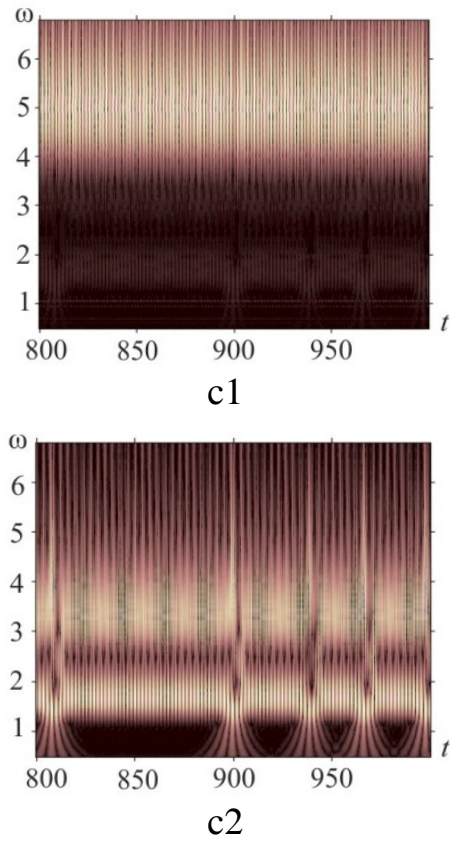

Fig. 5. Contact interaction of the plate $w_{1}(0.5 ; 0.5, t)$ and the first beam $w_{2}(0.5 ; t)$ under the influence of white noise $a_{i}^{0}=0.001$

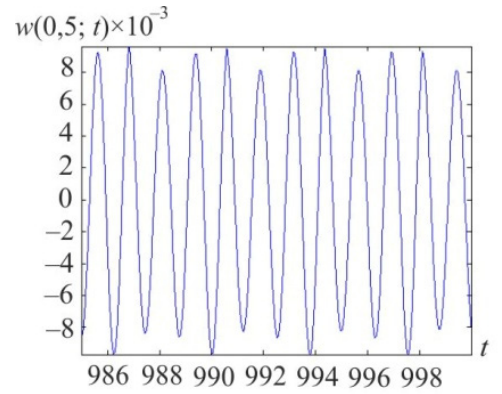

a1

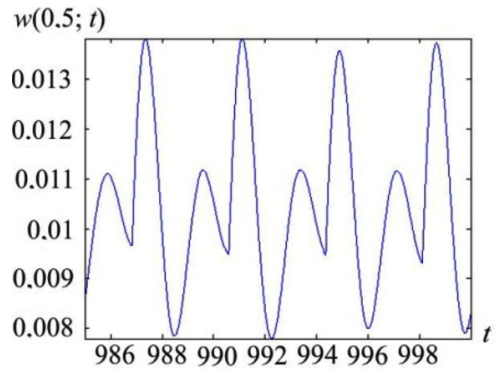

a2

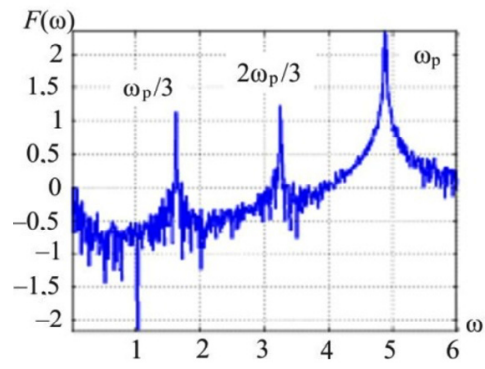

b1

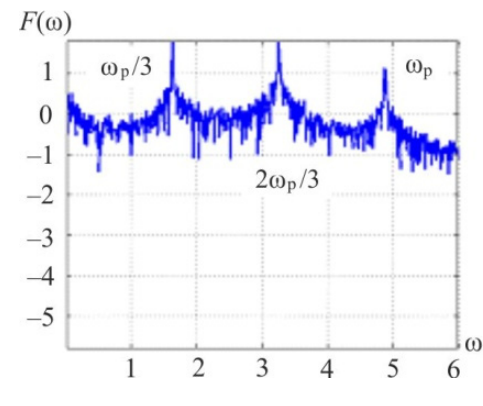

b2
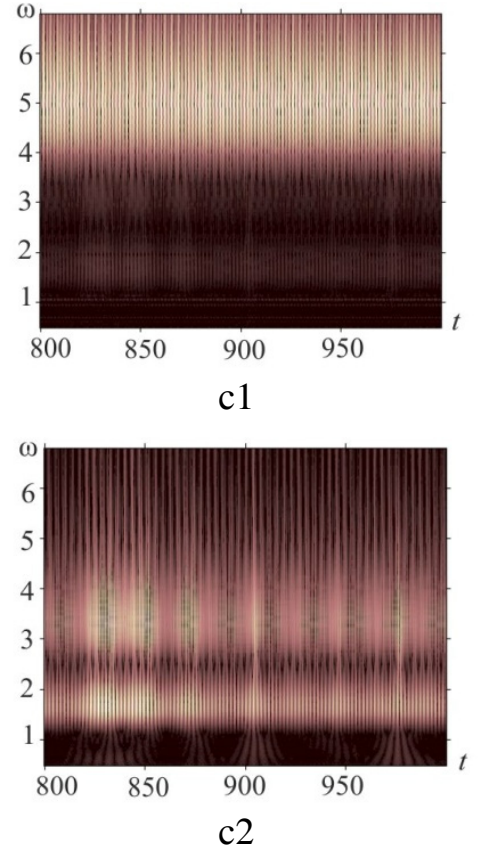

Fig. 6. Contact interaction of the plate $w_{1}(0.5 ; 0.5, t)$ and the third beam $w_{4}(0.5 ; t)$ under the influence of white noise $a_{i}^{0}=0.031$

plate and the beam execute vibrations during period tripling, while the second $(y=0.4)$ and third $(y=0.7)$ beams are at standstill. The system changes with increase of the additive noise intensity up to $a_{i}^{0}=0.001$. The second and third beams execute chaotic vibrations with a small amplitude compared to the gap between the plate and beams, phase portraits have the form of a solid spot, the Fourier power spectra and wavelet-spectra show a deep chaos. The contact interaction occurs between the plate and the first beam during period tripling (see Fig. 5, b1, b2), but there is intermittency of frequencies of these elements (see Fig. 5, c1, c2). Fig. 5 shows the graphs of the signal (a1, a2), the
Fourier power spectrum (b1, b2) and 2D Morlet wavelet spectra (c1, c2) of the plate and the first beam, respectively.

When the noise intensity is $a_{i}^{0}=[0.002 ; 0.029]$, the plate and the third beam come into contact interaction during period tripling, the first and second beams make chaotic oscillations, but there is no contact with the plate. When $a_{i}^{0}=0.002$, the Fourier power spectrum of the plate is cleared, the plate and the third beam are synchronized with small noise components. The vibrations are executed during period tripling, but a dominating frequency of the plate is $\omega_{p}=5$, and dominating frequencies of the beam 
are $\omega_{p} / 3=1.6$ and $2 \omega_{p} / 3=3.3$. When the white noise intensity is $a_{i}^{0}=0.03$, the plate executes harmonic vibrations due to the fact that there is no contact with any of the beams, although they are in a state of deep chaos. With increase of the noise intensity up to $a_{i}^{0}=0.031$, the plate once again touches the third beam with a tripling of the frequency period, i. e. these two elements of the beam-plate structure are synchronized (see Fig. 6).

\section{Conclusion}

This work presents a mathematical model of the contact interaction of a plate reinforced by ribs with gaps under the influence of white noise. As a part of the study, the authors have studied behavior of complex vibrations of a multilayer system depending on three types of load under the influence of white noise. We can draw a conclusion that as soon as elements of the system come into contact, regardless of the presence of white noise, their vibrations become chaotic at linearly dependent frequencies $\omega_{p}=5$, $\omega_{p} / 3=1.6$ and $2 \omega_{p} / 3=3.3$.

The external additive white noise can affect the vibration behavior (presence or absence of the contact interaction of elements of a multi-layer system). The absence of contact interaction causes the system to execute harmonic vibrations.

This work was financially supported by the Russian Science Foundation (Project No. 15-19-10039).

\section{References}

1. Krysko A.V. [et al.] Chaotic nonlinear dynamics of cantilever beams under the action of signsvariables loads. PAMM. Special Issue: 82nd Annual Meeting of the International Association of Applied Mathematics and Mechanics (GAMM). Graz, 2011, vol. 11, iss. I, pp. 327-328.

2. Awrejcewicz J., Zhigalov M.V., Krysko V.A., Nackenhorst U., Papkova I.V., Krysko A.V. Nonlinear dynamics and chaotic synchronization of contact interactions of multi-layer beams. Dynamical Systems - Theory. Eds. J. Awrejcewicz, M. Kaëmierczak, P. Olejnik, J. Mrozowski. TU of Lodz Press, 2013, pp. 283-292.

3. Krys'ko V.A. et al. Fazovaia khaoticheskaia sinkhronizatsiia mnogosloinykh balochnykh struktur [Phase synchronization of chaotic laminated beam structures]. Prikladnaia mekhanika I tekhnicheskaia fizika, 2012, no. 3, pp. 166-175.

4. Awrejcewicz J. et al. Chaotic synchronization of vibrations of a coupled mechanical system consisting of a plate and beams. Latin American Journal of Solids and Structures, 2013, vol. 10, pp. 161-172.

5. Dzhashitov V.E. et al. Ierarkhicheskie teplovye modeli besplatformennoi inertsial'noi navigatsionnoi sistemy na volokonno-opticheskikh giroskopakh [Hierarchical thermal models strapdown inertial navigation system based on fiber-optic gyros]. Giroskopiia i navigatsiia, 2013, no. 1 (80), pp. 49-63.
6. Dzhashitov V.E., Pankratov V.M., Barulina M.A Matematicheskie modeli termouprugogo napriazhenno-deformirovannogo sostoianiia i pogreshnosti masshtabnogo koeffitsienta volokonnoopticheskogo giroskopicheskogo datchika [Mathematical models of thermal stress-strain state and the scale factor error of the fiber optic gyro sensor]. Problemy mashinostroeniia $i$ nadezhnosti mashin, 2013, no. 2, pp. 43-52.

7. Awrejcewicz J., Krysko A.V., Krysko V.A., Papkova I.V. Routes to chaos in continuous mechanical systems. Part 1: Mathematical models and solution methods. Chaos. Solitons \& Fractals. Nonlinear Science, and Nonequilibrium and Complex Phenomena, 2012, vol. 45, 22 p.

8. Dobriian V.V., Papkova I.V., Krys'ko V.A. Metod Liapunovskikh pokazatelei dlia issledovaniia khaoticheskikh kolebanii konstruktivnonelineinykh raspredelennykh system [Method of Lyapunov expo nents for the study of chaotic oscillations structurally nonlinear distributed systems]. Materialy mezhdunarodnogo nauchnogo foruma "Lomonosov-2013". Moscow: MAKS Press, 2013, available at: http://lomonosovmsu.ru/archive/Lomonosov_2013/2192/47410_3549.pdf.

9. Yang Caixia, Wu Christine Qiong A robust method on estimation of Lyapunov exponents from a noisy time series. Nonlinear Dyn., 2011, vol. 64, no. 3, pp. 279-292.

10. Tarinejad R., Damadipour M. Modal identification of structures by a novel approach based on FDD-wavelet method. Journal of Sound and Vibration, 2014, vol. 333, no. 3, pp. 1024-1045.

11. Horsthemke W., Lefever R. Noise-Induced Transitions. Berlin, New York: Springer-Verlag, 1984.

12. Feng Ju et al. Stochastic minimax optimal time-delay state feedback control of uncertain quasi-integrable Hamiltonian systems. Acta mech., 2011, vol. 222, no. 3-4, pp. 309-319.

13. Baneen U. et al. Vibration based damage detection of a beam-type structure using noise suppression method. J. Sound and Vibr., 2012, vol. 331, no. 8, pp. 1777-1788.

14. Chen Lincong et al. Stationary response of Duffing oscillator with hardening stiffness and fractional derivative. Int. J. Non-Linear Mech., 2013, vol. 48, pp. 44-50.

15. Vaganova N.I., Rumanov E.N. Predvestniki katastrof [Harbingers of disaster]. Materialy mezhdunarodnoi konferentsii "Neizotermicheskie iavleniia $i$ protsessy: Ot teorii teplovogo vzryva k strukturnoi makrokinetike”. Chernogolovka, 2011. 131 p.

16. Slepnev A.V., Vadivasova T.E. Bifurkatsii udvoeniia perioda i effekty shumovogo vozdeistviia $\mathrm{v}$ mul'tistabil'noi avtokolebatel'noi srede [Period-doubling bifurcations and the effects of noise exposure in the multi stable self-oscillating environment. Applied Nonlinear Dynamics]. Prikladnaia nelineinaia dinamika, 2011, vol. 19, no. 4, pp. 53-67.

17. Potapov V.D. Ob ustoichivosti stokhasticheskikh viazkouprugikh system [On the stability of stochastic systems viscoelastic]. Problemy mashinostroeniia $i$ nadezhnosti mashin, 2009, no. 6, pp. 85-90.

18. Wouw N. van de, Kraker A. de, Campen D.H. van, Nijmeijer H. Non-linear dynamics of a stochastically excited beam system with impact. Int. J. Non-Linear Mech., 2003, vol. 38, no. 5, pp. 767-779.

19. Awrejcewicz J., Krylova E.Y., Krysko V.A. Regular and chaotic dynamics of flexible plates. Proceedings of the International Conference on Structural Engineering Dynamics (ICEDyn 2013). Portugal: Sesimbra, 2013. 10 p.

20. Yao Xiongliang [et al.] Raschet kolebanii i radiatsii zvuka konechnykh podkreplennykh plastin, pokrytykh dempfiruiushchim sloem [Calculation of vibrations and sound radiation supported by 
end plates coated with a layer of damping]. J. Huazhong Univ. Sci. and Technol. Natur. Sci., 2012, vol. 40, no. 7, pp. 119-123.

21. Denisov S.I., Bondar' E.A. Novyi klass indutsiruemykh shumom perekhodov [A new class of noise-induced transitions]. Mater.ali ta programma naukovo-tekhn.chno. konferents.. "F.zika, elektron.ka, elektrotekhn.ka”. Sumi, 2014, p. 52.

22. Nikos S., Grigorios P., Kalliadasis S. Contact lines over random topographical substrates. J. Fluid Mech., 2011, vol. 672, pp. 358-383.

23. Kantor B.Ia. Kontaktnye zadachi nelineinoi teorii obolochek vrashcheniia [Contact problems of the nonlinear theory of shells of revolution]. Kiev: Naukova dumka, 1990. 100 p.
24. Faedo S. Un nuovo metodo per lanalisi esistenziale e quantitative dei problem di propogazione. Ann. Scuola Norm. sur. Pisa, 1949, pp. 1-40.

25. Krysko A.V., Ghigalov M.V. Matematicheskie modeli i metody issledovaniia slozhnykh kolebanii neklassicheskikh raspredelennykh mekhanicheskikh system [Mathematical models and methods of complex mechanical vibrations of non-classical distributed systems]. Saratovskii gosudarstvennyi tekhnicheskii universitet, 2008, p. 301.

26. Grossman A., Morlet S. Decomposition of Hardy functions into square separable wavelets of constant shape. SIAM J. Math. Anal., 1984, vol. 15, no. 4, p. 723.

Original Russian Text:

Yakovleva T.V., Bazhenov V.G., Krysko V.A., Krylova E.Yu. Contact interaction plates, reinforced by ribs, with gaps under the influence of white noise. PNRPU Mechanics Bulletin. 2015, no. 4, pp. 259-272. DOI: 10.15593/perm.mech/2015.4.15 


\section{PNRPU \\ MECHANICS BULLETIN}

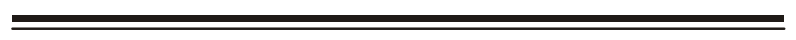

№ 3-4

Технический редактор E.M. Сторожева

Выход в свет 25.12.18. Формат 60×90/8.

Усл. печ. л. 21,25. Заказ № 297/2018.

Свободная цена

Отпечатано в типографии Издательства

Пермского национального исследовательского политехнического университета.

Адрес: 614990, г. Пермь, Комсомольский пр., 29, к. 113.

Тел. (342) 219-80-33. 